\title{
Impact of Formation Properties and Well Design on Cumulative Gas Production from Devonian Shale
}

Jacques Ita

West Virginia University

Follow this and additional works at: https://researchrepository.wvu.edu/etd

\section{Recommended Citation}

Ita, Jacques, "Impact of Formation Properties and Well Design on Cumulative Gas Production from Devonian Shale" (2011). Graduate Theses, Dissertations, and Problem Reports. 2254.

https://researchrepository.wvu.edu/etd/2254

This Thesis is protected by copyright and/or related rights. It has been brought to you by the The Research Repository @ WVU with permission from the rights-holder(s). You are free to use this Thesis in any way that is permitted by the copyright and related rights legislation that applies to your use. For other uses you must obtain permission from the rights-holder(s) directly, unless additional rights are indicated by a Creative Commons license in the record and/ or on the work itself. This Thesis has been accepted for inclusion in WVU Graduate Theses, Dissertations, and Problem Reports collection by an authorized administrator of The Research Repository @ WVU. For more information, please contact researchrepository@mail.wvu.edu. 
Impact of Formation Properties and Well Design on

Cumulative Gas Production from Devonian Shale

$$
\text { Jacques Ita }
$$

Thesis submitted to the

College of Engineering and Mineral Resources at West Virginia University

in partial fulfillment of the requirements for the degree of

\author{
Master of Science \\ in \\ Petroleum and Natural Gas Engineering
}

H. Ilkin Bilgesu, Ph.D., Chairperson

Samuel Ameri, M.S.

Yueming Cheng, Ph.D.

Daniel E. Della-Giustina, Ph.D.

Department of Petroleum and Natural Gas Engineering

Morgantown, West Virginia

2011

Keywords: Devonian Shale, Eclipse, CMG, Monte Carlo, Modeling, Gas production. 


\section{Abstract \\ Impact of Formation Properties and Well Design on Cumulative Gas Production from Devonian Shale}

\section{Jacques Ita}

Devonian Shale refers to all the shale strata sandwiched between two different formations; the younger Berea sandstone above it and the older limestone termed Onondaga or Coniferous below it. Devonian Shale consists of exceptionally rich source rocks; were it not for their low porosity and permeability, the shales would represent one of the greatest oil and gas producing provinces of the world. It is estimated that up to 90 TCF of natural gas could be recovered from Devonian Shale. However, production potential of Devonian Shale is difficult and expensive to determine with production being variable because shale is a very complex sedimentary rock that is difficult to characterize on a particular basis. Additionally, a lot of hole stability problems are encountered when drilling in shale formations. The key therefore in improving production of gas from Devonian Shale lies in studying and analyzing the properties of shale and developing technologies that would eventually overcome shale's undesirable problems and ultimately enhance production.

The objective of the proposed work is to understand the behavior of shales by examining its internal stratigraphy, structure, reservoir characteristic, production controls, drilling and development history and using this knowledge to model the effect of the various properties (fracture length, lateral wellbore length, fracture half length and shale permeability and porosity) on the production of gas from a Devonian shale bearing 
reservoir. A sensitivity analysis was then performed to identify which parameter has the most influence on cumulative gas production. 


\section{Acknowledgements}

First, I would like to record my gratitude to Dr. Ilkin Bilgesu for his supervision, advice, and guidance and above all, for providing me unflinching encouragement and support in various ways. I am indebted to him more than he knows.

Next, I wish to thank the complete Thesis Committee: Prof. Sam Ameri, Dr. Yueming Cheng and Dr. Daniel Della- Guistina. Each individual provided insights that challenged my thinking, substantially improving the finished product.

I gratefully acknowledge Dr. Kashayar Aminian and Dr Shahab Mohaghegh for their advice, and courses, which they taught me. My appreciation also goes to Katherine Lee Avary of the Morgantown Geological and Economic survey for providing me with very important materials for this research.

Where would I be without my family? My parents deserve special mention for their inseparable support and prayers. My Father, Chief Ayuk Ita Erem, in the first place is the person who put the fundamentals of learning, showing me the joy of intellectual pursuit ever since I was a child. My Mother, Stella Egrea, is the one who sincerely raised me with her caring and gentle love. Ayum Eric, Kingsley Ita, Jacqueline Ita, Ernest Ita, Lovejoy Ita, Effim Ita, and Ayuk Ita Jr, thanks for being supportive and caring siblings.

Finally, my sincere thanks go to Allen Nfonsam, Michael Enoh, Raymond Sama, Jalal Jalali, Targ Ali, Osade Edo-Osagie, Ike Eleanya Onuoha and Peter Fadesere who were important to the successful realization of this thesis.

This research work is dedicated to my children, Janie Ita Eri and Jaison Ngock-Ita who have been the motivating factors in my life. 


\section{Table of Contents}

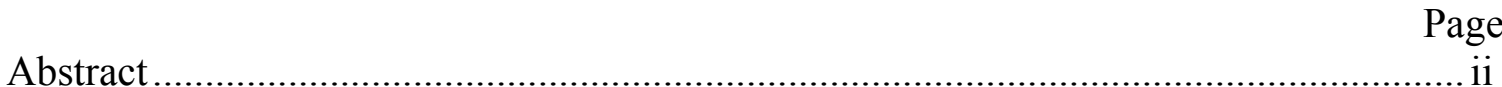

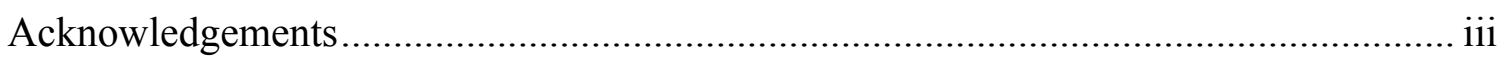

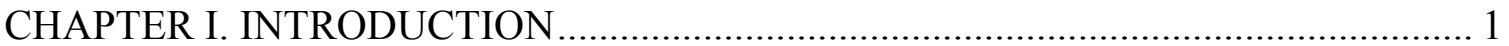

I-1 Statement of the Problem ........................................................................ 2

1.2 Origin/History of Devonian Shale. .......................................................... 3

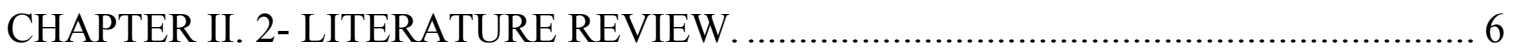

II.1 Introduction to Properties of Devonian Shales ......................................... 6

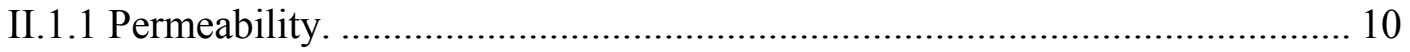

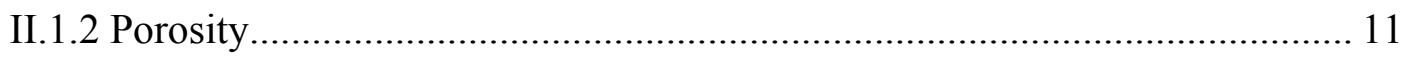

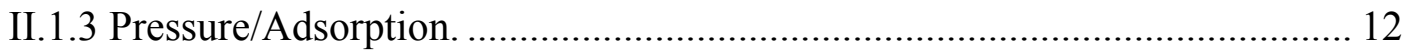

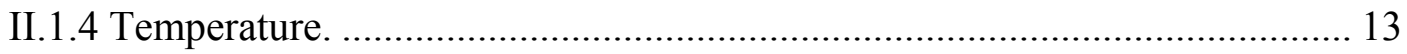

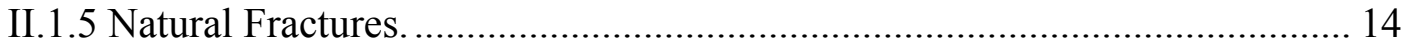

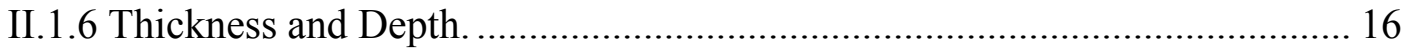

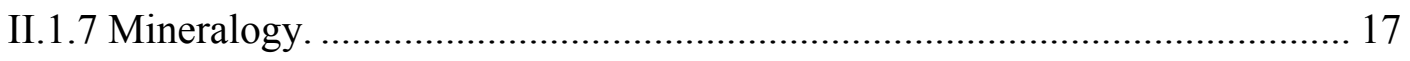

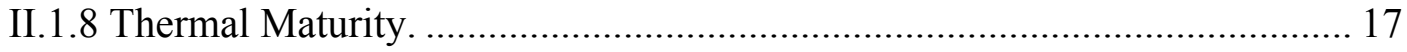

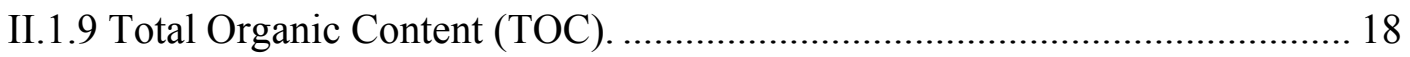

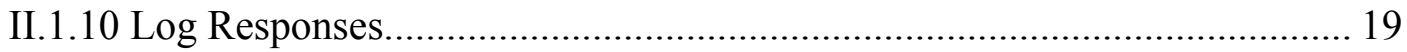

II.1.11 Completion Types. ........................................................................... 19

II.1.12 Decline Curve for Devonian Shale Gas Production.................................. 20

II.1.13 Previous Studies Done on Devonian Shale. ............................................ 24

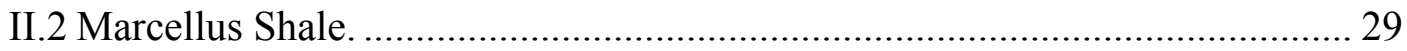




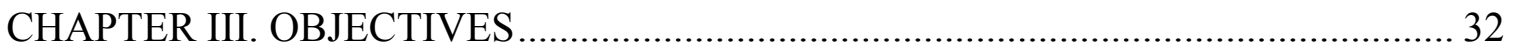

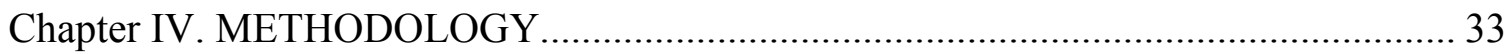

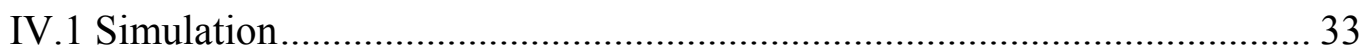

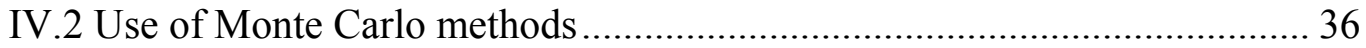

IV.3 Simulation with non-uniform properties................................. 38

CHAPTER V. RESULTS AND DISCUSSION ........................................................... 40

V-1 Comparison of horizontal and vertical well performance. ……….................. 40

V-2 Effect of Fracture Porosity on Production............................. 44

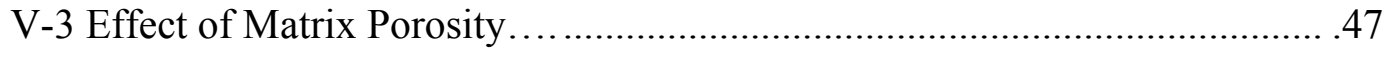

V-4 Effect of Fracture Permeability ………………..................................... 50

V-5 Effect of Matrix Permeability:.................................................................... 53

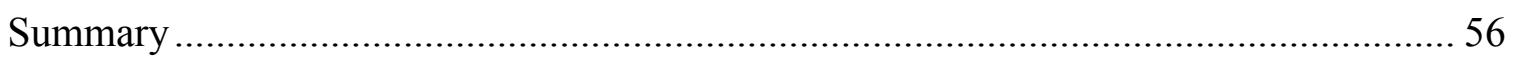

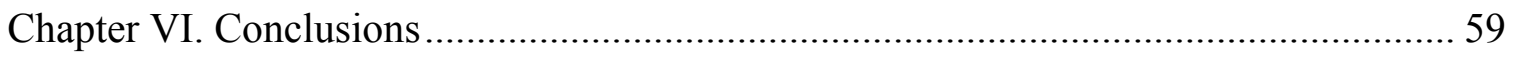

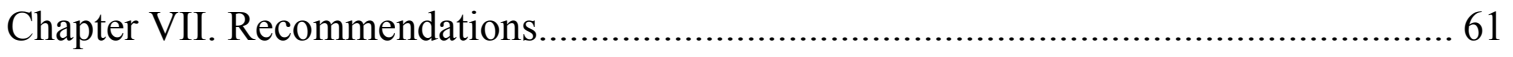

Chapter VIII. References.......................................................62

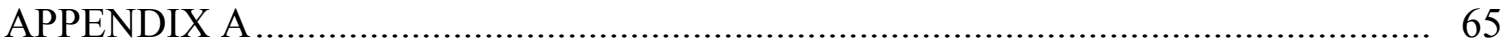

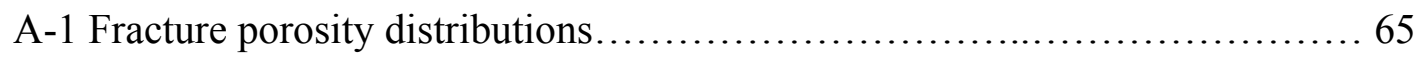

A-2 Matrix Porosity distributions............................................ 65

A-3 Fracture permeability distributions................................... 76

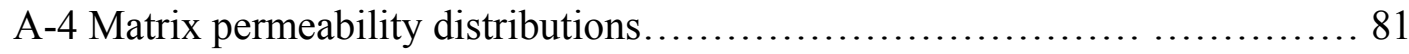




\section{List of Figures}

Page

Figure1-1; Appalachian Basin Province (USGS, 2002) ............................................. 2

Figure I-2; Major shale gas basins in the United States (Nome, 2008)........................

Figure II-1; Fractured EasternBlack Shale (geology.com). ....................................... 6

Figure II-2; U.S demand for Natural Gas (EIA, 2008). ......................................... 7

Figure II-3; Annual U.S. natural gas gross production per year (EIA, 2008).............8

Figure II-4;Typical Barnett shale restimulation results (Pickering, 2005)..............16

Figure II-5. Vitrinite Reflectance (Pickering, 2006)............................ 18

Figure II-6;Averaged production decline curves for Devonian shale gas wells in

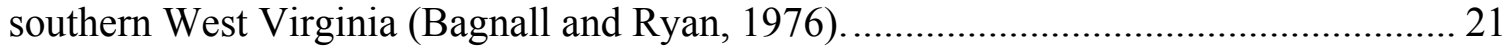

Figure II-7 Distribution of $\mathrm{J}_{1}$ joints (Engelder \& Lash, 2008).................................... 31

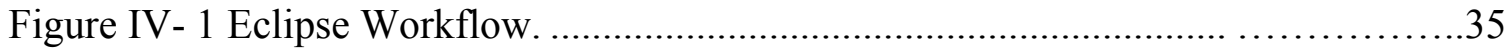

Figure V-1 Total gas production for horizontal and vertical well $\ldots \ldots \ldots \ldots \ldots \ldots \ldots \ldots 41$

Figure V-2 Total gas production for different fracture half lengths..................42

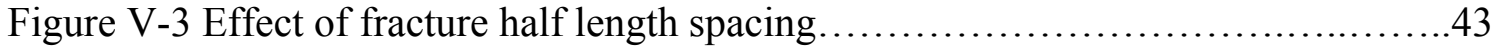

Figure V-4 Effect of lateral length and hydraulic fracture treatments.................44

Figure V-5, Effect of fracture porosity distributions on cumulative gas production......46

Figure V-6, Variation of cumulative gas production with fracture porosity distributions.

Figure V-7; Effect of matrix porosity distributions on cumulative gas production.......49

Figure V-8; Variation of cumulative gas production with matrix porosity distributions.......................................................... 50

Figure V-9; Effect of fracture permeability distributions on cumulative gas production. 
Figure V-10; Variation of cumulative gas production with fracture permeability

distributions..... .53

Figure V-11; Effect of matrix permeability distributions on cumulative gas

production.... 55

Figure V-12; Variation of cumulative gas production with matrix permeability distributions. .56

Figure V-13; Influence of reservoir parameters..................................57

Figure V-14; Impact of all parameters on cumulative gas production...................58

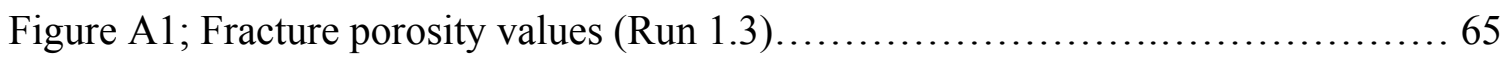

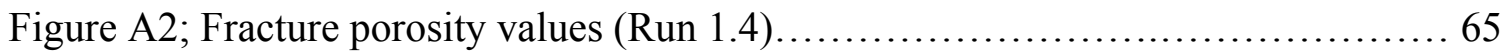

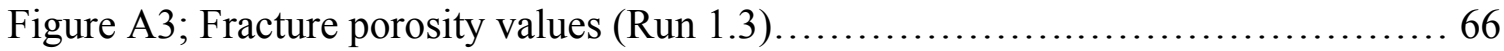

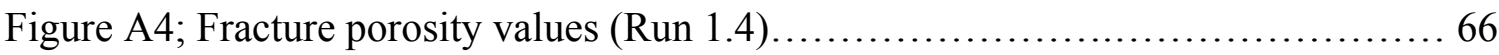

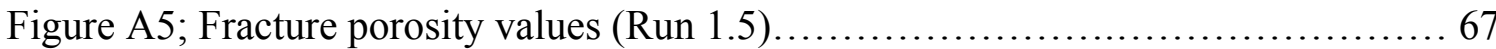

Figure A6; Fracture porosity values (Run 1.6) .................................. 67

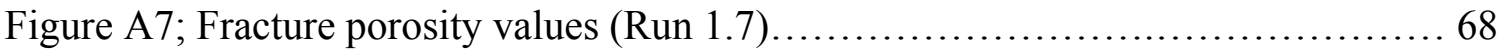

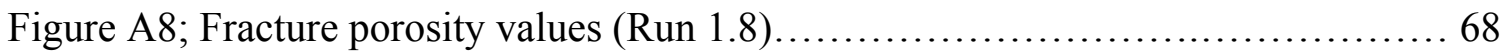

Figure A9; Fracture porosity values (Run 1.9) ....................................... 69

Figure A10; Fracture porosity values (Run 1.10)................................. 69

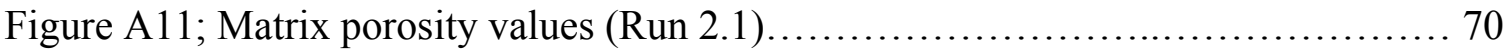

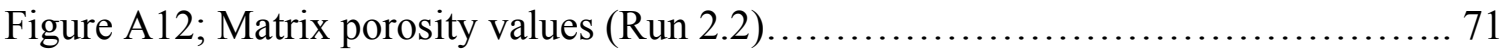

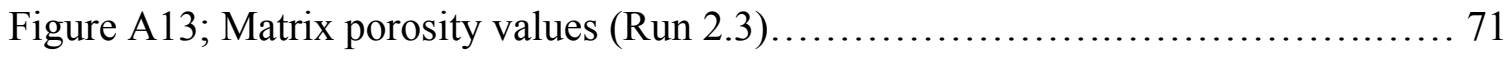

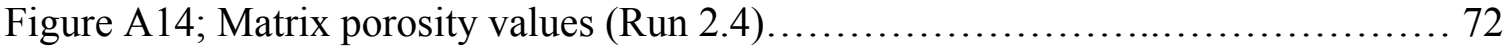

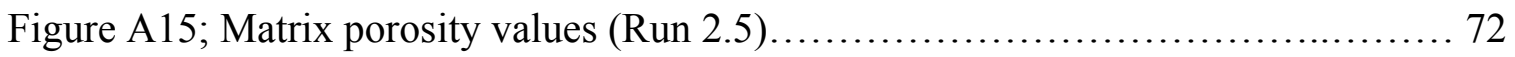

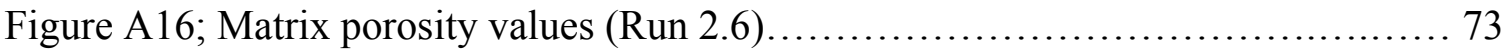

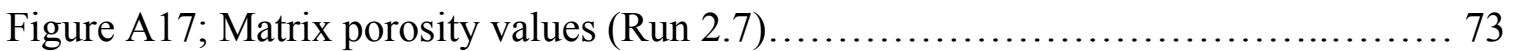


Figure A18; Matrix porosity values (Run 2.8)................................... 74

Figure A19; Matrix porosity values (Run 2.9 ).................................. 74

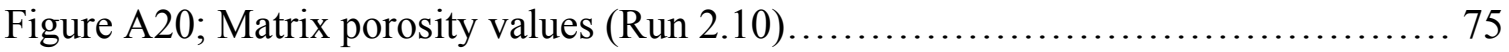

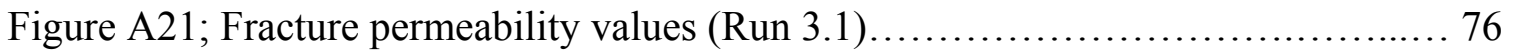

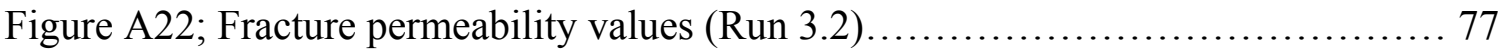

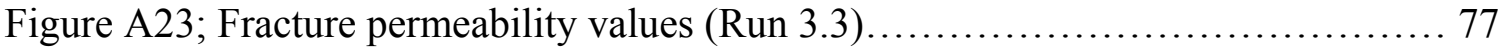

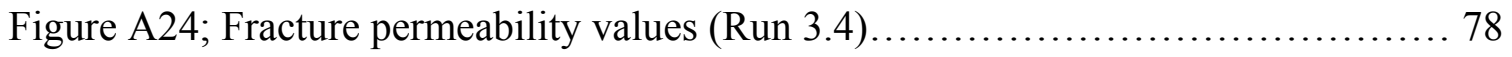

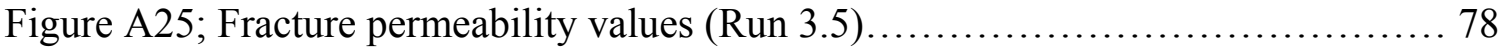

Figure A26; Fracture permeability values (Run 3.6)............................... 79

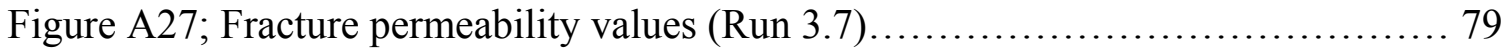

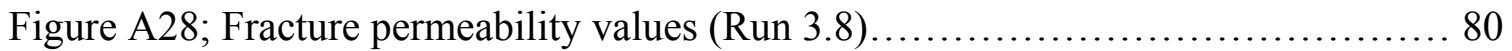

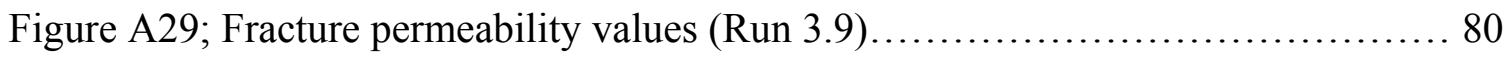

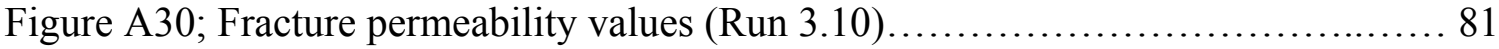

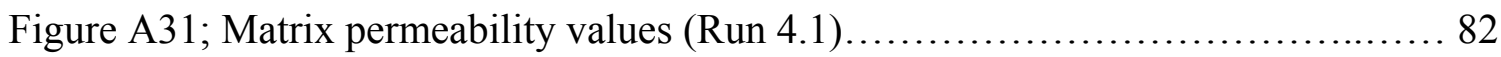

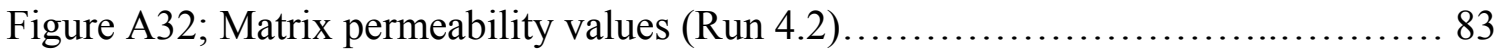

Figure A33; Matrix permeability values (Run 4.3) .............................. 83

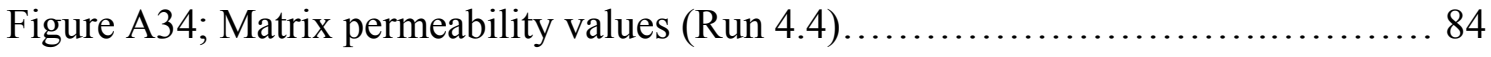

Figure A35; Matrix permeability values (Run 4.5) ............................. 84

Figure A36; Matrix permeability values (Run 4.6)............................... 85

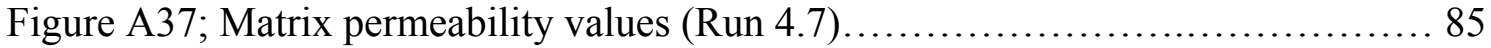

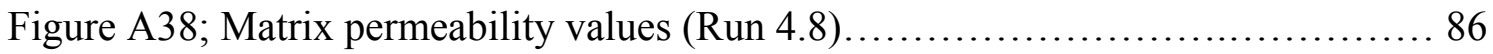

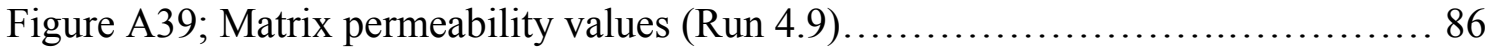

Figure A40; Matrix permeability values (Run 4.10)............................. 87 


\section{List of Tables}

Page

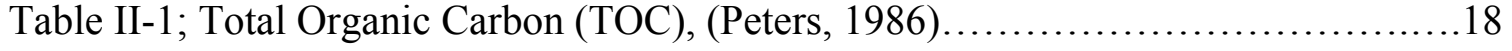

Table II-2; Summary of results for Devonian shale. (GTI and Pickering, 2005) ............ 23

Table V-1 Formation properties used in runs with different fracture porosity

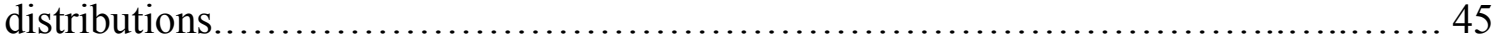

Table V-2, Cumulative gas produced with different fracture porosity distributions.....45

Table V-3 Formation properties used in runs with different matrix porosity

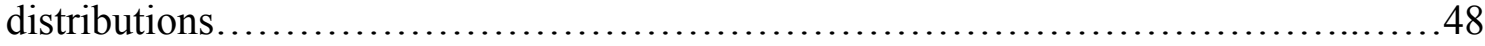

Table V-4; Cumulative gas produced with different matrix porosity distributions........48

Table V-5 Formation properties used in runs with different fracture permeability distributions.................................................................. 51

Table V-6; Cumulative gas produced with different fracture permeability

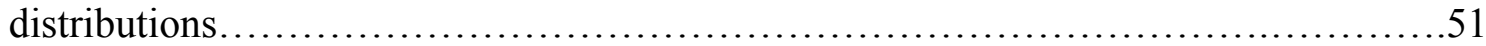

Table V-7 Formation properties used in runs with different matrix permeability distributions............................................................. 54

Table V-8; Cumulative gas produced with different matrix permeability distributions. 


\section{CHAPTER I - INTRODUCTION}

Devonian shale refers to all the shale strata sandwiched between two different formations; the younger Berea sandstone above it and the older limestone termed Onondaga or Coniferous below it. The Devonian shale can be characterized as an impermeable, low-pressured reservoir requiring special effort to enhance its gas recovery.

Figure 1-1 shows the areal extent of an assessment of the undiscovered oil and gas potential of the Appalachian Basin Province conducted by the U.S Geological Survey (USGS). The USGS estimated a mean of 70.2 trillion cubic feet of gas (TCFG), a mean of 54 million barrels of oil (MMBO), and a mean of 872 million barrels of total natural gas liquids (MMBNGL) as the recoverable hydrocarbons. These Devonian shale are predominant in the Appalachian Basin (this area includes part of New York, Pennsylvania, Ohio, Maryland, West Virginia, Kentucky, Tennessee, Georgia and Alabama) and cover a total surface area of some 209,000 square miles, Michigan and Illinois basin respectively (USGS, 2003). 


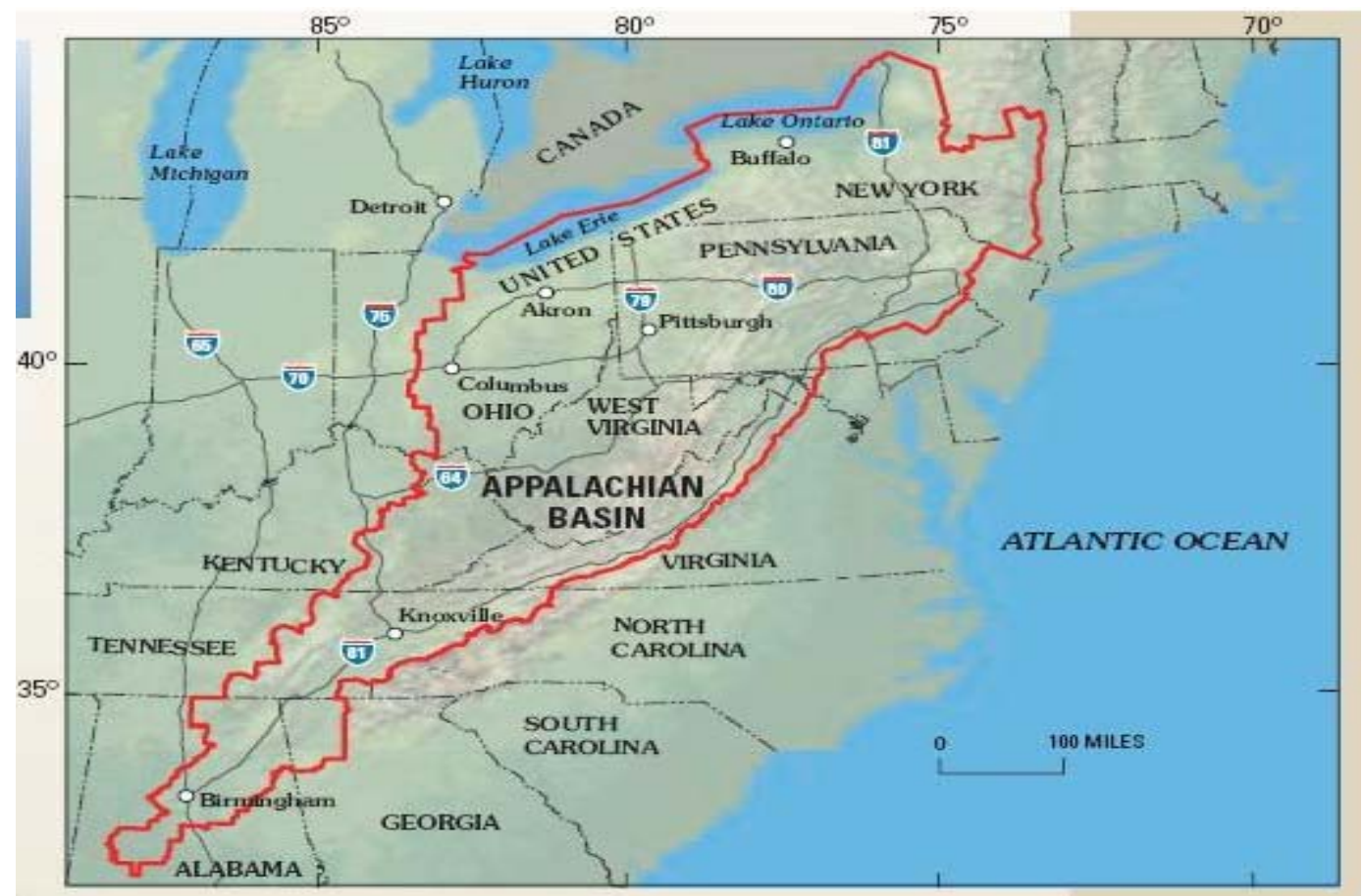

Figure1-1; Appalachian Basin Province (USGS, 2002)

Devonian shale is of various types in different strata; namely, gray, greenish gray, grayish brown, and deep brown to black. The deep brown to black shales contains much organic matter and is locally productive of gas.

\section{I-1 Statement of the Problem}

Producing natural gas from shale gas reservoirs has gained momentum over the past few years in North America and will become an increasingly important component of the world's energy supply. The Devonian shale is important due to its large size and the economic impact that it could have on the U.S. This study presents a comprehensive reservoir model to study the impact of reservoir parameters, fracture half-length, lateral length and natural fractures on cumulative gas production. An analysis would be performed to identify which parameter has the most influence on cumulative gas 
production. Through reservoir simulation, the Devonian formation could be studied to find the effects of these parameters. The premise of this work is to use a reservoir modeling software package to investigate the Marcellus shale reservoir in a selected area that is deep and over pressured. The objective of the study is to compare and contrast the gas production changes between variable reservoir parameters and fixed reservoir parameters. The reservoir would be heterogeneous, that is random values would be assigned to each grid block in the reservoir for the parameter under study. These random numbers would be within the range of reservoir values used for Devonian shale.

\section{I.2 Origin/History of Devonian Shale}

The origin of the Appalachian Devonian shale goes as far back as 350 million years ago when elevated or high mountains were constantly being eroded. The erosion of the mountains produced immense volumes of mud, silt and sand, which were carried westward by streams and deposited in a great compound delta, the Catskill delta. The delta was built out into a seaway that covered parts of what is now the Appalachian Basin.

Shale gas drilling and production was started in Western New York as early as 1820, and moved westward along the south shore of Lake Erie across northwestern Pennsylvania and into Ohio as far as Cleveland. Shallow wells supplied Louisville, KY with gas in the 1880's. Two facts about this early production stand out. First, the rate of gas production was low; only enough to supply a small local industry, or a small cluster of households for heating and cooking could be expected from a given well. Secondly, the wells were very long-lived, with production in some wells lasting well over 30 years. This low rate, 
long-live production is very typical of shale gas and led to studies in understanding the movement of shale gas. It was realized that shales exhibit dual porosity where fractures provide the primary mechanism for transport of "free" gas to the well while a vast bulk of the gas is held in the shale mass or matrix, from which it will move into fractures and wellbores at very low rates and over long time periods. This is evidenced in production decline curves in Devonian shale wells where there is an initial rapid drop in production rate followed by an extended period of consistent production stabilization. The matrix of Devonian shales is so tight that the effect of pressure drawdown takes a long time to be felt deep in the interior of the matrix. For this reason the rock matrix has infinite acting characteristics and can remain at initial conditions for many years.

It has been estimated that natural gas of up to $90 \mathrm{Tcf}$ (Fontaine et. al. 2007) could be recovered from Devonian shales. Although production from shale gas is difficult and expensive because shale is a very complex sedimentary rock that is difficult to characterize on a particular basis, its increasing demand has attracted industry attention in researching means of increasing production from them. The major U.S. shale plays are shown in Figure I-2. The Marcellus shale is not shown but is contained within the Devonian/Ohio shale. The Marcellus formation has an estimated gas in place (GIP) at $168-516$ TCF or $70-150$ BCF/sq mile (Armas, 2008) (Chernoff, 2008) (Sumi, 2008). Another new large field not shown is the Haynesville shale with an estimated GIP of 150$250 \mathrm{BCF} / \mathrm{sq}$ miles. 
Technological discoveries have been implemented with great production success in the Barnett Shale in the Forth Worth Basin, Texas, Fayetteville shale, Antrim in the Michigan Basin, New Albany in Indiana, Illinois Basin etc. Therefore, the key in improving production of gas from Devonian Shales lies in improved technology and a better understanding of the properties of shale.

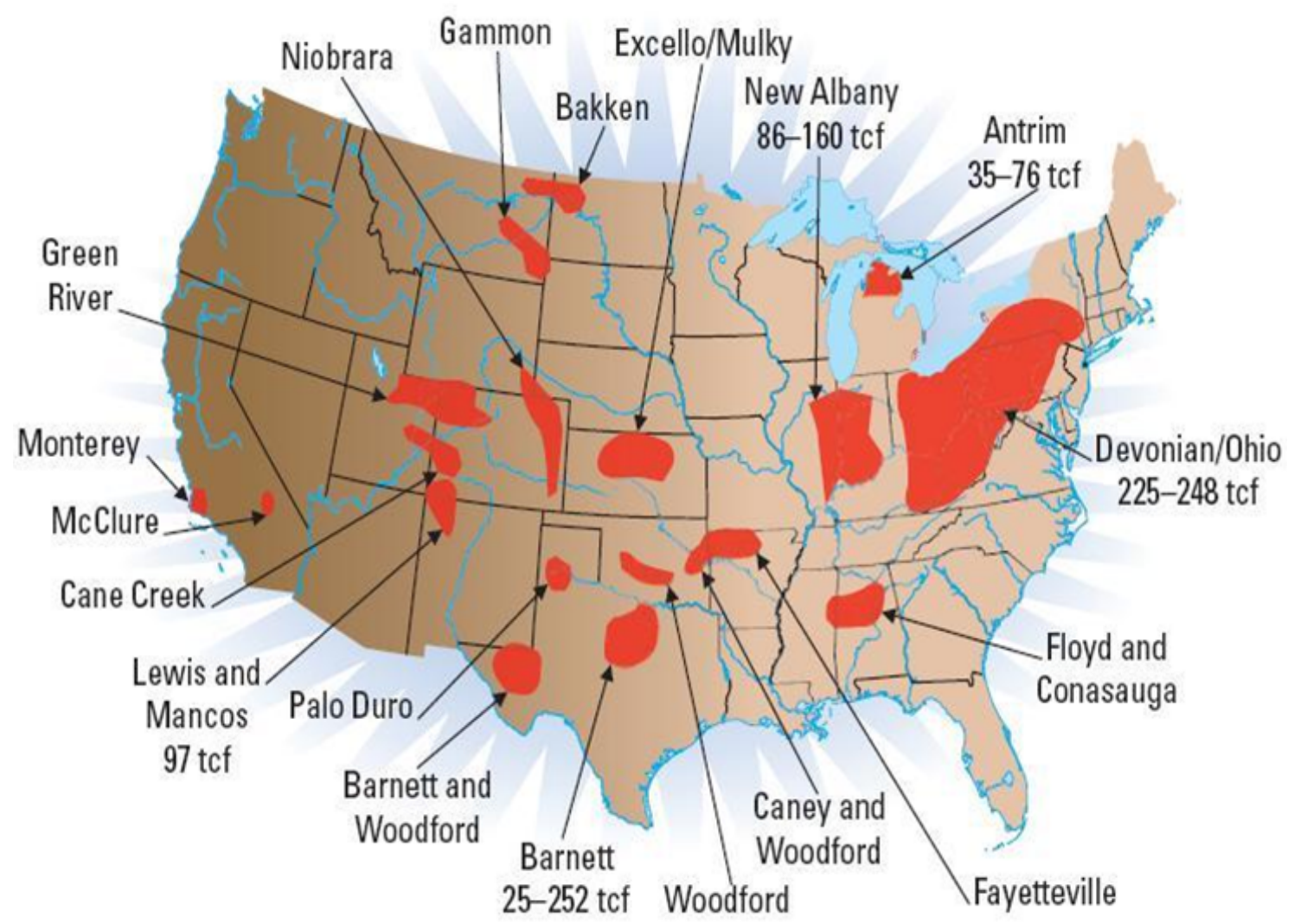

Figure I-2; Major shale gas basins in the United States (Nome, 2008). 


\section{CHAPTER II - LITERATURE REVIEW.}

\section{II.1 Introduction to properties of Devonian Shale}

At present the U.S consumes about $23 \mathrm{Tcf} /$ year of natural gas, while it produces only 19 Tcf/year. This consumption of $23 \mathrm{Tcf} /$ year is projected to exceed $30 \mathrm{Tcf} / \mathrm{year}$ within the next two decades. Figure II-1 shows typically fractured black Devonian shale.

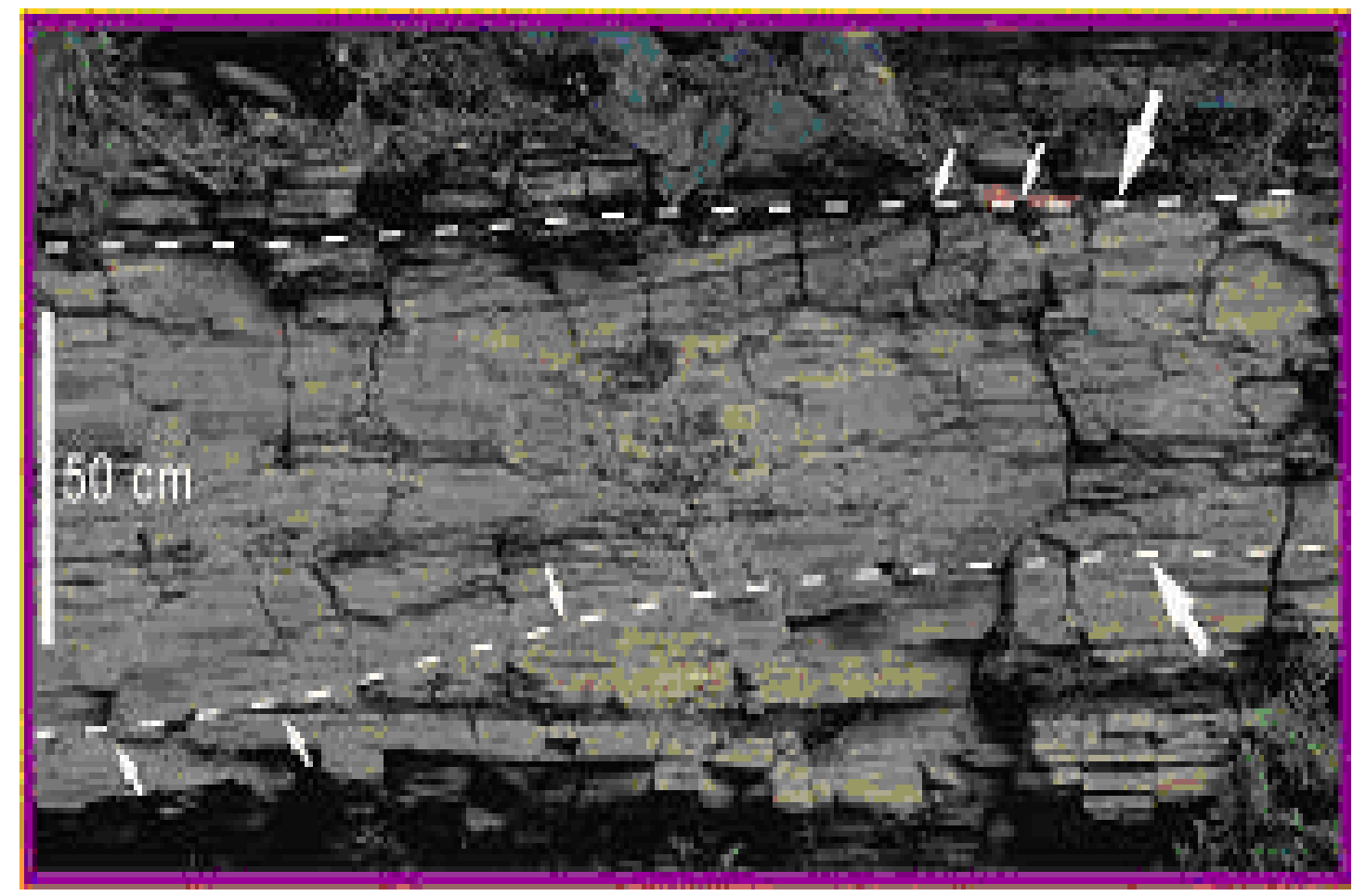

Figure II-1. Fractured Eastern Black Shale (geology.com).

In Figure II-2, the demand for natural gas keeps increasing compared to production. By 2003 , the U.S was importing up to $15 \%$ of natural gas to keep up with the increasing demand. More gas wells and better drilling techniques have to be discovered and 
developed in the U.S to stop or reduce the reliance on foreign energy to meet up with demands in the U.S.

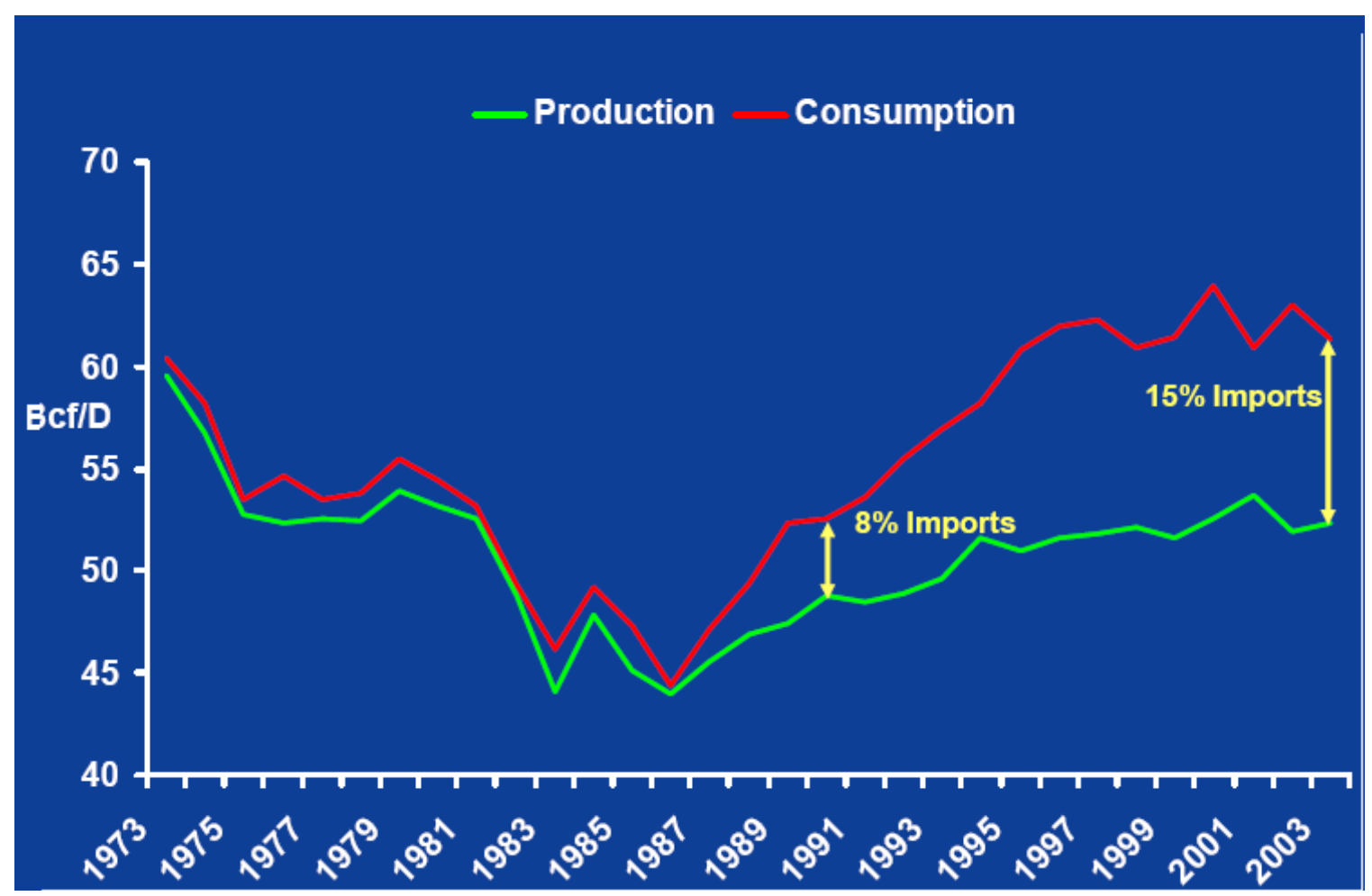

Figure II-2 U.S demand for Natural Gas (EIA, 2008).

Mainly Canada and other countries like Venezuela supply most of the deficiency or shortages. These countries, however, are facing declines in natural gas production as their gas fields are depleting and their internal demand is on the increase. Therefore, to meet this increasing demand, producers will increasingly rely on production from unconventional gas such as tight sands, coaled methane, and gas shales. Production from these unconventional sources is, however, difficult and expensive and technologies have to be developed to economically and successfully produce from them. It is estimated that with the successful application of technology in unconventional gas fields, the nation's 
energy needs could expand to $28 \%$ of the total production or about $7.5 \mathrm{Tcf} / \mathrm{year}$ for the next two decades.

Our domestic gas production has been on a good run over the last five years due to the development of unconventional production - specifically from shale deposits across the United States. As seen in Figure II-3 below, U.S. production has been growing steadily. From the 1940 's to the 1970 's U.S production steadily increased mostly from conventional reservoirs. In the late 1970's, the production started to decline, primarily due to fact that most of the easier conventional reservoirs had or were being depleted. The Barnett shale in Texas was first produced in 1982 and the Antrim shale of Michigan in 1985 (Drake, 2007). Around this point in time, the U.S. gas production continued to increase due to the increase in production of those unconventional reservoirs.

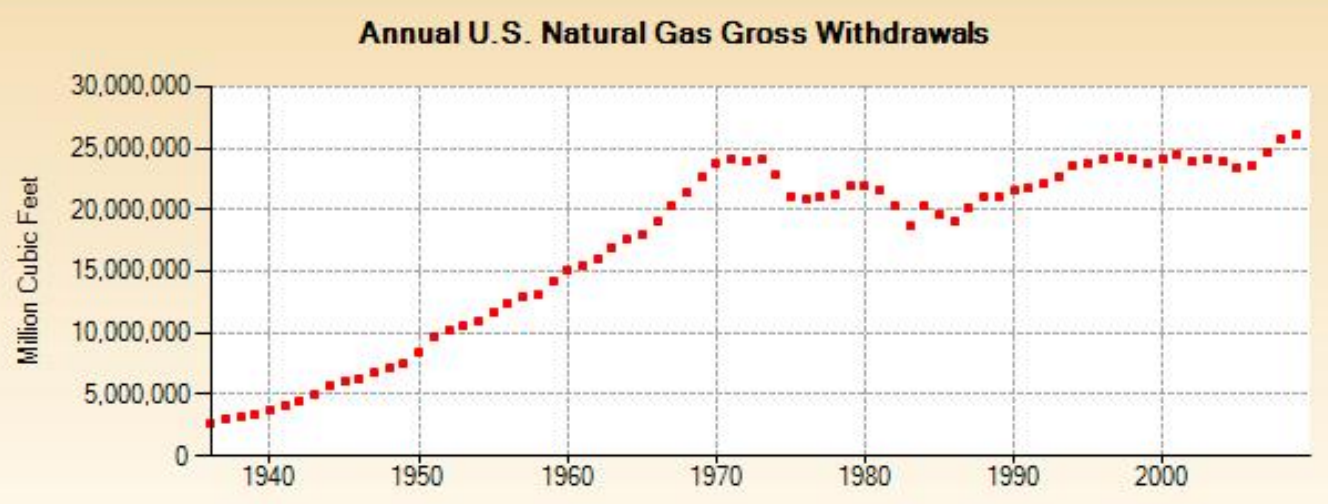

Source: U.S. Energy Information Administration

Figure II-3; Annual U.S. natural gas gross production per year (EIA, 2008).

The complexity of Devonian shale leaves many questions unanswered like,

a) What is it that can make shale a commercial play?

b) How do you evaluate the potential of these shales? 
c) What new technology has been developed to exploit these plays?

d) What can we learn from one play that can be applied to other plays?

e) Why is most well bore stability problems encountered in shales?

These questions can be answered if in-depth research is done in understanding the behavior of shales by examining its internal stratigraphy, reservoir characteristics, production controls, drilling and development history. Below is an overview of characteristics of Devonian shales with an examination on the following

-Permeability.

-Porosity.

-Pressure.

-Temperature.

-Natural Fractures.

-Thickness and Depth.

-Mineralogy.

-Thermal Maturity.

-Total Organic Content.

-Completion Types.

-Log Response.

-Decline Curve. 


\section{II.1.1 Permeability}

This is the ability, or measurement of a rock's ability, to transmit fluids through a porous medium, typically measured in Darcie's or millidarcies. It is described by Darcy's law;

$$
Q=\frac{K A}{\mu L}\left(P_{1}-P_{2}\right)
$$

Where; $\mathrm{Q}$ is the total discharge (units per time, e.g., $\mathrm{ft}^{3} / \mathrm{s}$ ) is equal to the product of the permeability of the medium, the cross sectional area to flow, and the pressure difference, all divided by the dynamic viscosity and the length over which the pressure drop is taking place.

$\mathrm{K}$ is the permeability,

$\mathrm{A}$ is the cross sectional area,

$\mathrm{P}$ is the pressure,

$\mu$ is the viscosity and

$\mathrm{L}$ is the length

Shale is an impermeable formation because its pores are few or less interconnected and thus has poor to fair permeability. Two forms of permeability are distinguished in Devonian Shales; matrix permeability and fracture permeability. Matrix or micro pore permeability contains most of the gas but transmits the gas at a very slow rate to the fracture and wellbore. The matrix permeability is therefore one of the controls on long term gas production in Devonian Shales even though the major flow network in the reservoir is through the natural fractures. Devonian Shales have matrix permeability 
values that typically range from 10 to 100 nano-Darcies (or 0.00001 to $0.0001 \mathrm{md}$ )

(Zhang et al 2009). Fracture permeability values range from 0.0001 to $0.001 \mathrm{md}$.

\section{II.1.2 Porosity}

This is the percentage of void space, or that volume within a rock that can contain fluids and this is very little or small in shales. Gas storage mechanisms in Devonian shale formations are quite different from those in conventional gas reservoirs and are classic examples of dual porosity, fractured-reservoir model. In this dual-porosity, fractured reservoir model, the reservoir is composed of matrix elements and fractures. The matrix is a portion of the reservoir that can store large quantities of gas, but it does not have the conductivity to transport gas for long distances. The fractures, which partition the matrix elements can transport the gas but have limited storage capability and therefore have low porosity values. Therefore, unlike conventional reservoirs where production follows a single-porosity system, in Devonian shales (dual-porosity reservoir) gas flows through the fracture network to the well. The fracture network, in turn, is being constantly recharged by flow from matrix elements. Thus, due to its lack of open pore space; shales store an enormous amount of gas in a sorbed (adsorbed or absorbed) state (Pritchett, 1980).

Studies on Devonian shales indicate an average fracture porosity of 0.2 to $0.8 \%$ and a matrix rock porosity of $2-8 \%$. 


\section{II.1.3 Pressure and Adsorption}

The Langmuir isotherm states that whenever a gas is in contact with a solid there will be an equilibrium established between the molecules in the gas phase and the corresponding absorbed species (molecules or atoms), which are bound to the surface of the solid. Initially, the gas is limited to the matrix and is in equilibrium with the surface of the rock (Langmuir isotherm) and there is, therefore, no interaction between molecules absorbed on neighboring sites. When fractures are created, pore space or interconnectivity is increased and because molecules of gas attract each other, and increase in volume (Van der Waals), they move or diffuse from the fracture network (high concentration of gas) to the well (low gas concentration) (Fick's law).

Two equations used for adsorption data that describe the volume of gas adsorbed as a function of pressure at constant temperature is Langmuir and Freundlich isotherms. The Freundlich isotherm is a power-law relationship between adsorbed volume and pressure, and thus it does not limit the total volume adsorbed. Studies, however, show that the adsorbed volume reaches a limit at high pressure; therefore, the Freundlich isotherm may be unsuitable when the reservoir pressure is high. The Langmuir isotherm does limit the total methane adsorbed. It can be written as;

$$
V_{E}=\frac{V_{L} P_{g}}{P_{L}+P_{g}}
$$

Where;

$P_{g}=$ gas pressure,

$P_{L}=$ Langmuir pressure, the pressure at which total volume adsorbed, $\mathrm{V}_{\mathrm{E}}$, is equal to 
one-half of the Langmuir volume, $\mathrm{V}_{\mathrm{L}}$.

$\mathrm{V}_{\mathrm{E}}=$ volume of gas adsorbed per unit volume of reservoir in equilibrium at pressure $P_{g}$

$\mathrm{V}_{\mathrm{L}}=$ Langmuir volume, the maximum sorption capacity of the coal.

The Langmuir adsorption isotherm is thus the most popular model used for describing the gas adsorption/desorption process. The matrix is so tight that it takes a long time for pressure drawdown to be felt deep within the matrix. Thus, pressures can remain at initial conditions for years resulting in the rock matrix having infinite acting characteristics. Carlson (1991) calls this semi-infinite flow. Natural fracturing, however, is the reservoir trait which most dominates the flow behavior for Devonian shale gas reservoirs.

Therefore fracture permeability is a major parameter in the performance of a single well system. Devonian Shales appear to be at irreducible water content and exhibits singlephase behavior. Production decline curves demonstrate relatively high initial flow rates which indicate initial natural fracture depletion, followed by a long period of low flow rate with very little decline indicating flow from the low permeability matrix (Sweeney, 1986).

Typical reservoir pressure readings for Devonian Shales range from 500-2000 psi (Fontaine et. al. 2007).

\section{II.1.4 Temperature}

This is an important parameter in Devonian Shales as it can be used to evaluate thermal stimulation as a recovery method and to extrapolate laboratory measurements to reservoir 
conditions (Chun Lu et al, 1995). Bottom hole temperatures in Devonian shales typically range from $60-100^{\circ} \mathrm{F}$ (Minthorn and Garvin, 1991).

\section{II.1.5 Natural Fractures}

This is by far the most important play or parameter in Devonian Shales with gas production controlled largely by fractures, with the production rate dependent on the number, length, openness, and direction of these fractures. Fractures create the permeability and increase the storage capacity within the shale and thus necessary to release the entrapped gas into the wellbore for commercial production or drilling.

Unfortunately, determining these fractures is not an easy task mainly because the cause of fracturing is not well understood and many theories have been proposed especially for the Appalachian Basin. Some suggest that the fracture system may be related, for example, to the deformation that produced the Appalachian Mountains; to settling above deep-lying faults, thousands of feet below the Devonian Shales; or to major zones of fracturing, scores or even hundreds of miles long, that are known or suspected to exist in the region. Until the origin is known, a rational search for fracture-controlled gas accumulation will be difficult.

Much research, however, has/is being done to determine these fractures, as it is the key in enhancing production from Devonian Shales. Remote-sensing techniques (LANDSAT imagery) can be used to detect fractures and their patterns that extend upward through overlying rocks and reach the surface. Gaskari and Mohaghegh (SPE, 2006) introduced a new strategy for estimating major and minor natural fractures using production data by 
combining the Geographic Information System (GIS) and Intelligent Production Data Analysis (IPDA), which if properly used would increase the probability of drilling more productive wells in the shale reservoir. Most recent advancement has been done by Schlumberger who have been able to develop a geophysical tool (Azimuthal Seismic) which is capable of detecting fracture systems and fracture trend directions that can be used to plan horizontal drilling directions and thus result in significant additional production.

Fracturing involves isolating sections of the well in the producing zone, and then pumping fluids and proppant (grains of sand or other material used to hold the cracks open) down the wellbore through perforations in the casing and out into the shale. The pumped fluid, under pressures up to $8,000 \mathrm{psi}$, is enough to crack shale as much as 3,000 $\mathrm{ft}$ in each direction from the wellbore. In the deeper high-pressure shales, operators pump slick water (low-viscosity water-based fluids) and proppant. Nitrogen-foamed fracturing fluids are commonly pumped on shallow shales and shales with low reservoir pressures.

As seen in Figure II-4, the use of substantial volumes of slick waters and low quantity of proppant sand to refracture the Barnett Shale resulted in productivities as good as or better than the original completion. In some cases, the well productivities after refracturing were the highest ever recorded in the field. 


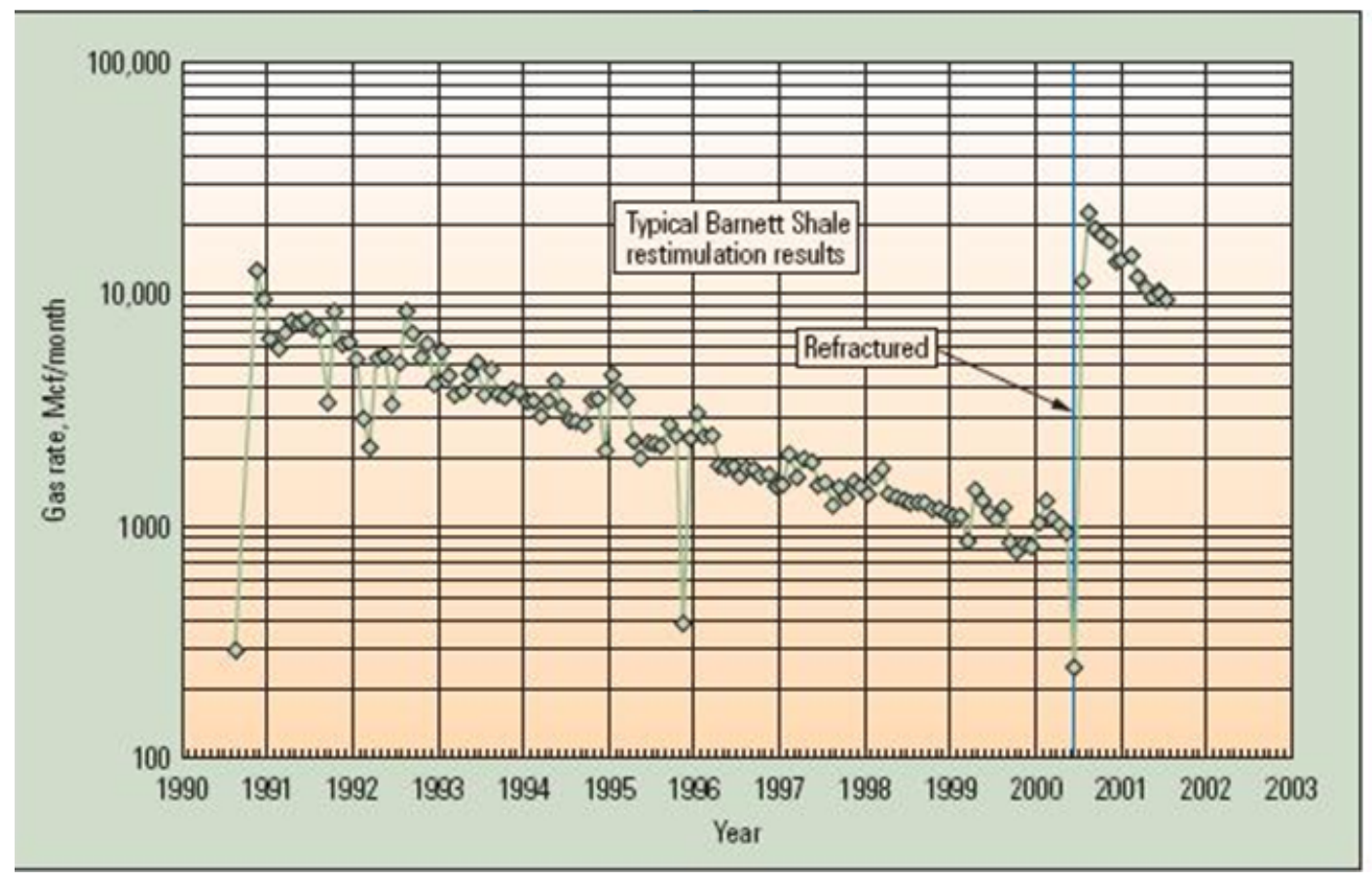

Figure II-4.Typical Barnett shale restimulation results (Pickering, 2005).

\section{II.1.6 Thickness and depth}

There is a great variation in thickness of Upper Devonian rocks with the rocks being thin and shaly on the west and becoming thicker and more sandy towards the east. Overall, thickness of the total Devonian Shales is about 2.000 feet at the west end of the section and 6,600 feet at the east end.

Devonian Shales have a gentle inclination, or dip to the southeast with values up to 6,000 feet (Fontaine et. al. 2007). One good thing with the Appalachian Basin with regard to depth is that at no place is depth to the shale too great to be reached by the drill. 


\section{II.1.7 Mineralogy}

The major mineral compositions of Devonian Shales are clay minerals, quartz and organic materials, principally kerogen; other minerals like feldspar, dolomite, calcite, siderite and gypsum exist and are considered to be basically inert and not affected by the chemical environment of drilling fluids, although their presence may result in mechanical instabilities. Other minerals such as kaolinite, illite, chlorite, and montmorillonite and mixed-layer clays absorb water when exposed to water-base fluids and are the reactive portion of a shale formation that causes varying degrees of instability.

\section{II.1.8 Thermal maturity}

Thermal maturity of a shale helps in determining reservoir potential, that is, whether a reservoir contains oil, gas or no hydrocarbon. It is measured in the laboratory using core samples by vitrinite reflectance (gives a measure of the maximum temperature the shale has been exposed to and thereby whether or not the organics in the rock have been baked enough to generate oil/gas). Thermal maturity thus converts kerogen to gas and oil ( $1^{\circ}$ cracking) and also converts retained oil to gas $\left(2^{\circ}\right.$ cracking). Figure II- 5 below gives an indication of the likelihood of gas and oil. A reading greater than 1.0 usually indicates the gas window, while a reading greater than 1.4 indicates a dry gas. Values less than 0.6 indicate that the reservoir is too immature to produce hydrocarbons. 


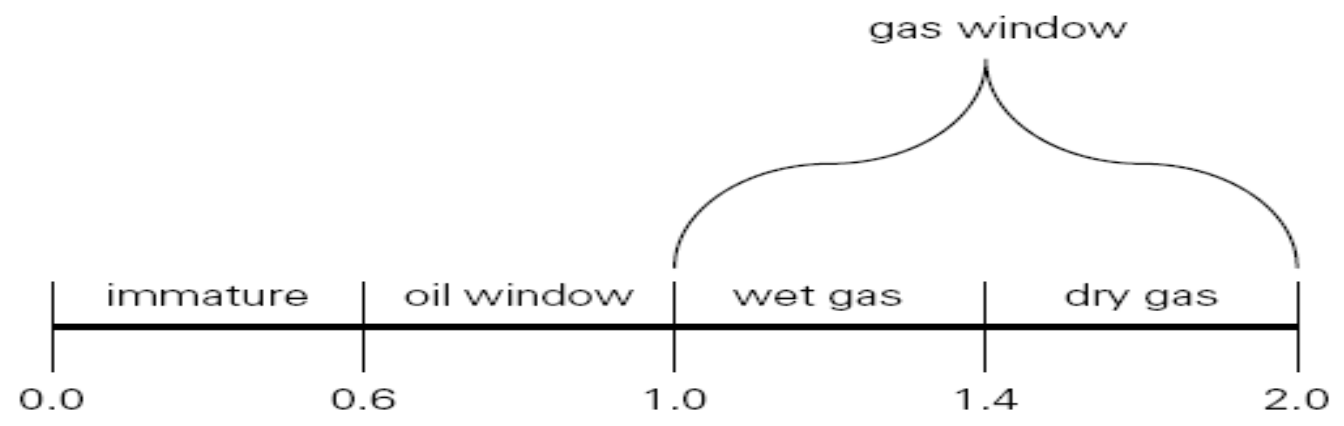

Figure II-5. Vitrinite Reflectance (Pickering, 2006).

\section{II.1.9 Total Organic Content (TOC)}

The TOC content of sediment is expressed as a weight percent. The TOC is an indicator of the total amount of organic matter present in the sediment (Ronov, 1958). When using TOC, the hydrocarbon-generating potential is commonly interpreted using a semi quantitative scale such as shown in Table II-1 (Peters, 1986; Jarvie, 1991). Although a good source rock should have a high TOC, not all-organic matter is created equal. Some organic matter will generate oil, some will generate gas, and some will generate nothing (Tissot et al., 1974).

Source Richness Interpretation of Weight Percent Total Organic Carbon (TOC)*

\begin{tabular}{lc}
\hline Richness & TOC (wt. \%) \\
\hline Poor & $0.0-0.5$ \\
Fair & $0.5-1.0$ \\
Good & $1.0-2.0$ \\
Very good & $>2.0$ \\
\hline
\end{tabular}

Table II-1. Total Organic Carbon (TOC), (Peters, 1986) 
For organic matter to generate hydrocarbons, the carbon has to be associated with hydrogen. The more hydrogen associated with the carbon, the more hydrocarbons it can generate. This is important in gas production in Devonian Shales. It is measured in the laboratory using a technique called pyrolysis, thus core samples of the shale must be available. There is a linear relationship between TOC and gas content. A high TOC value suggests a large potential to generate hydrocarbons. Successful drilling for gas in shale should have TOC values from 3-5\% but Devonian Shales have TOC values that range from $0-4.7 \%$ (Fontaine et. al. 2007).

\section{II.1.10 Log response}

The log readings are a good indication of the presence of gas in Devonian Shales. Porosity value greater than $8 \%$ on the log scale is a good indicator. Gamma ray response is high in shales because they contain radioactive elements and so emit lots of gamma rays. Shales that contain gas also have high resistivities. In fact a higher resistivity reading is better because it is indicative of better maturity, possible presence of quartz and/or carbonate. Lower resistivity reading can be indicative of high clay content. A log bulk density reading less than $2.58 \mathrm{~g} / \mathrm{cc}$ is a good indication of gas in Devonian Shales (Fontaine et. al. 2007).

\section{II.1.11 Completion Types}

Gas wells completed in the Devonian shale fall into three categories:
a) Open-hole natural.
b) Open hole stimulated.
c) Cased hole perforated and stimulated. 
"Natural" open-hole completions have been made in wells within which no casing was run and gas flow volumes were sufficient to preclude stimulation (Sweeney, 1986).

Stimulated open-hole wells have been treated with explosives to increase production rates by localized shattering of the reservoir rock over long intervals. Most wells that have had casing run for completion were selectively perforated in discreet intervals. Each individual shaped charged could be placed at any point within the well, and then the well could be fractured by hydraulic means.

Explosive stimulation of open-hole wells is rarely practiced at present, having been used from the late 1800 's to the late 1960 's.Hydraulic fracturing of cased and perforated wells has become common practice since the middle 1960's.

\section{II.1.12 Decline curve for Devonian Shale Gas Production}

The Devonian shales have been a major source of gas in West Virginia, and continue to be a target for new drilling. Although first year production is seldom very high, and production declines rapidly in the first three or four years, this decline usually tails off to a near-constant level for up to three decades or more. Thus, gas decline curves from Devonian shale wells appear to possess a distinctive shape. One explanation for this is that early production comes primarily from gas contained within natural fractures. This gas becomes depleted early in the history of a well, and production then consists of gas contained within the pore spaces of the rock. Although a large proportion of the total gas 
in place is in the matrix, this matrix-bound gas migrates to fractures and the well bore at a slow rate, so production is not high, but steady (Neal and Price, 1986).

Bagnall and Ryan (1976) published decline curves for gas wells in Lincoln, Mingo, and Wayne Counties (Figure II-6). They divided the full range of initial potentials into four intervals, and drew an average decline curve for wells falling in each interval. In general, wells with the highest initial potentials continued having the highest annual production. The curves tend to flatten out after about 15 years. Two conclusions can be made from their findings. First, initial potential or observed first year production indicates subsequent behavior of the typical Devonian shale well throughout its productive life. Second, differences in decline curves between Devonian shale wells appear to be ones of intensity rather than kind; for all categories of initial potential, the average decline curve has the same shape. Apparently, the same geologic factors appear to control Devonian shale production throughout the geographic area studied by Bagnall and Ryan (1976).

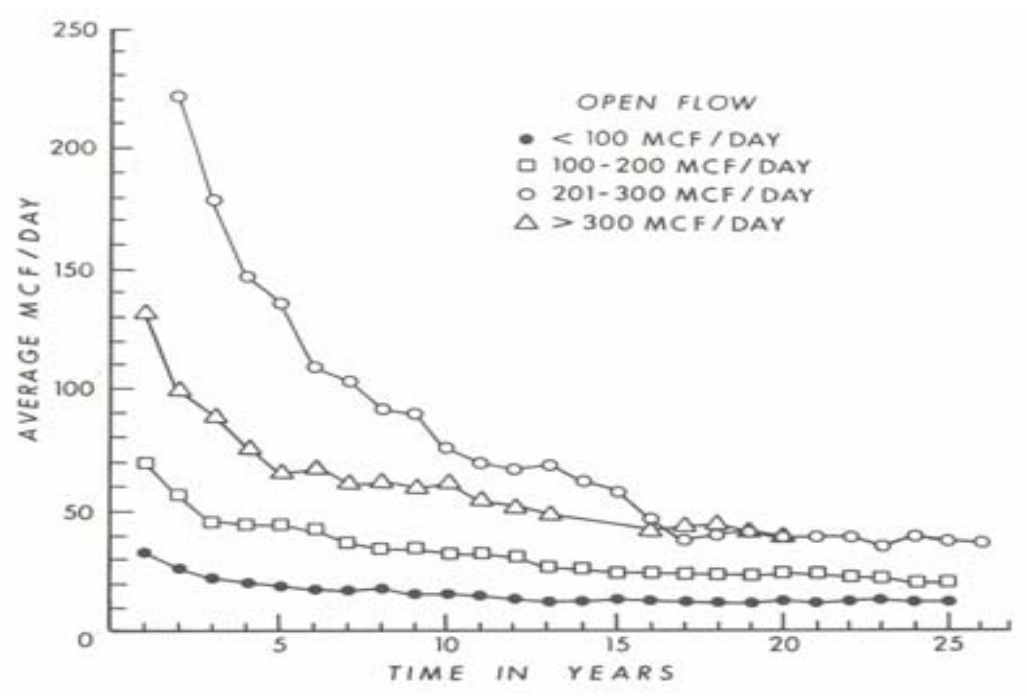

Figure II-6.Averaged production decline curves for Devonian shale gas wells in southern West Virginia (Bagnall and Ryan, 1976). 
Table II-2 below gives a summary of properties for different Devonian shales. The Barnett, Ohio, Antrim, New Albany, Lewis and Fayetteville shales are different with regards to depth, gross thickness, temperature, porosity, permeability, fracture orientation, reservoir pressure, etc. Technological successes applied in one area cannot be fully implemented in Devonian shale because of these differences. It is realized, however, that although separated by 30 million years in time, the Marcellus and Barnett shale were generated by a similar depositional system and tectonic setting. The Marcellus and Barnett shale were the initial sediments deposited in a very deep, sediment starved, anoxic trough that formed in response to an impinging tectonic plate. Reservoir properties of the Barnett shale are, therefore, not much different from the Marcellus shale. 


\begin{tabular}{|c|c|c|c|c|c|c|}
\hline & Barnett & Ohio & $\begin{array}{l}\text { Antrim } \\
\text { Michigan }\end{array}$ & $\begin{array}{l}\text { New Albany, } \\
\text { Illinois }\end{array}$ & $\begin{array}{l}\text { Lewis } \\
\mathrm{WV}\end{array}$ & $\begin{array}{l}\text { Fayetteville } \\
\text { WV }\end{array}$ \\
\hline Depth, $\mathrm{ft}$ & $6500-8500$ & $2,000-5,000$ & $600-2200$ & $500-2000$ & $3000-6000$ & $1500-6500$ \\
\hline Gross thickness, $\mathrm{ft}$ & $150-700$ & $300-1,000$ & 160 & 180 & $500-1900$ & $50-325$ \\
\hline Net thickness, ft & $100-600$ & $30-100$ & $70-120$ & $50-100$ & $200-300$ & $20-200$ \\
\hline $\begin{array}{l}\text { Bottomhole } \\
\text { Temperature, F }\end{array}$ & 200 & 100 & 75 & $80-105$ & $130-170$ & \\
\hline TOC \% & 4.5 & $0.0-4.7$ & $1-20$ & $1-25$ & $0.45-2.5$ & $4-9.5$ \\
\hline Total porosity $\%$ & $4-5$ & 4.7 & 9 & $10-14$ & $3-5.5$ & 2.8 \\
\hline $\begin{array}{l}\text { Gas Filled } \\
\text { Porosity, } \%\end{array}$ & 2.5 & 2 & 4 & 5 & $1-3.5$ & \\
\hline $\begin{array}{l}\text { Water Filled } \\
\text { Porosity, \% }\end{array}$ & 1.9 & $2.5-3.0$ & 4 & $4-8$ & $1-2$ & \\
\hline $\begin{array}{l}\text { Flow Capacity- kh, } \\
\text { md-ft }\end{array}$ & $0.01-2$ & $0.15-50$ & $1-5000$ & $40-80$ & $6-400$ & \\
\hline Gas Content, scf/ton & $300-350$ & $60-100$ & $40-100$ & $40-60$ & $15-45$ & $60-220$ \\
\hline Adsorbed Gas, \% & 25 & 50 & 70 & $300-600$ & $60-85$ & $50-70$ \\
\hline $\begin{array}{l}\text { Reservoir pressure, } \\
\text { psi }\end{array}$ & $3,000-4,000$ & $500-2,000$ & 400 & 0.43 & $1000-1500$ & $600-2000$ \\
\hline $\begin{array}{l}\text { Pressure Gradient, } \\
\text { psi/ft }\end{array}$ & 0.43 & $0.15-0.40$ & 0.35 & $5-500$ & $0.20-0.25$ & \\
\hline $\begin{array}{l}\text { Water Production } \\
\text { BWPD }\end{array}$ & 0 & 0 & $5-500$ & 80 & 0 & \\
\hline Spacing, Acres & $60-160$ & $40-160$ & $40-160$ & $10-20$ & $80-320$ & \\
\hline Recovery Factors \% & $10-20$ & $10-20$ & $20-60$ & $7-20$ & $5-15$ & \\
\hline $\begin{array}{l}\text { Gas in place } \\
\mathrm{BCF} / \text { section }\end{array}$ & $50-150$ & $5-10$ & $6-15$ & $7-10$ & $8-50$ & $25-60$ \\
\hline Reserves, MMCF & $500-4,000$ & $150-600$ & $200-1200$ & $150-600$ & $600-2000$ & \\
\hline
\end{tabular}

Table II-2; Summary of properties for Devonian shale. (GTI and Pickering, 2005) 


\section{II.1.13. Previous studies on Devonian Shale}

The Division of Energy set the pace in research to enhance production from Devonian shales. Before the Division of Energy's research on enhancing production of oil and gas from unconventional sources in 1976, only less than $7 \%$ of natural gas produced from gas wells came from unconventional sources. Today more than $40 \%$ of the natural gas produced from gas wells in the United States comes from unconventional gas sources: fractured gas shales, tight gas sands and coal seams (Lancaster et al, 1992).

Tax credits that began in 1980 and higher natural gas prices driven by rapidly growing demand have played a part in supporting economics but the tools for tapping into these resources when economics began to make sense would not have been there, or would not have been adapted quickly, if the groundwork had not been laid by research carried out through the Division of Energy's Unconventional Gas Research (UGR) Programs. For example, the first use of nitrogen foam to effectively stimulate production of gas from shale wells, the discovery of how natural gas is stored in coal seams and fractured shales, recognition of the importance of interconnected natural fractures in the production of gas from such reservoir, the first use of directional drilling in shale reservoir to improve productivity by intersecting fractures, the creation of advanced tools and methods for measuring the properties of unconventional reservoir rocks, and the early development of micro-seismic monitoring techniques for mapping hydraulically created fractures were done by the division of energy's unconventional gas research programs. Thus, a lot of studies have been done in Devonian Shale especially in trying to determine the natural 
fracture networks, which is the single and most determining factor in enhancing production in Devonian Shales. Other areas of studies include but not limited to, are; -Matrix permeability of Devonian Shales.

-Adsorption Mechanism of Devonian Shale.

-Swelling and sloughing problems in Devonian Shale.

-Estimating Major and Minor Natural fracture Patterns.

-Thermal maturity of Devonian Shale.

-Quantitative determination of the mechanical properties of Shale.

Talabani et. al. (1993), in their paper on shale sloughing and swelling, explained problems encountered when drilling in shale formations. Their research that was based on laboratory studies offers possible solution techniques in drilling successfully through shale formations that shows heaving problems.

Compressive wellbore failure is the major cause of stuck pipe, hole enlargement, poor log quality, poor primary cement jobs, and excessive drilling costs. Most wellbore-stability problems occur in shales (Stelger et al, 1992). Shale heaving is a major problem encountered when drilling in shale formations and if left unsolved could result in hole stability problems, may cause pipe stucking, high cost of drilling the hole, excessive solid buildup in the mud, hole bridging and possible abandonment of the well because the anticipated pay depth is difficult to reach. All these problems are compounded especially when drilling through heterogeneous shale lithologies because of variations in shale composition, ion exchange capacity, formation water content and shale strength. 
High degree of compaction and overburden pressure dehydrate subsurface shales. Now drilling a well relieves the lateral pressure and the shale formation imbibes or absorbs water from the drilling fluid. The stability of the borehole is thus compromised by the increase in high swelling pressure. It is therefore imperative to understand the interactions between the drilling fluids and the exposed shales. So, if the incorrect type of drilling fluid is used to drill these formations, productivity is restricted and hole stability problems may result. Highly bentonitic shale for instance can absorb water, soften, and become incorporated into the drilling fluid, thus increasing the viscosity of the drilling fluid to detrimental high values.

The three types of shale commonly encountered in drilling a borehole are;

A) Brittle (sloughing) shale and they have a low montmorrillonite content, high kaolinite and illite fractions;

B) Gumbo (plastic) shale contain about $10-20 \%$ of montmorillonite, $20-30 \%$ illite and may contain formation water;

C) Hydratable (swelling) shales have high content of montmorillinite and contain almost no formation water. This clay type contributes to excessive drilling fluid viscosity.

They proposed the use of calcium ions to improve shale stability. In fact a 50/50 mixture of calcium ions and potassium ions produced better shale stability results. Also, they realized that the use of polymers alone is not recommended for drilling through heaving 
shaly formations as this resulted to the loss of fluid to the formation in the form of polymer solution, causing an increase in osmotic pressure; thus weakening the shale bonds which eventually may cause shale swelling and heaving. They recommended a drilling fluid composed of $70-80 \%$ polymers, and having the same salinity as the formation, or using $\mathrm{CaCl}_{2}$ or $\mathrm{KCl}$ and then adding $20-30 \%$ of PHMP (Partially hydrolyzed high molecule weight polymers) when the $\mathrm{pH}$ is approximately equal to 8.0. This will result in a stable hole condition while drilling through sloughing shale formation. The presence of $\mathrm{CaCl}_{2}$ or $\mathrm{KCl}$ helps to eliminate the differential osmotic pressure.

Luffel et. al. (1993) developed three laboratory methods to measure matrix gas permeability $\left(\mathrm{k}_{\mathrm{m}}\right)$ of Devonian Shale. They point to the fact that previous studies on Devonian Shale permeability that gave a range from $<0.01$ to 800 microdarcies $\left(1 \times 10^{-5}\right.$ to $0.8 \mathrm{md}$ ) are erroneous or unreliable for two reasons. Firstly, the pulse test experiment have generally been limited to measuring permeability greater than $0.01 \mu \mathrm{d}$. Secondly, laboratory tests show that even when the shale cores are loaded to reservoir stress, one or two coring-induced micro fractures are usually present that remain partially open. These micro fractures dominate flow, so observed permeability exceeds true matrix permeability by several orders of magnitude.

Their study was focused on $\mathrm{K}_{\mathrm{m}}$ values in the range $10^{-9}$ to $10^{-6} \mathrm{md}$. Matrix permeability values greater than $10^{-6} \mathrm{md}(0.001 \mu \mathrm{d})$ had productivity controlled solely by fracture properties and so recovery is independent of $\mathrm{K}_{\mathrm{m}}$. Matrix permeability values less than $10^{-}$ 
${ }^{9}$, recovery is too low to be commercial. In order to measure $K_{m}$ at levels 100 to 10,000 times lower than previous methods, and in the presence of micro fractures, they choose three methods.

a) Pulse pressure testing of core plugs with helium.

b) Pulse pressure testing of crushed core chips with helium.

c) Degassibility testing of core plugs with helium and methane.

Using core plugs that were injected with fluorescent dyed epoxy at in situ stress of 2000 psig, each thin section was examined with a petrography microscope under both transmitted light (plane and cross-polarized) and reflected light. This permitted the detection of smaller fractures. They realized that all of the thin sections showed from 1 to 5 large continuous fractures, and 5 to 20 discontinuous large and small fractures.

In pulse pressure tests, core chips/cuttings for a measured weight of crushed shale (15 to $30 \mathrm{gm})$ are placed in a small cell. A pressure drop to a level dictated by dead space in the sample cell is noticed once helium is expanded into the sample cell from a reference chamber at 200-psig. The pressure data are then modeled using a reservoir simulator. The results of their laboratory studies show matrix permeability to be equal to 0.2 to $45 \times 10^{-8}$ md.

The degassibility measures matrix permeability in the presence of gas adsorption. The degassibilty tests with helium shows $\mathrm{K}_{\mathrm{m}}=0.67$ to $200 \times 10^{-8} \mathrm{md}$ and $\mathrm{K}_{\mathrm{m}}$ higher than for pulse tests on plugs and chips by a factor of 3 to 10 on average. 
Lu et. al. (1995) wrote a report on the determination of gas storage in Devonian Shale with the use of x-ray computed tomography scanning. They used krypton gas instead of xenon gas that is commonly used because as they realized the properties obtained using krypton gas more closely approximates those of natural gas and the adsorption force is also a superior saturating fluid for studies of natural gas storage. Their findings show that there is a decrease in storage with pressure in the presence of a condensed phase.

\section{II.2 Marcellus Shale}

The Marcellus shale spans a distance of approximately 600 miles, trending northwestward from West Virginia all the way into New York. The Marcellus is approximately $7000-8000$ feet deep, with thickness ranging from 100 to 150 feet.

What is the best method to drill in the Marcellus is the question to be answered. Maybe it is vertical wells or possibly horizontal wells; maybe it is a combination of both. Maybe some areas will be better suited for verticals due to geology. Either way, these shale wells need stimulation to increase the permeability. Currently, the pore spaces in shales are typically not large enough for even tiny methane molecules to flow through easily. Shales may contain natural fractures due to stress from overlying rocks. Shale gas has long been produced when natural fractures are present. Recently, however, there has been more development of gas shales due to the use of techniques that create artificial fractures around well bores known as hydraulic fracturing (Sumi, 2008). The shale formations are naturally fractured, and made up of two distinct porous media, a shale matrix and a fracture network. Gas can be stored in the molecular size micro spore space of the shales; 
it can also be absorbed on the surface of the shale, or may be dissolved in the organic content of the shales.

The key in enhancing gas production from the Marcellus shale is in tapping into the cluster of fractures. The Marcellus shale has two sets of fractures, or joints - referred to as $J_{1}$ and $J_{2}$ as described by Engelder and Lash (2008). The $J_{1}$ joints, which run east northeast are denser, more closely spaced and are crosscut by the less well - developed, northwest - trending $\mathrm{J}_{2}$ joints. The key to operators is to drill horizontal wells to the north-northwest, or south-southwest and cross and drain a whole bunch of the densely developed $\mathrm{J}_{1} \mathrm{~s}$.

Figure II-7 shows semi-proprietary reports of $\mathrm{J}_{1}$ joints in fullbore formation micro imager (FMI) logs or reports of north north west horizontal drilling. This is in order to drill across the maximum amount of $\mathrm{J}_{1}$ joints thus to theoretically produce the most gas in the Marcellus shale (Engleder \& Lash, 2008). 


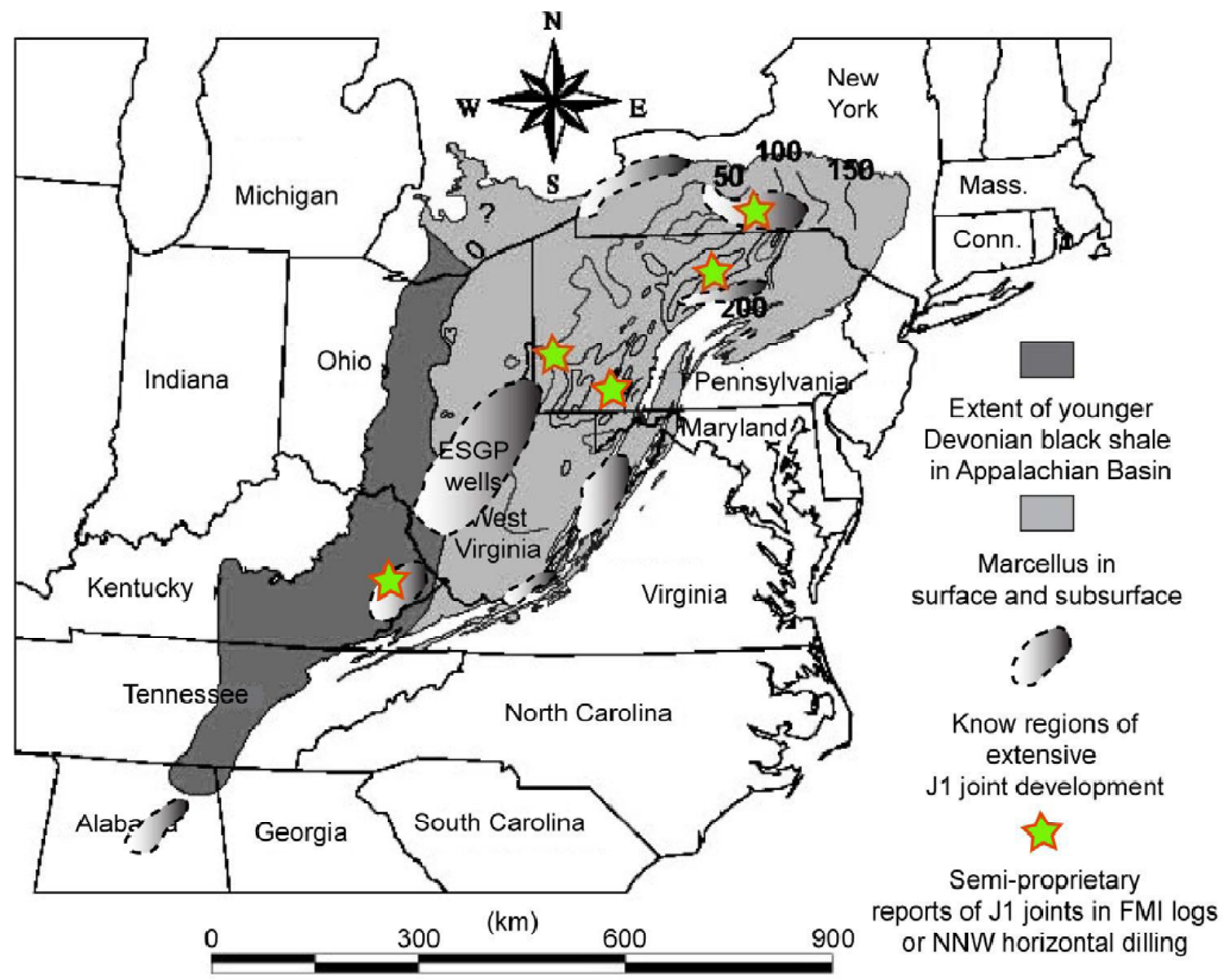

Figure II-7 Distribution of $\mathbf{J}_{\mathbf{1}}$ joints (Engelder \& Lash, 2008). 


\section{CHAPTER III. OBJECTIVES}

The objective of this study was to determine the impact of formation properties on the production of gas from shale formations. With many variables and uncertainty about the shale properties, the outcome of a well drilled can significantly change from economic success to failure. In this study, it is envisaged to understand the most influential parameters that affect the gas recovery and cumulative production from shale reservoirs. Additional study was conducted to study the impact of well completion and fracture treatment design on the cumulative gas production. 


\section{CHAPTER IV. METHODOLOGY}

In this study, a shale formation represented with the $12,000 \mathrm{ft}$ long and $6,000 \mathrm{ft}$ wide rectangular system is used with either one vertical well or horizontal well. A large area was considered in order to eliminate the boundary effects. The study consists of two parts with the first part representing the work conducted to determine the impact of well and fracture design parameters specifically the fracture half length using uniform formation properties. In the second part, the reservoir properties specifically the matrix and fracture porosity and permeability values were varied within the given range using a Monte Carlo approach.

The approach taken in this study is the utilization of two software applications. One software application is used for simulation of the shale reservoir parameters like porosity and permeability, the other for parameters like hydraulic fracture, half-length and lateral length. The objective of this research is to quantify the influence of reservoir parameters on cumulative gas production. These included studies on the permeability and porosity of the reservoir matrix and fracture, half-length, lateral length and number of hydraulic fracture treatments. Only one parameter was changed at a time to validate the effect of the parameter under study.

\section{IV.1 Simulation}

To find the effect of fracture half length, lateral length and hydraulic fracture network on cumulative gas production, a two-phase reservoir simulation is used. A variety of single 
well simulations were done on a 160-acre plot. The workflow below (Figure IV-8) illustrates the order of steps taken to achieve the results of our simulation. First, the model is defined by giving information on the title, simulation length and reporting time and then the model parameters that would be used. The next step is to define the layer (s) name if there is more than one layer; in this case the layer name is entered as the Marcellus. A description of the reservoir and then rock properties like fracture porosity, compressibility, bulk $\mathrm{x}, \mathrm{y}$ and $\mathrm{z}$ permeability are then entered to validate the rock property. The aquifer section of the reservoir description is also available but it is not used in this study, thus it is only included here for a complete description of properties needed for reservoir description. A description for fractures is included in the workflow to show the effect of fracturing on production performance. The reservoir description is followed by well description where vertical deviation survey data were entered. In the case of a horizontal well, a lateral was added. Once the well is defined, the next step is the production section where the well control is set. Also, the user can select the starting date for producing the well. For all runs, the well started producing at the beginning of simulation and stayed open until a preset condition is met. A bottom hole pressure was used to set the well production limit although the gas rate can also be used. Under the production reservoir description, necessary properties for the perforations are also entered for the horizontal segment of the well. The next step after the production information is to enter fluid properties like the Langmuir pressure and concentration. In the last step, simulation controls if any is included. Run were conducted and results were viewed and analyzed. 

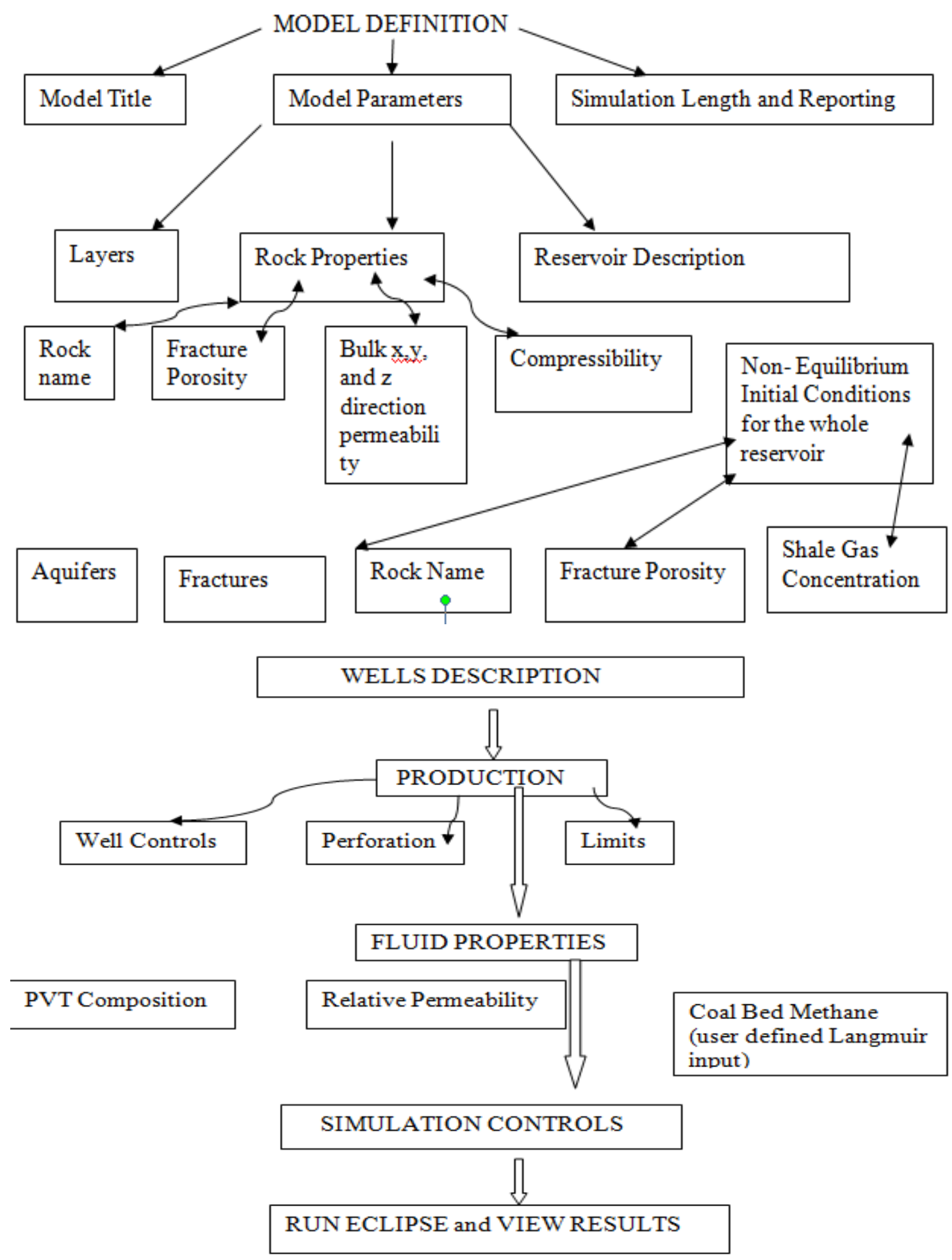

Figure IV-1 Eclipse Workflow. 


\section{IV.2 Use of Monte Carlo methods}

As part of the objective of this project, a Monte Carlo simulator has been incorporated into the simulation study to assign the selected property values within the given range. A Monte Carlo simulation is a large amount of random sampling or random test to find some large aggregate property of a system. In other words, this method enables us to examine the effects of randomness upon the predicted outcome of numerical models.

Monte Carlo requires that we have a model defined that relates the input variables (e.g. reservoir properties, drift, volatility properties etc) to the feature of interest (e.g. oil recovery, breakthrough time, water cut, dispersion, and oil or gas cumulative gas.) The model is not random, only the input variables are random. The distribution of the output quantity and in particular its variability are used to make decisions about economic viability, data acquisition, and exploitation strategy.

Monte Carlo (MC) methods are stochastic techniques, meaning they are based on the use of random numbers and probability statistics to investigate problems. Monte Carlo simulation is often used in business for risk and decision analysis, to help make decisions given uncertainties in market trends, fluctuations, and other uncertain factors. In the science and engineering communities, MC simulation is often used for uncertainty analysis, optimization, and reliability-based design. In manufacturing, MC methods are used to help allocate tolerances in order to reduce cost. In petroleum economics, by far the most frequent use of Monte Carlo is in reserves calculations and price return estimates. 
The stock-tank oil initially in place (STOIP) is given by

$$
\mathrm{STOIP}=\frac{\Phi\left(1-S_{W}\right)}{B_{o i}} A h
$$

Where $\quad A h=$ Net reservoir volume,

$B_{o i}=$ Initial oil formation volume factor?

$S_{w}=$ Interstitial water saturation, and

$\Phi=$ Porosity

In this case, this equation is the model and $\Phi, S_{w}$ and Ah may all be considered as independent random variables. In particular, $\Phi$ and $S_{w}$ can have meaning as independent random variables only if they represent average values over a given net reservoir volume, Ah.

To use the Monte Carlo method, the distributions for all the input variables have to be determined. Experience from other fields, data from the field under study, and geological knowledge all contribute to the selection of the cumulative distribution function for each variable. Interdependence between the variables (e.g., low $\Phi$ and high $S_{w}$ ) can be accommodated if it is known how the variables are interrelated. While Monte Carlo may seem like an easy option to theoretical approaches, it should be recognized that the results are sensitive to the input variables and consequently variability in the data will affect the results (Jensen et al, 1997). For example, in reserves estimation, if $\Phi$ and $S_{w}$ do not vary much while the rock volume Ah varies considerably, the STOIIP Probability Distribution Function (PDF) will be virtually identical to the Ah. 
For this study, the RAND function in excel spreadsheet program was used to generate random numbers. The RAND function returns numbers from the interval $(0,1)$, but to generate numbers from another interval, I used the formula

$$
=\text { RAND }()^{*}(\mathrm{~b}-\mathrm{a})+\mathrm{a}
$$

The above formula is the model while the porosity and permeability values are the variables. The equation above will return random numbers from the interval $(a, b)$, greater than or equal to $\mathrm{a}$, and less than $\mathrm{b}$.

\section{IV.3 Simulation with non-uniform properties}

For this study, a range of formation properties were selected from the values reported in literature. Due to the differences in the published data and also the variable nature of shale formations, a reasonable range was selected for each property investigated. The reservoir properties studied were formation and fracture porosity and permeability values.

In this study, the matrix permeability values varied between 0.00005 and $0.0005 \mathrm{md}$ which is a typical range for ultra-low permeability of the shale matrix considered in this research. Fracture permeability range of 0.0005 to $0.005 \mathrm{md}$ was used based on research on the range of fracture permeability for shale rock. The variation in the porosity of the stimulated fracture network was assumed to be 0.2 to $0.8 \%$ and the matrix porosity ranged from 2 to $8 \%$. 
The properties that are kept constant were the formation depth of $6000 \mathrm{ft}$, reservoir pressure of $3000 \mathrm{psi}$ and a formation thickness of $120 \mathrm{ft}$. Rock compressibility (3e-6psi), fluid properties, well perforation and descriptions were the same for all runs.

Several runs were conducted with different distributions of the same formation property and the results are presented in the next section. 


\section{CHAPTER V. RESULTS AND DISCUSSION}

In this section, the results from runs are presented with discussions on the production performance. The first set of results is from the simulator runs to determine the effect of hydraulic fracture network, lateral length and half length on cumulative gas production. The second set of results is presented for simulation runs where the impact of uncertainty of permeability and porosity values on cumulative gas production is discussed. At the end of all runs, an analysis is done to identify the most influential parameter on gas production.

\section{V-1 Comparison of horizontal and vertical well performance.}

Figure V-1 below shows the total gas production for a horizontal well versus a vertical well over a time period of 50 years. The horizontal well produces more gas (1000 MMSCF) than the vertical well. This is primarily because the horizontal well has more surface area of contact with shale and intersects more natural fractures.

The cumulative gas production from the vertical well is not as high as the horizontal well, however, it may still be economical to use a vertical well to produce gas if the formation characteristics support the production values obtained in this comparison. Additionally, it is observed that the cumulative production trends from both wells follow a parallel trend and there is a potential for more gas production in both cases. 


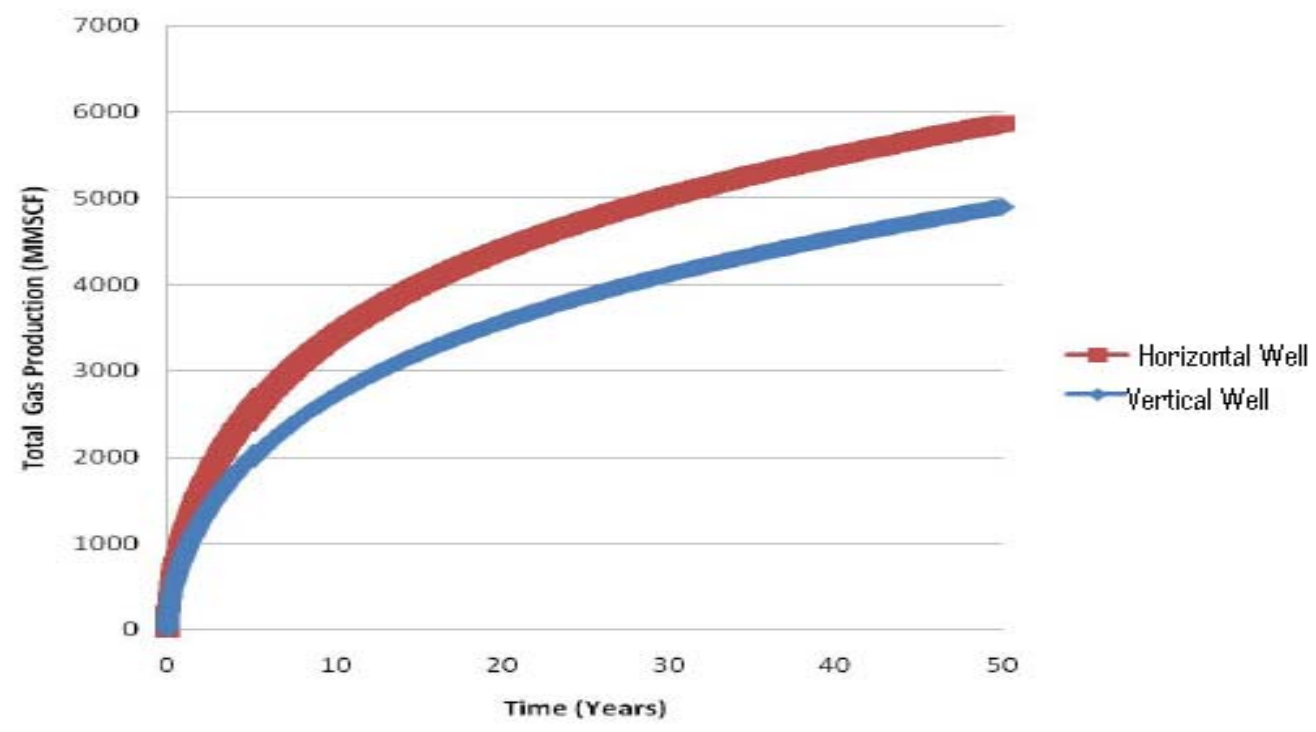

Figure V-1 Total gas production for horizontal and vertical well

Figure V-2 below compares the total gas production for four different horizontal well designs with four hydraulic fracture treatments with equal spacing along the lateral section. As the fracture half lengths increase from $200 \mathrm{ft}$ to $500 \mathrm{ft}$, the total gas production also increases. Each 100 foot difference in fracture half length produces more than $1300 \mathrm{MMCF}$ gas at the end of the 50 year period. Fracture half lengths are therefore a major contributor to increase in gas production. 


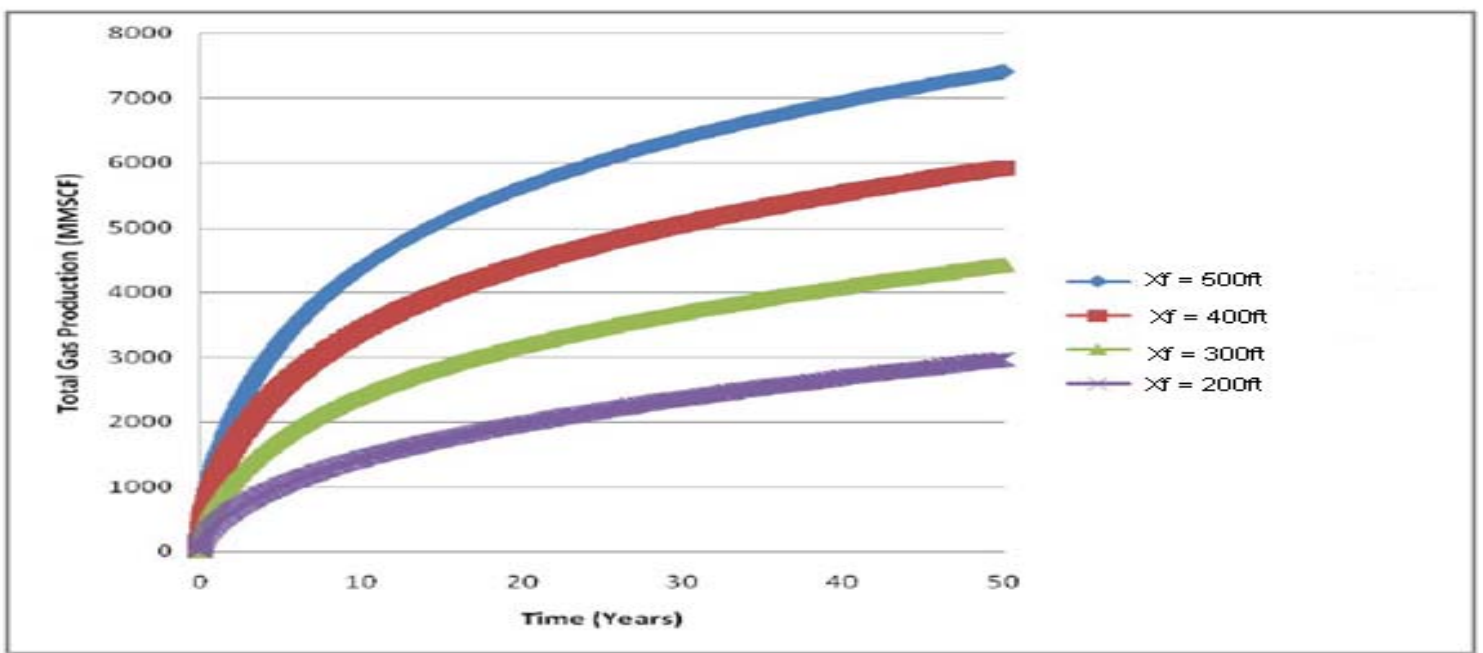

Figure V-2 Total gas production for different fracture half lengths.

Figure V-3 below compares the total gas production for four different horizontal well designs with four fracture treatments. Even with a small increase of $50 \mathrm{ft}$ in fracture half length from $450 \mathrm{ft}$ to $500 \mathrm{ft}$ the gas production increases approximately by $10 \%$. To produce more gas, it is necessary to increase the fracture half length and the number of fractures. The multi-stage fractures intercepted more areas of the lateral well as they come in contact with more of the pay zone, thereby increasing the probability of having a good flow path for the natural gas. 


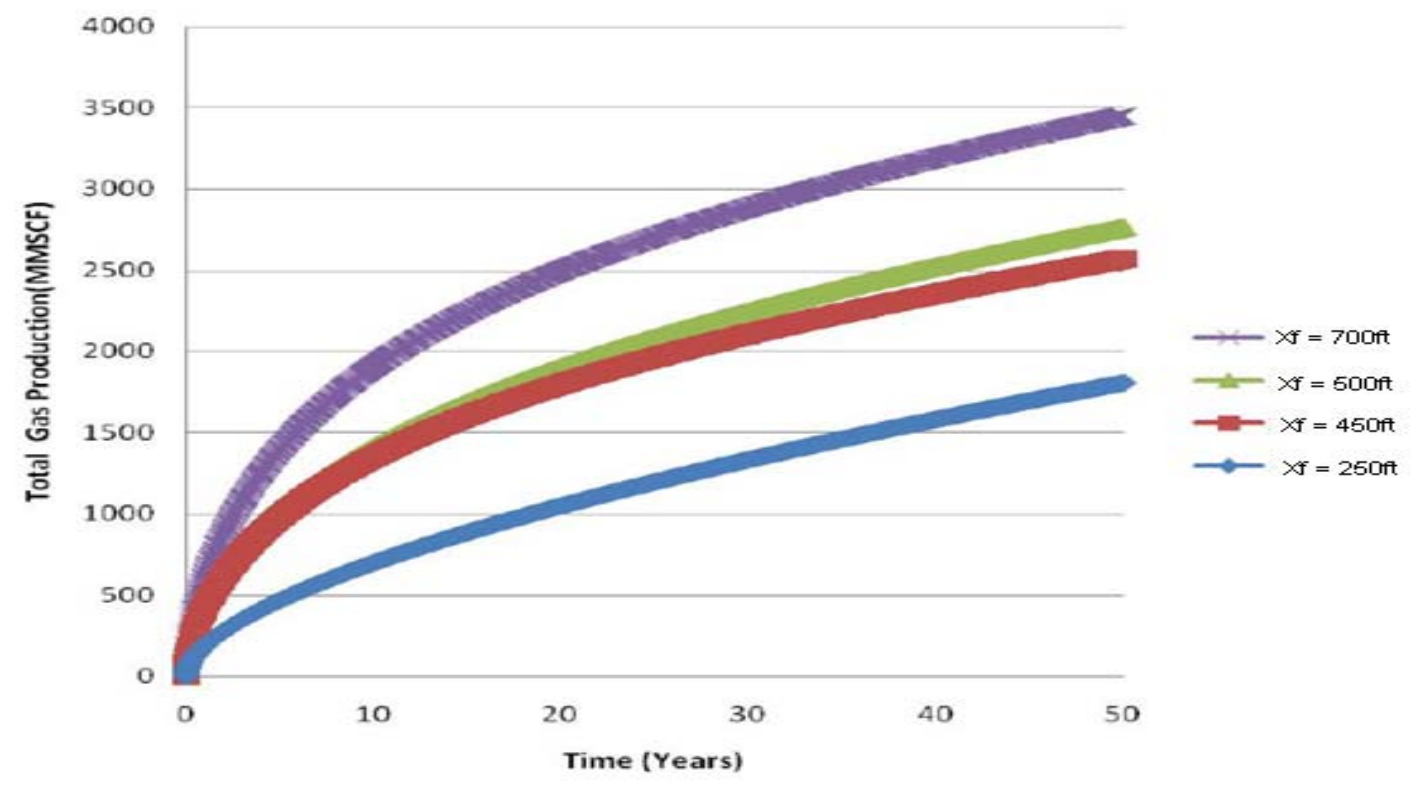

Figure V-3 Effect of fracture half length spacing.

In Figure V-4 below shows the cumulative gas production for 50 years where lateral length and fractures were varied in the simulation and the other reservoir parameters were kept constant. The results are presented for three different lateral lengths (3000, 4000 and $5000 \mathrm{ft}$ ) and three different fracture treatments (four, six and eight). The wells with high lateral length and more hydraulic fractures produced more gas over time compared to wells with lower fracture lengths and less fractures. Therefore, well stimulation increases the hydrocarbon production rate by improving the flow of hydrocarbon from reservoir to wellbore. Also, the longer the extent of the lateral length, the more gas production rate over the 50 year period. Although horizontal wells cost more to drill than vertical wells, their performance in terms of gas recovery in the long run yields more production and makes up for the cost in drilling. 


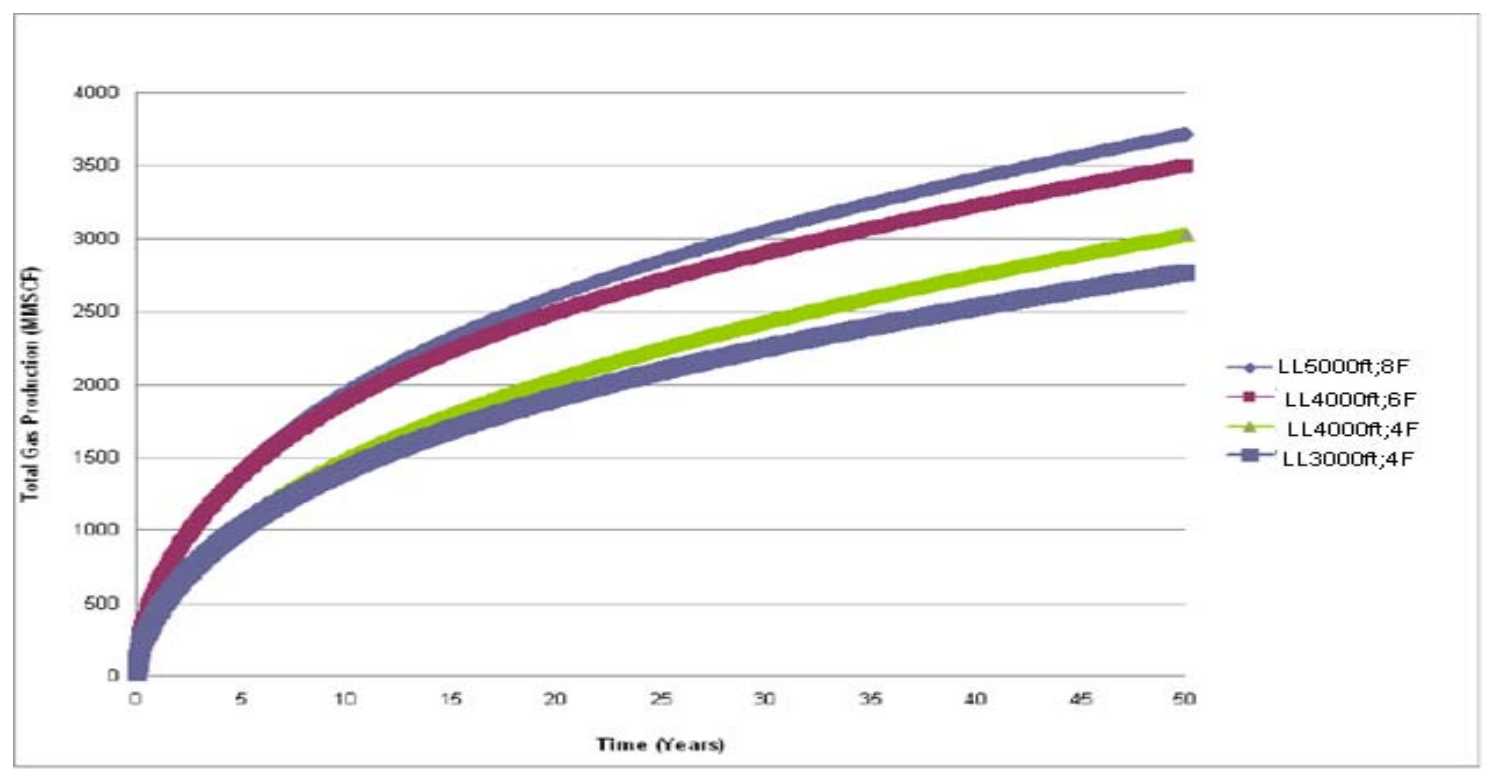

Figure V-4 Effect of lateral length and hydraulic fracture treatments.

\section{V-2 Effect of fracture porosity on production}

Ten runs were conducted with a single well in a heterogeneous reservoir to see the effect of variations of fracture porosity values on cumulative gas production over a forty (40) year period. All other reservoir parameters were kept constant. The range of fracture porosity (in fraction) used was based on the average fracture porosity values for Devonian shale $(0.2-0.8 \%)$. The range of fracture porosity was varied from 0.001 to 0.01 (Table V-1). The cumulative gas produced for every run is presented in Table V-2 below. Results show that the cumulative production values differ slightly with different distributions of fracture porosity values. The differences in cumulative gas produced for these runs are also plotted in Figure V-5. The distribution of fracture porosity values are graphically shown in Figures A.1 through A.10 in Appendix A. 


\begin{tabular}{|c|c|}
\hline Property & Values \\
\hline Depth (ft) & 6000 \\
\hline Reservoir Pressure (psi) & 3000 \\
\hline Formation Thickness (ft) & 120 \\
\hline Reservoir Temperature ( $\left.{ }^{\circ} \mathrm{F}\right)$ & 150 \\
\hline Fracture Permeability (md) & 0.0008 \\
\hline Matrix Porosity (fraction) & 0.04 \\
\hline Fracture Porosity (fraction) & $0.001-0.01$ \\
\hline Matrix Permeability (md) & 0.00005 \\
\hline
\end{tabular}

Table V-1 Formation properties used in runs with different fracture porosity distributions.

\begin{tabular}{|c|c|}
\hline Run Number & $\begin{array}{c}\text { Cumulative Gas Production, } \\
\text { MMSCF }\end{array}$ \\
\hline 1.1 & 1081.5 \\
\hline 1.2 & 1077.8 \\
\hline 1.3 & 1082.5 \\
\hline 1.4 & 1080.3 \\
\hline 1.5 & 1073.5 \\
\hline 1.6 & 1084.4 \\
\hline 1.7 & 1084.9 \\
\hline 1.8 & 1088.7 \\
\hline 1.10 & 1071.2 \\
\hline
\end{tabular}

Table V-2, Cumulative gas produced with different fracture porosity distributions.

It is observed that the cumulative gas production varies slightly with different distribution of fracture porosity over a forty year period as seen in Figure V- 5 below. 


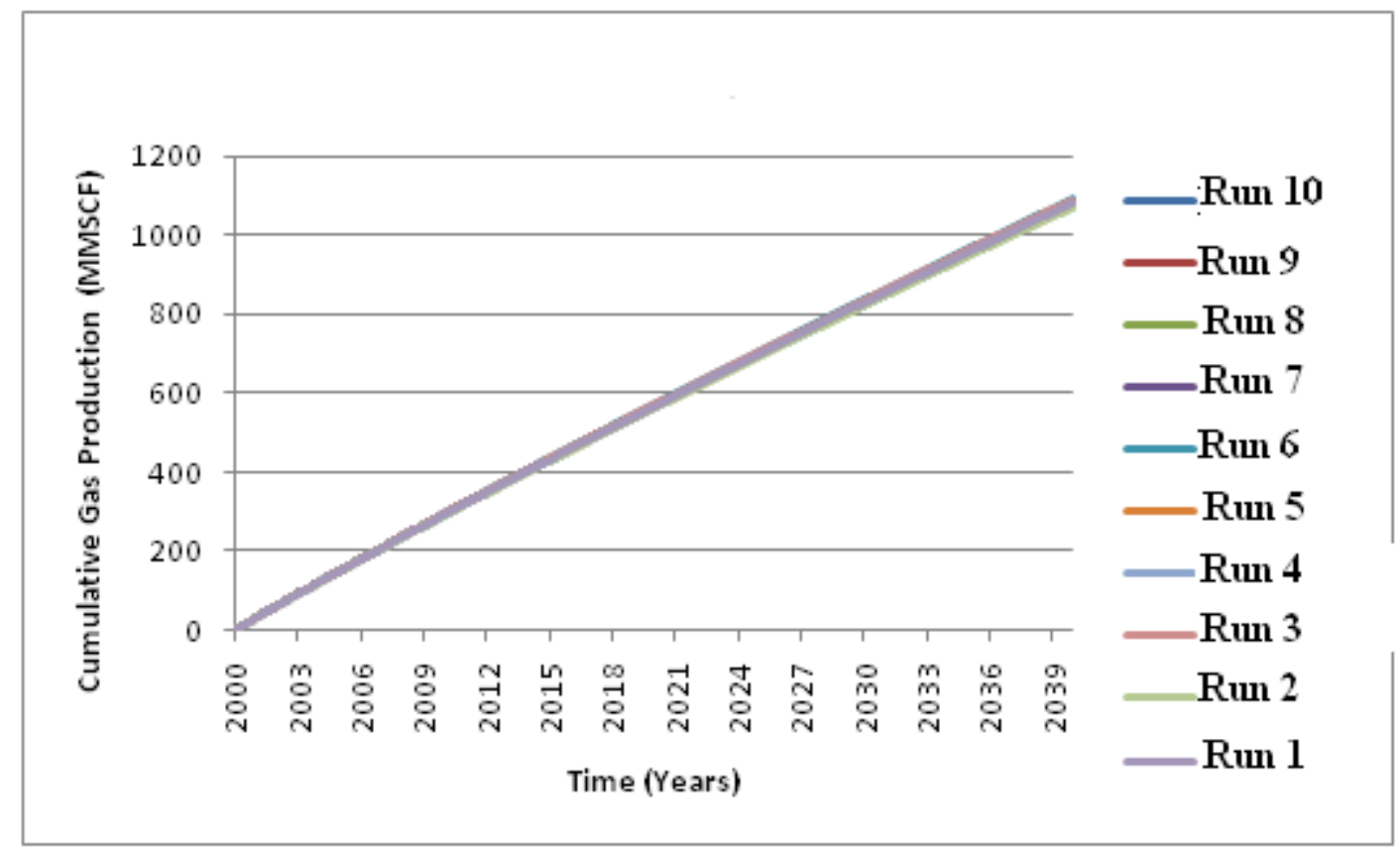

Figure V-5, Effect of fracture porosity distributions on cumulative gas production.

The histogram below (Figure V-6) shows the difference between the highest cumulative gas produced (1091 MMSCF) and the lowest cumulative gas produced (1071MMSCF) over the forty year period. The impact of fracture porosity values yielded a difference of 20 MMSCF gas production at the end of 40 years indicating a small uncertainty related to the input values used in these runs. 


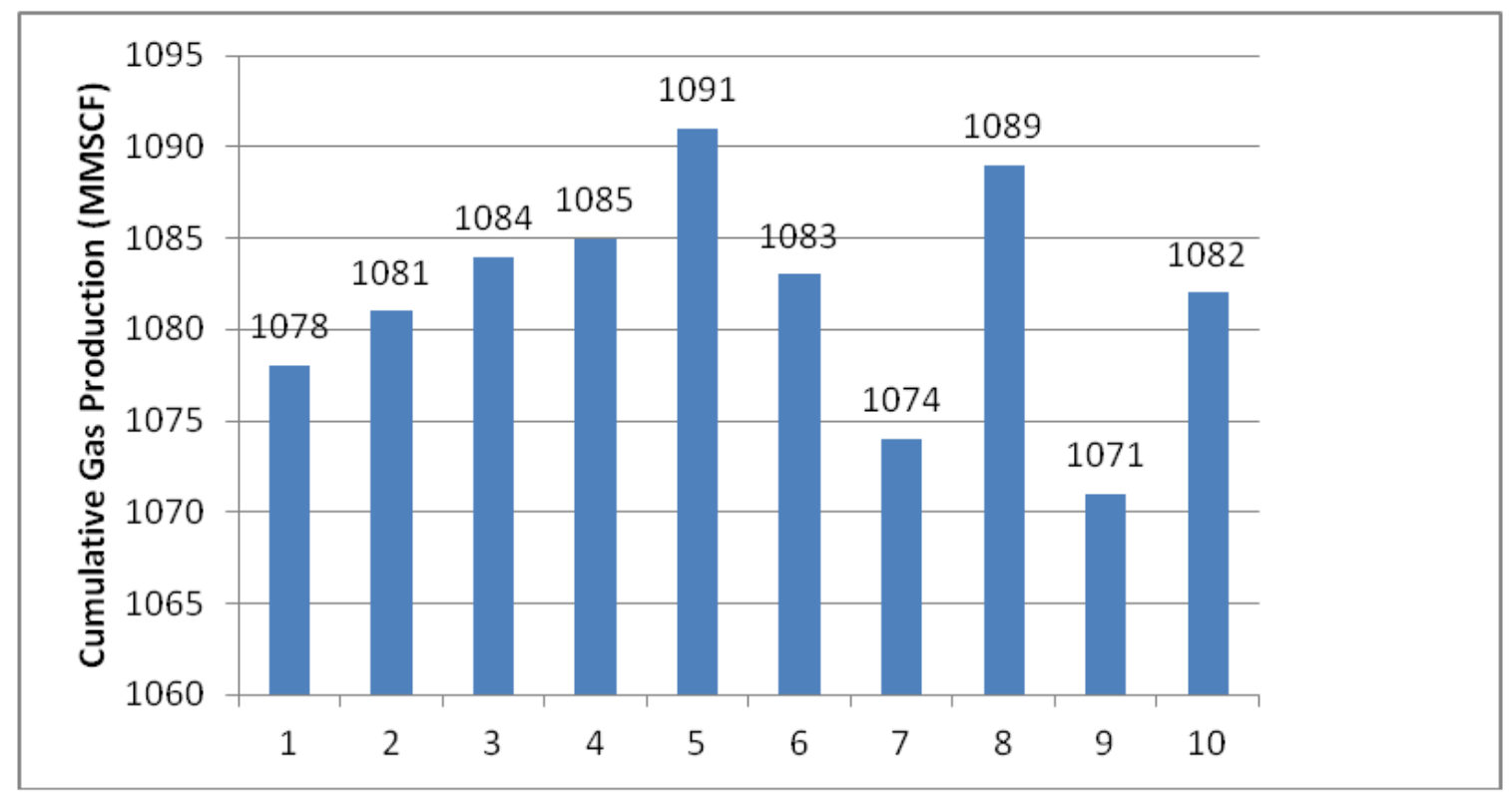

Figure V-6, Variation of cumulative gas production with fracture porosity distributions.

\section{V-3 Effect of matrix porosity}

Ten different runs at different matrix porosity distributions were conducted with a 900 grid block reservoir. All other reservoir parameters (depth, matrix permeability, fracture permeability, thickness, reservoir pressure etc) were kept constant to validate the effect of matrix porosity values on cumulative gas production as seen in Table V-3. In Table V-4 the results for ten runs (Run 1 to Run 10) at different matrix porosity distributions (from 0.01 to 0.1 ) are presented. Different cumulative gas production rates are obtained at the different matrix porosity distribution values. Run 2.2 for instance, the cumulative gas produced is $1067.7 \mathrm{MMSCF}$, in run 2.10, the cumulative gas produced is $1072.8 \mathrm{MMSCF}$ and in run 2.7, the cumulative gas produced is 1086.7 MMSCF. The distributions of fracture porosity values used in these runs are graphically shown in Figures A.11 through A.20 in Appendix A. 


\begin{tabular}{|c|c|}
\hline Property & Values \\
\hline Depth (ft) & 6000 \\
\hline Reservoir Pressure (psi) & 3000 \\
\hline Formation Thickness (ft) & 120 \\
\hline Reservoir Temperature ( $\left.{ }^{\circ} \mathrm{F}\right)$ & 150 \\
\hline Fracture Permeability (md) & 0.0008 \\
\hline Matrix Porosity (fraction) & $0.01-0.1$ \\
\hline Fracture Porosity (fraction) & 0.004 \\
\hline Matrix Permeability (md) & 0.00005 \\
\hline
\end{tabular}

Table V-3 Formation properties used in runs with different matrix porosity distributions.

\begin{tabular}{|c|c|}
\hline Run Number & $\begin{array}{c}\text { Cumulative Gas Production, } \\
\text { MMSCF }\end{array}$ \\
\hline 2.1 & 1082.0 \\
\hline 2.2 & 1067.7 \\
\hline 2.3 & 1090.6 \\
\hline 2.4 & 1068.9 \\
\hline 2.5 & 1065.0 \\
\hline 2.6 & 1073.5 \\
\hline 2.7 & 1086.0 \\
\hline 2.8 & 1070.7 \\
\hline 2.9 & 1086.0 \\
\hline 2.10 & 1072.8 \\
\hline
\end{tabular}

Table V-4; Cumulative gas produced with different matrix porosity distributions.

Figure V-7 shows the cumulative gas production results obtained with different matrix porosity distributions. The results are repeated in Figure V-8 to distinguish the values at the end of the 40 year production period. 


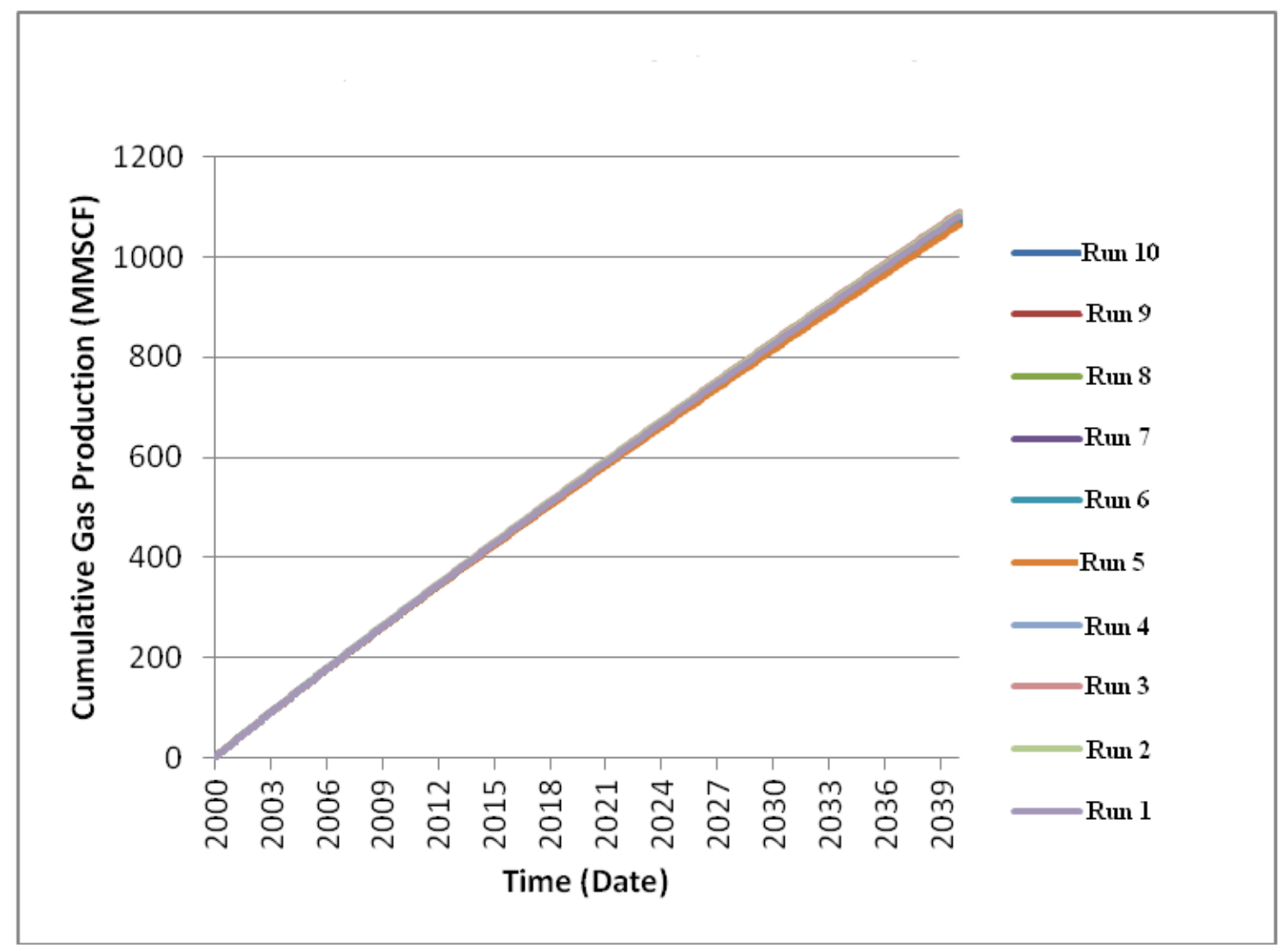

Figure V-7; Effect of matrix porosity distributions on cumulative gas production. 


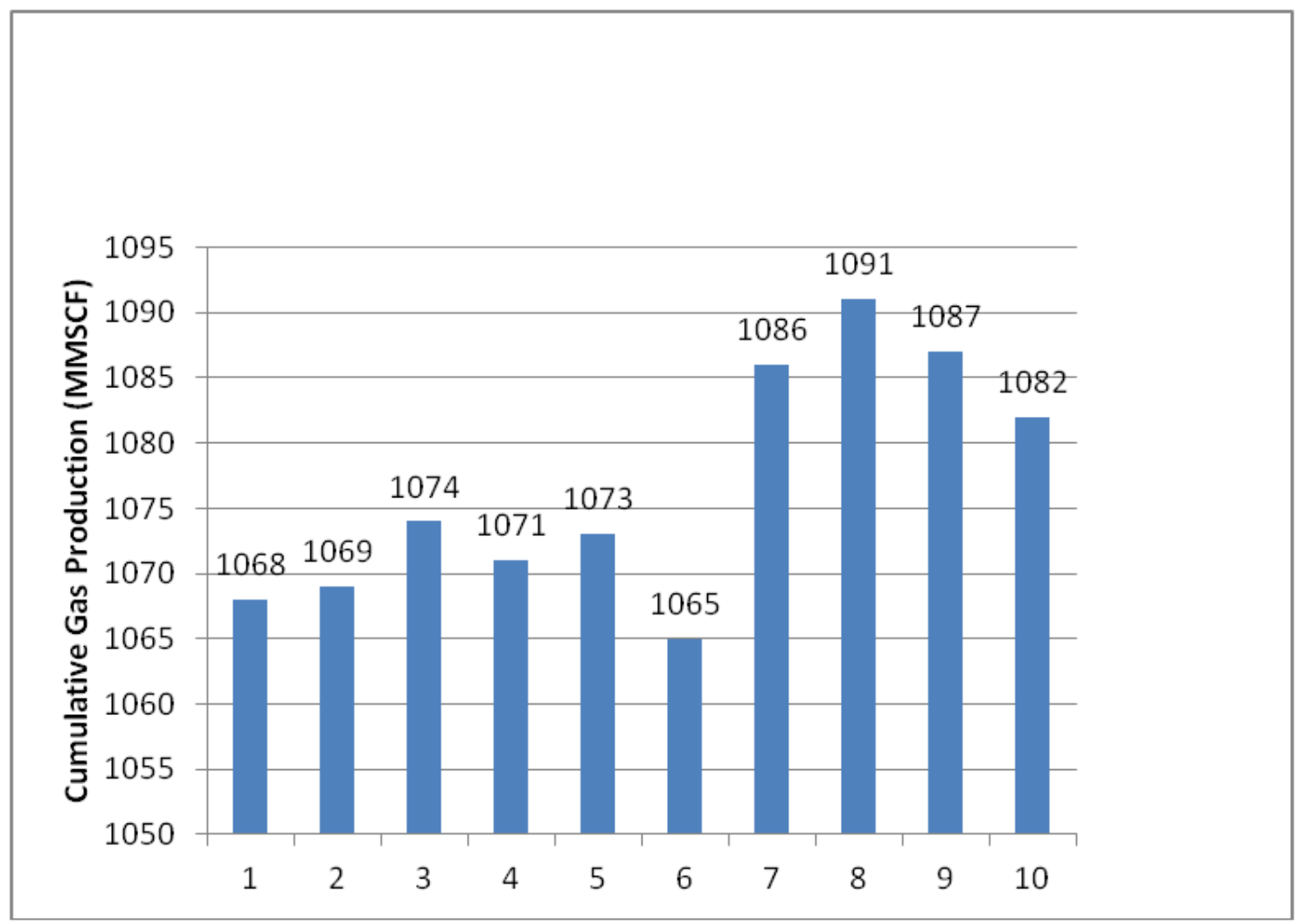

Figure V-8; Variation of cumulative gas production with matrix porosity distributions.

Results from the chart and histogram above show that although different matrix porosity distribution values were used, there is a small change in cumulative gas produced over the forty years study period. The difference between the maximum cumulative gas produced (1091 MMSCF) and the minimum gas produced (1065 MMSCF) is only 26 MMSCF at the end of $40^{\text {th }}$ year.

\section{V-4 Effect of Fracture Permeability}

Ten runs with variable fracture permeability distribution values from 0.0005 to $0.005 \mathrm{md}$ were conducted to observe their effect on cumulative gas produced over a forty year period. Table V-5 lists the properties used in these runs and the results are tabulated in 
Table V-6 below. It is observed that the cumulative gas production values showed greater difference than the previous two cases. In run 3.1 for instance the cumulative gas produced is $1574.1 \mathrm{MMSCF}$. In run 3.6, the cumulative gas produced is $2196.9 \mathrm{MMSCF}$ and in run 3.10, a cumulative gas of 4315.5 MMSCF was produced. The distribution of fracture porosity values are graphically shown in Figures A.21 through A.30 in Appendix

A.

\begin{tabular}{|c|c|}
\hline Property & Values \\
\hline Depth (ft) & 6000 \\
\hline Reservoir Pressure (psi) & 3000 \\
\hline Formation Thickness (ft) & 120 \\
\hline Reservoir Temperature ( $\left.{ }^{\circ} \mathrm{F}\right)$ & 150 \\
\hline Fracture Permeability (md) & $0.0005-0.005$ \\
\hline Matrix Porosity (fraction) & 0.06 \\
\hline Fracture Porosity (fraction) & 0.004 \\
\hline Matrix Permeability (md) & 0.00005 \\
\hline
\end{tabular}

Table V-5 Formation properties used in runs with different fracture permeability distributions.

\begin{tabular}{|c|c|}
\hline Run Number & $\begin{array}{c}\text { Cumulative Gas Production, } \\
\text { MMSCF }\end{array}$ \\
\hline 3.1 & 1574.1 \\
\hline 3.2 & 1391.8 \\
\hline 3.3 & 1580.9 \\
\hline 3.4 & 1068.9 \\
\hline 3.5 & 2009.5 \\
\hline 3.6 & 2196.9 \\
\hline 3.7 & 2730.0 \\
\hline 3.8 & 2982.5 \\
\hline 3.9 & 3706.2 \\
\hline 3.10 & 4315.5 \\
\hline
\end{tabular}

Table V-6; Cumulative gas produced with different fracture permeability distributions. 
The results of these runs are quite different compared to the results observed for matrix and fracture porosity runs. As seen in Figure V-9 and Figure V-10, there is a big difference in cumulative gas produced at different fracture permeability value distributions in the reservoir. In fact the histogram distribution shows that the difference between the maximum cumulative gas produced (4316 MMSCF) and the minimum gas produced (1392MMSCF) is 2924 MMSCF. The distribution of fracture permeability values has a huge effect on cumulative gas produced. This outcome is not easily understood, however, it is attributed to the increase in the intensity of fracture permeability yielding different width and drainage area and/or conductivity for fluid flow.

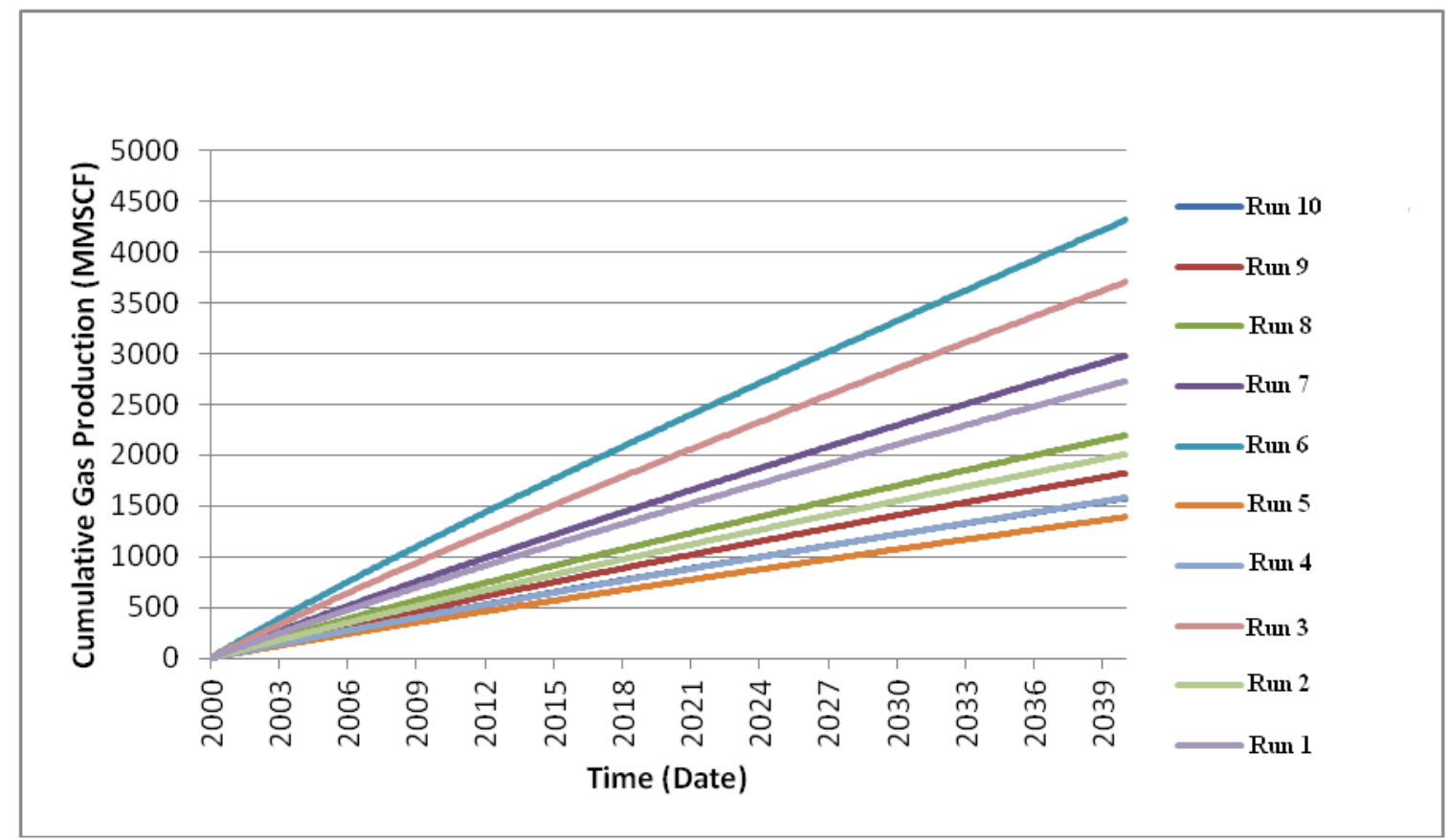

Figure V-9; Effect of fracture permeability distributions on cumulative gas production. 


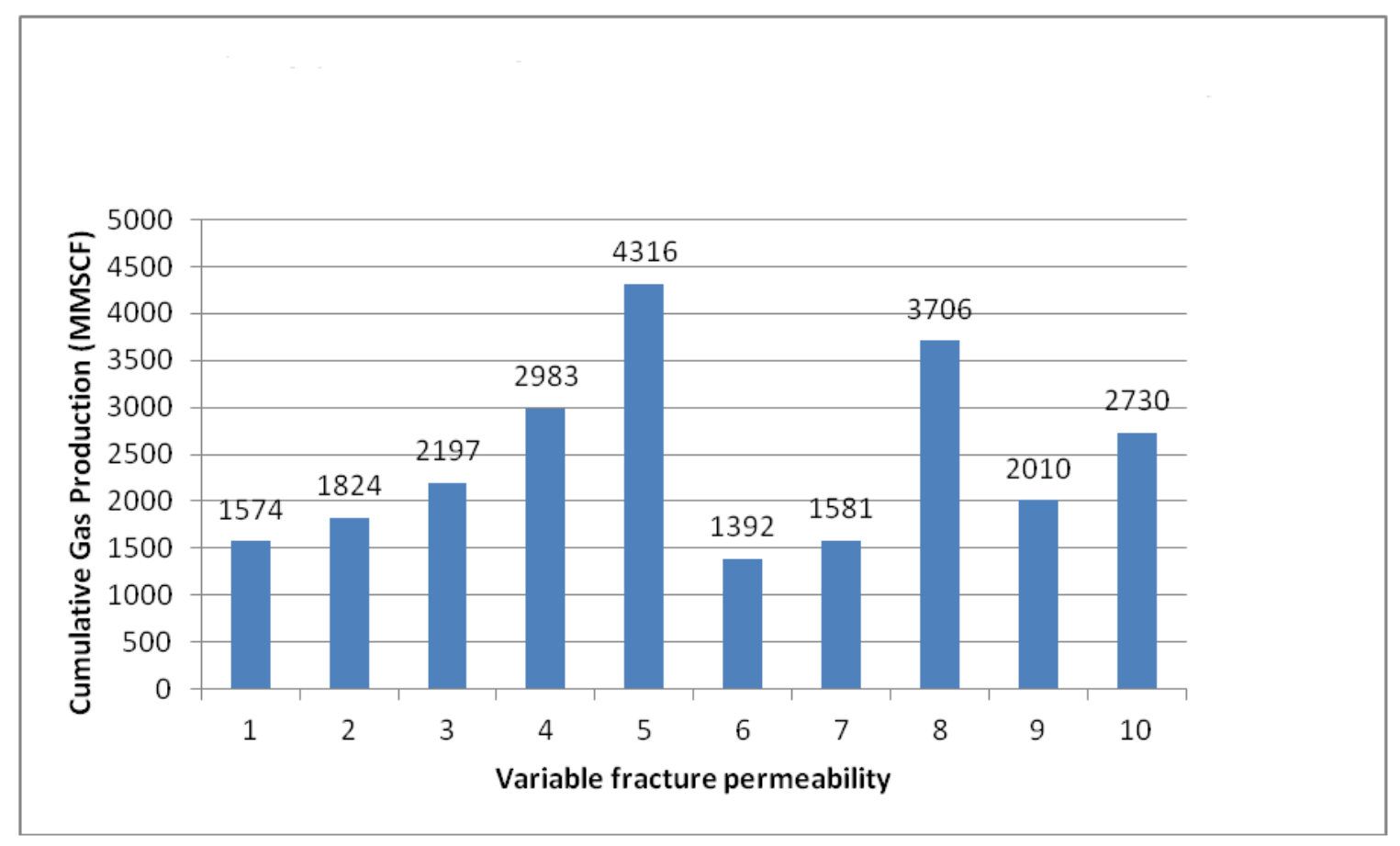

Figure V-10; Variation of cumulative gas production with fracture permeability distributions.

\section{V-4 Effect of Matrix Permeability}

Ten runs at variable matrix permeability distribution values between the ranges of 0.00004 to $0.0008 \mathrm{md}$ were conducted to determine their effect on the cumulative gas production after forty years. All other reservoir parameters were constant while matrix permeability values were varied. The properties used in these runs are given in Table V7. Runs with different matrix permeability distributions resulted with different cumulative gas production values shown in Table V-8. The difference in cumulative gas produced at the end of 40 years was not significant. Run 4.2 for instance produced a cumulative gas of 1059.1 MMSCF, in run 4.4, the cumulative gas produced is 1063.6 MMSCF and in run 4.8, the cumulative gas produced is 1083 MMSCF. The distributions 
of fracture porosity values are graphically shown in Figures A.31 through A.40 in Appendix A.

\begin{tabular}{|c|c|}
\hline Property & Values \\
\hline Depth (ft) & 6000 \\
\hline Reservoir Pressure (psi) & 3000 \\
\hline Formation Thickness (ft) & 120 \\
\hline Reservoir Temperature ( $\left.{ }^{\circ} \mathrm{F}\right)$ & 150 \\
\hline Fracture Permeability (md) & 0.0005 \\
\hline Matrix Porosity (fraction) & 0.06 \\
\hline Fracture Porosity (fraction) & 0.004 \\
\hline Matrix Permeability (md) & $0.00004-0.0008$ \\
\hline
\end{tabular}

Table V-7 Formation properties used in runs with different matrix permeability distributions.

\begin{tabular}{|c|c|}
\hline Run Number & $\begin{array}{c}\text { Cumulative Gas Production, } \\
\text { MMSCF }\end{array}$ \\
\hline 4.1 & 1059.5 \\
\hline 4.2 & 1059.1 \\
\hline 4.3 & 1060.5 \\
\hline 4.4 & 1063.6 \\
\hline 4.5 & 1060.0 \\
\hline 4.6 & 1067.4 \\
\hline 4.7 & 1074.3 \\
\hline 4.8 & 1083.0 \\
\hline 4.9 & 1091.0 \\
\hline 4.10 & 1058.8 \\
\hline
\end{tabular}

Table V-8; Cumulative gas produced with different matrix permeability distributions.

The results from the chart (Figure V-11) and histogram (Figure V-12) do not show any significant influence of variations in matrix permeability values on cumulative gas production after forty years. The difference between the maximum and minimum 
cumulative gas produced was only $31 \mathrm{MMSCF}$ after forty years. This small difference in gas produced over the forty years study period shows that the different reservoir matrix permeability distributions has little impact in gas production.

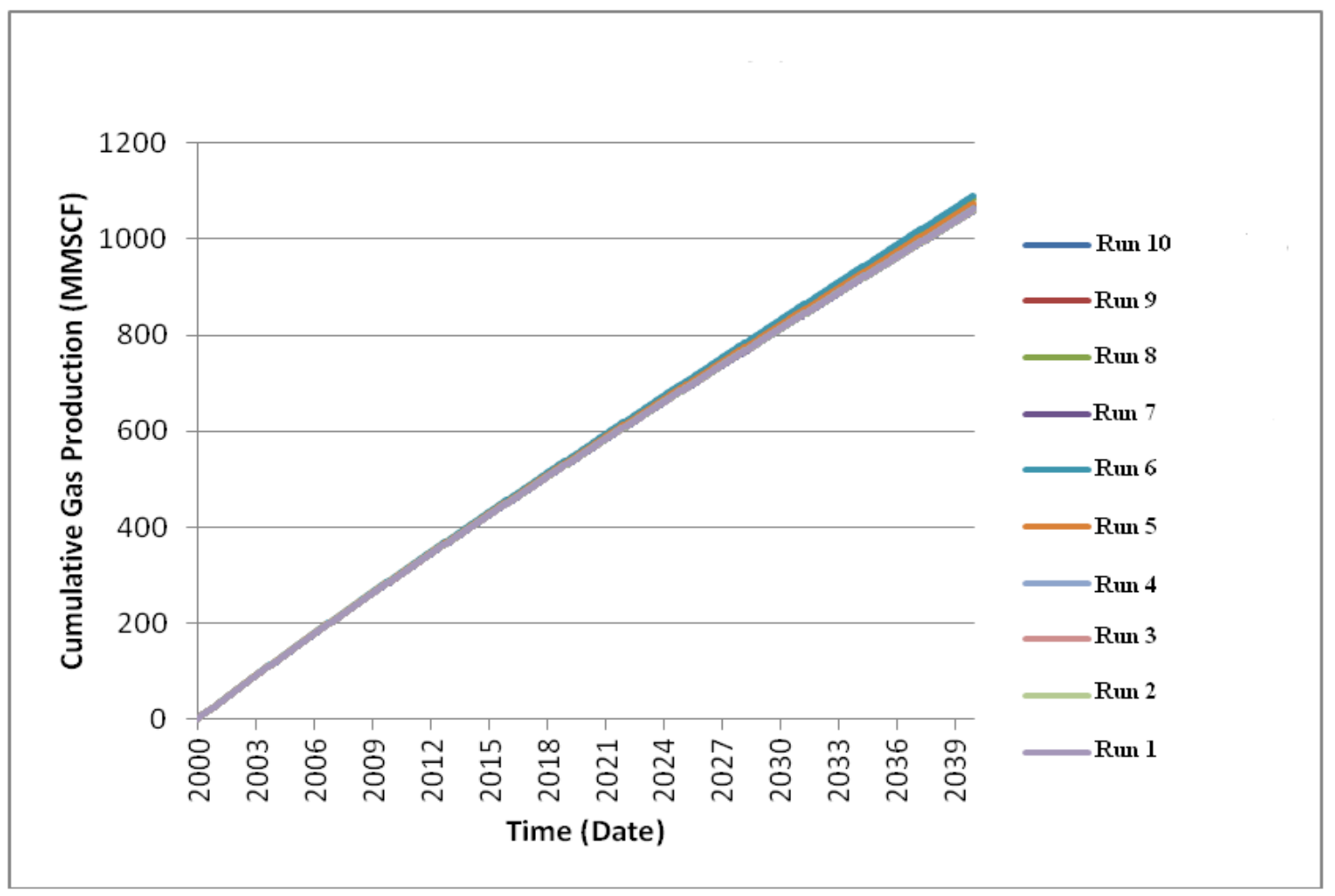

Figure V-11; Effect of matrix permeability distributions on cumulative gas production. 


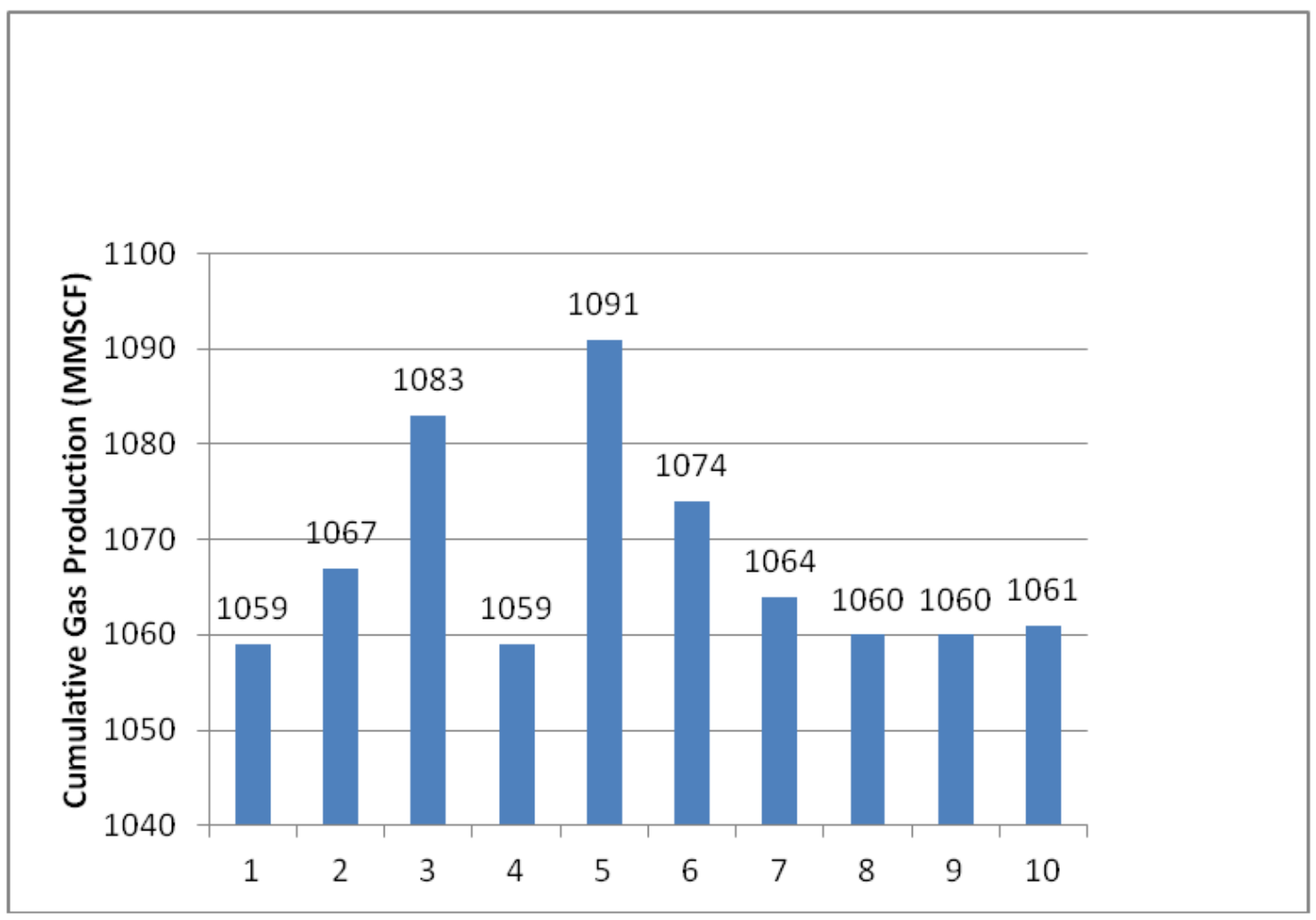

Figure V-12; Variation of cumulative gas production with matrix permeability distributions.

\section{Summary}

Figure V-13 below demonstrates that the most influential reservoir parameter on cumulative gas production is the fracture permeability. Fracture permeability enhances flow capability by activating existing natural fractures and increasing contact areas by cracking the shale rock. 


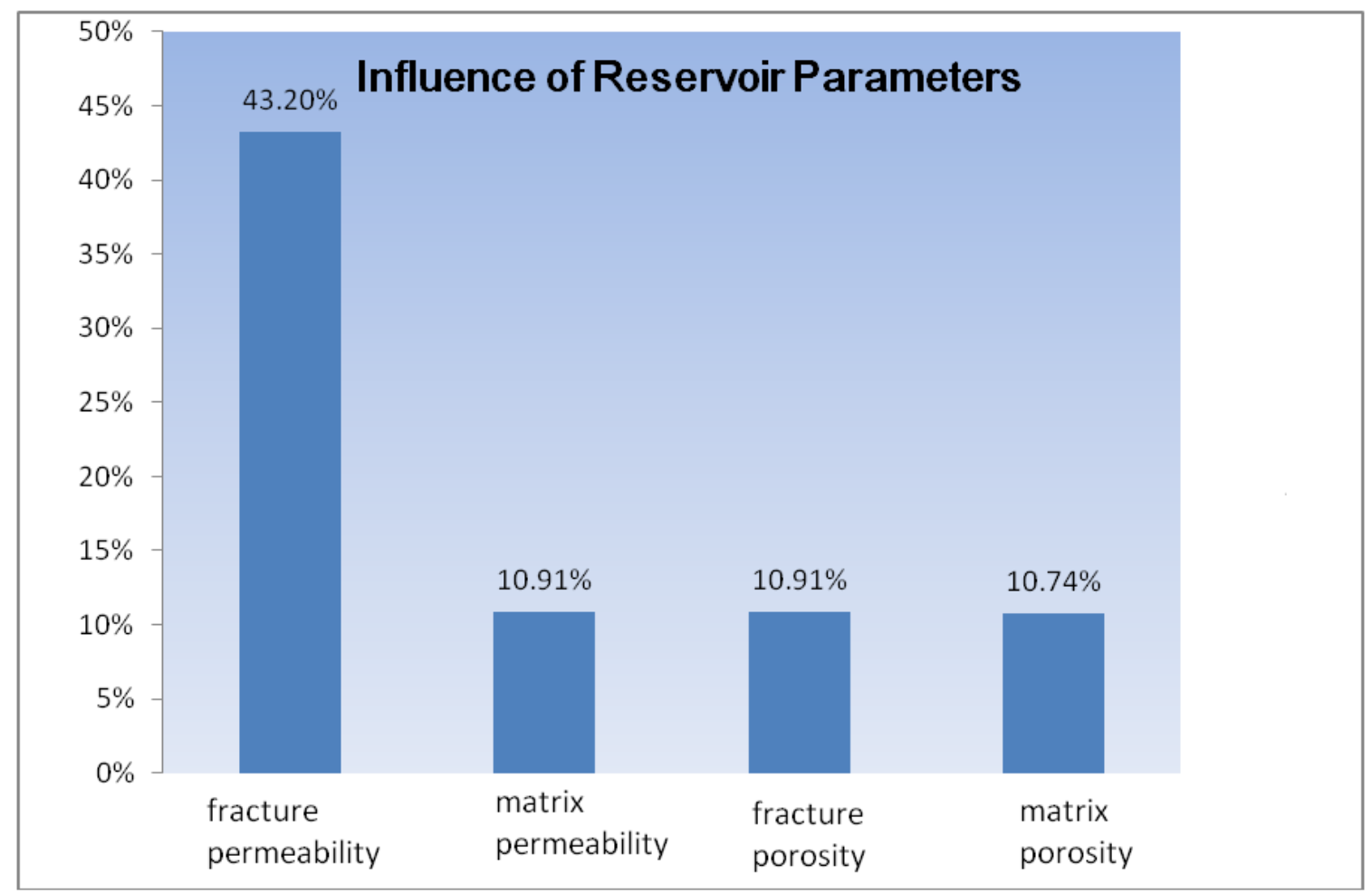

Figure V-13; Influence of reservoir parameters.

With variation of all parameters within their individual data ranges, Figure V-14 below summarizes the influential parameters on cumulative gas production. Half length and hydraulic fracture network, fracture spacing and fracture permeability are identified as the most influential parameters. The highly conductive primary fractures have significant impact on the gas production. The optimal hydraulic fracture spacing is essential for achieving high recovery factors and minimizing costs. The hydraulic fracture length determines the well drainage area, which is a crucial factor to estimate well spacing. 


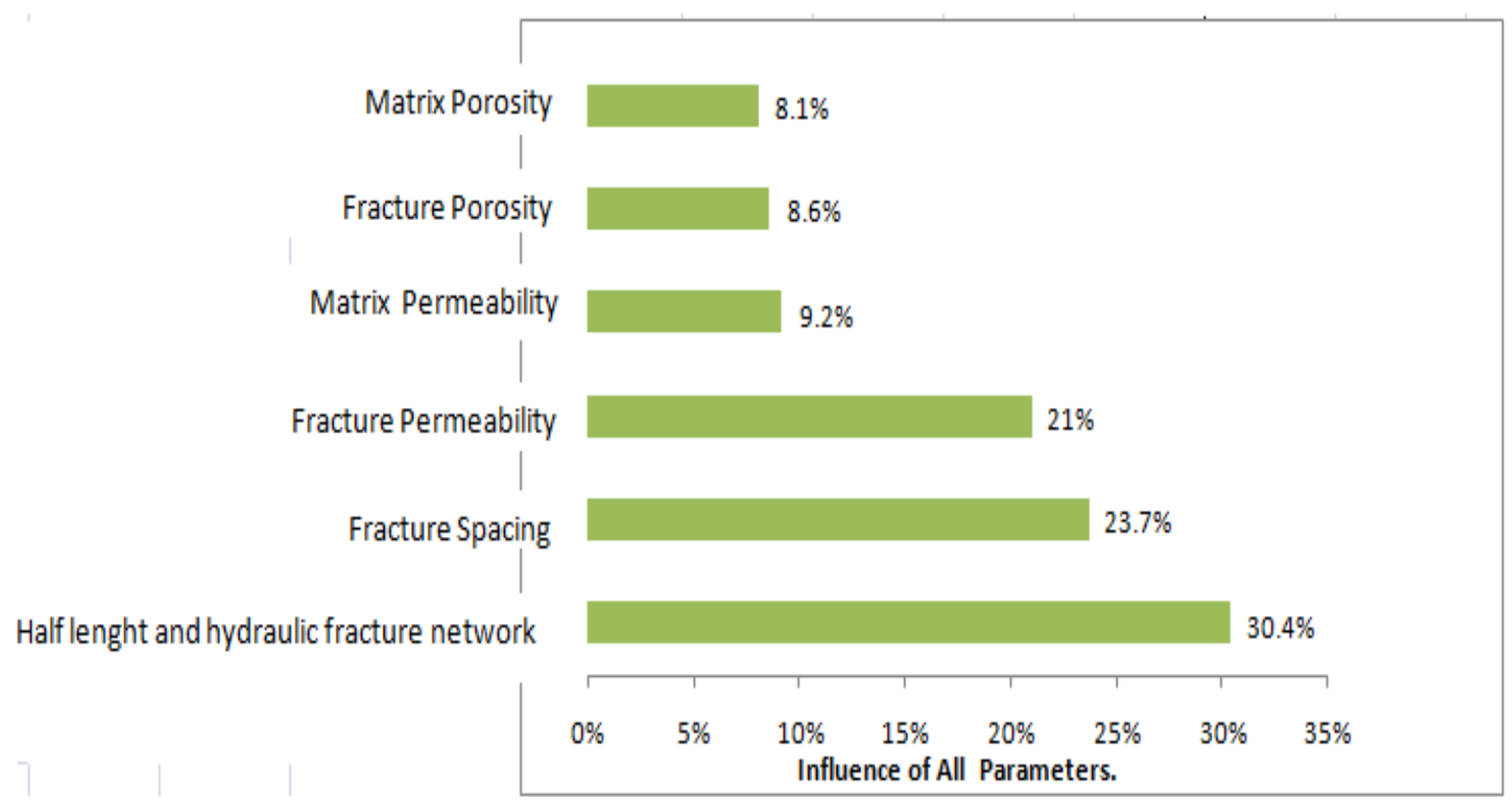

Figure V-14; Impact of all parameters on cumulative gas production. 


\section{CHAPTER VI. CONCLUSION}

Based on the runs conducted in this study, the following conclusions are presented:

- The hydraulic fracture network, half length and fracture spacing are the most influential parameters for gas production from shales. These three parameters affect the fracture intensity, width, and permeability, and/or conductivity and therefore result in higher cumulative gas production for shale gas. In this study, there was approximately a $200 \mathrm{MMCF}$ increase in total gas production for every thousand feet of lateral wellbore length. The results indicate that fracture half length is the most important parameter followed by number of fractures and lateral wellbore length.

- It was shown that using the longer fractured half length of 1000 feet and maximizing the number of fractures, were the most optimal designs. As far as the lateral length was concerned, it was not cost efficient to drill longer laterals if the number of fractures placed in the lateral are equal.

- Maximizing the fracture spacing in the lateral section of the wellbore resulted in the increased total gas production. Evenly spacing and increasing the number of fractures maximizes the total reservoir volume subject to drainage, thus reducing the amount of overlapped fractures and increasing the total production with a result of early recovery times. 
- The variations of formation properties within the given range have a minimum impact on the outcome of cumulative gas production at the end of $30^{\text {th }}$ year except for the fracture permeability values. Thus, the fracture permeability is the most important reservoir parameter affecting the cumulative gas production compared to matrix permeability, fracture and matrix porosity. In this study, there was a maximum difference of 2924 MMSCF total gas production when fracture permeability values were ranged between $0.0005 \mathrm{md}$ and $0.005 \mathrm{md}$.

- For all cases studied, the gas production from shale beyond the 30 years of study is still possible. The most important effect of the well completion design was the early recovery of gas during the first ten years. The production rates seem to be similar for late production times. 


\section{CHAPTER VII. RECOMMENDATIONS}

Some recommendations for future work in the continuation of this project are;

- To use gas production data from Marcellus Shale wells with simulation treatments to compare with results obtained from this study.

- To work with multi-well fields in order to evaluate the interference and impact of multi well drainage. 


\section{CHAPTER VIII. REFERENCES.}

- Armas, Genaro C. "Appalachia tantalizes natural gas drillers." USA Today. 3 Feb. 2008.

- Carlson, Eric S. and James C. Mercer, "Devonian Shale Gas Production: Mechanisms and Simple Models", SPE 19311, 1991.

- Chernoff, Harry. "Investing in the Marcellus Shale." Seeking Alpha., 17 Mar. 2008.

- Donald W.Neal, Belinda K. Price. "Oil and Gas Report and Maps of Lincoln, Logan and Mingo Counties" Bulletin B-41 WV Geological and Economic Survey 1986.

- Drake, Steve. "Unconventional Gas Plays.” Marsh Operating Company. 6 Dec. 2007.

- EIA, "Energy Information Administration Data” Aug 2007.

○ http://tonto.eia.doe.gov/dnav/ng/hist/n9010us2m.htm.

- EIA, Energy Information Administration. "Natural Gas- Year in Review." Mar. 2008.Oct.2008.

○ http://www.eia.doe.gov/pub/oil_gas/feature_articles.

- Engelder T., and Lash, G.G., "Systematic joints in Devonian black shale: A target for horizontal drilling in the Appalachian Basin" American Association of Petroleum Geologists Bulletin, Oct. 2008.

- Falchek, David. "Legislators Look to Protect Water During the Drilling for Natural Gas", CitizensVoice.com. 26 Aug. 2008.

- Fix, J.E., J.H.Frantx Jr. and D.E.Lancaster, ”Application of Microseismic Technology in a Devonian Shale in the Appalachian Basin", SPE 23425, 1991.

- Fontaine, J., N. Johnson and D. Schoen, "Design, Execution, and Evaluation of Typical Marcellus Shale Slick water Stimulation: A Case History", SPE 117772MS, 2007.

- Gaskari, R. and Mohaghegh, S.D., "Estimating Major and Minor Natural Fractures Pattern in Gas Shales Using Production Data", SPE 104554, 2006.

- Hopkins, C.W. and J.E. Jochen, and K.J. Fink, "A Comparison of Two Devonian Shale Wells: Why is One Well Better than the other", SPE 26918, 1993. 
- Jarvie, D. M., "Total organic carbon (TOC) analysis", Treatise of Petroleum Geology, Handbook of Petroleum Geology, Source and migration processes and evaluation techniques, R. K. Merrill, ed., AAPG, Tulsa,1991.

- Jensen, Jerry L., Larry W. Lake, Patrick W.M. Corbett, and David J. Goggin "Statistics for Petroleum Engineers and Geoscientists", Prentice-Hall, Inc. 1997.

- Lancaster, D.E., F.K.Guldry, P.H.Lowry, R.L.Graham, and D.G.Hill,"GRI's Devonian Research Program: A Progress Report", 1992.

- Lu, Xiao-Chun, Fan-Chang Li, and A. Ted Watson, "Adsorption Studies of Natural Gas Storage in Devonian Shales”, SPE 26632, 1995.

- Luffel, D.L., C.W.Hopkins, and P.D.Schettler Jr.,"Matrix Permeability Measurement of Gas Productive Shales", SPE 26633, 1993.

- Minthorn J.W., and T.Garvin, "Successful Application of New Technology in Antrim Shale", SPE 23421, 1991.

- Nome, Shannon. "From Shale to Shining Shale- A Primer on North American Natural Gas Shale", RedOrbitNews, July 2008.

- Peters, K. E., "Guidelines for evaluating petroleum source rock using programmed pyrolysis", AAPG Bull. 1986.

- Pickering, Hayden, J.; Pursell, D. "The Barnett Shale - Visitors Guide to the Hottest Gas Play in the U.S.” Presentation, October 2005.

- Plays.” Deutsche Bank, RedOrbit News. 7 Jul. 2008.

- Pritchett, William C., "Physical Properties of Shales and Possible Origin of High Pressures", SPE 7506, 1980.

- Ronov, A. B., “Organic carbon in sedimentary rocks”, Geochem, 1958.

- Stelger, Ronald P. and Peter K. Leung, "Quantitative Determination of the Mechanical Properties of Shales”, SPE 18024, 1992.

- Sumi, Lisa. "Shale Gas: Focus on the Marcellus Shale", Oil \& Gas Accountability, Project/Earthworks. May 2008.

- Sweeney, Joe, "Oil and Gas Report and Maps of Kanawha and Boone counties West Virginia", Bulletin B-40 WV Geological and Economic Survey 1986.

- Talabani, Soran, Godwin Chukwu and Dimitios Hatzignaiou, "Drilling Successfully Through Shale Formations: Case Histories", SPE 25867, 1993. 
- Tissot, B. P. and D. H. Welte, "Petroleum Formation and Occurrence", SpringerVerlag, Berlin Heidelberg, 1974

- Zhang, X., C. Du, F. Deimbacher, M. Crick, and A. Harikesavanallur. "Sensitivity Studies of Horizontal Wells with Hydraulic Fractures in Shale Gas Reservoirs", IPTC 13338, 2009. 


\section{APPENDIX A}

\section{FRACTURE POROSITY DISTRIBUTIONS}

Figure A1 through Figure A10 below show results for ten runs conducted for variable fracture porosity distribution.

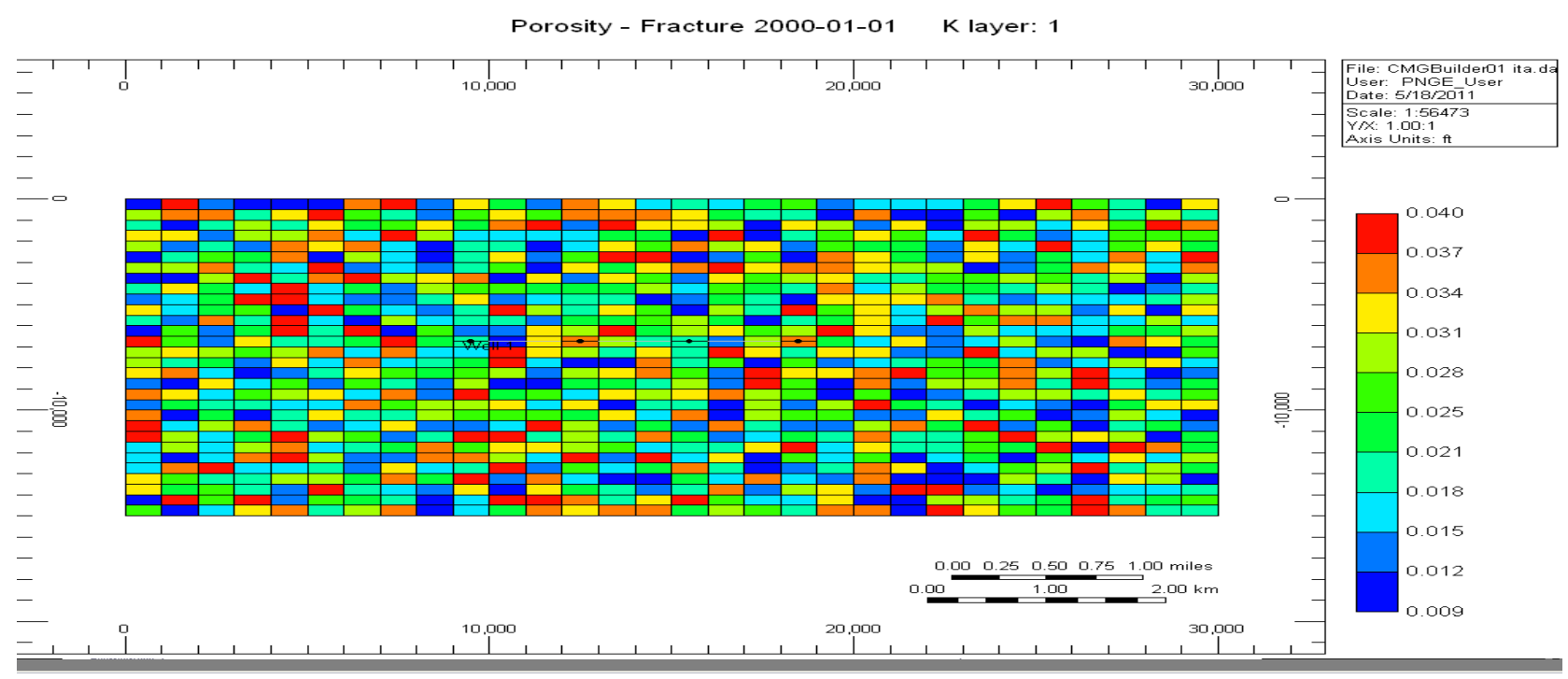

Figure A1; Fracture porosity values (Run 1.1)

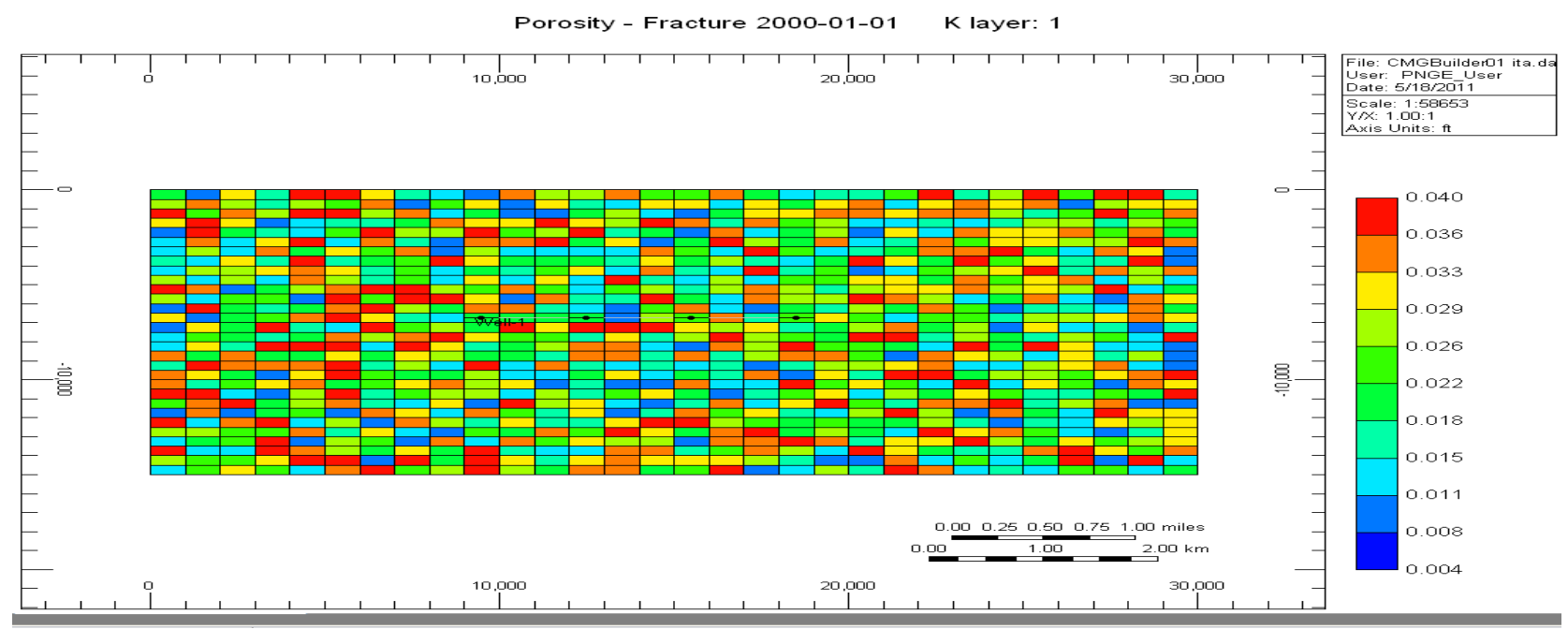

Figure A2; Fracture porosity values (Run 1.2) 


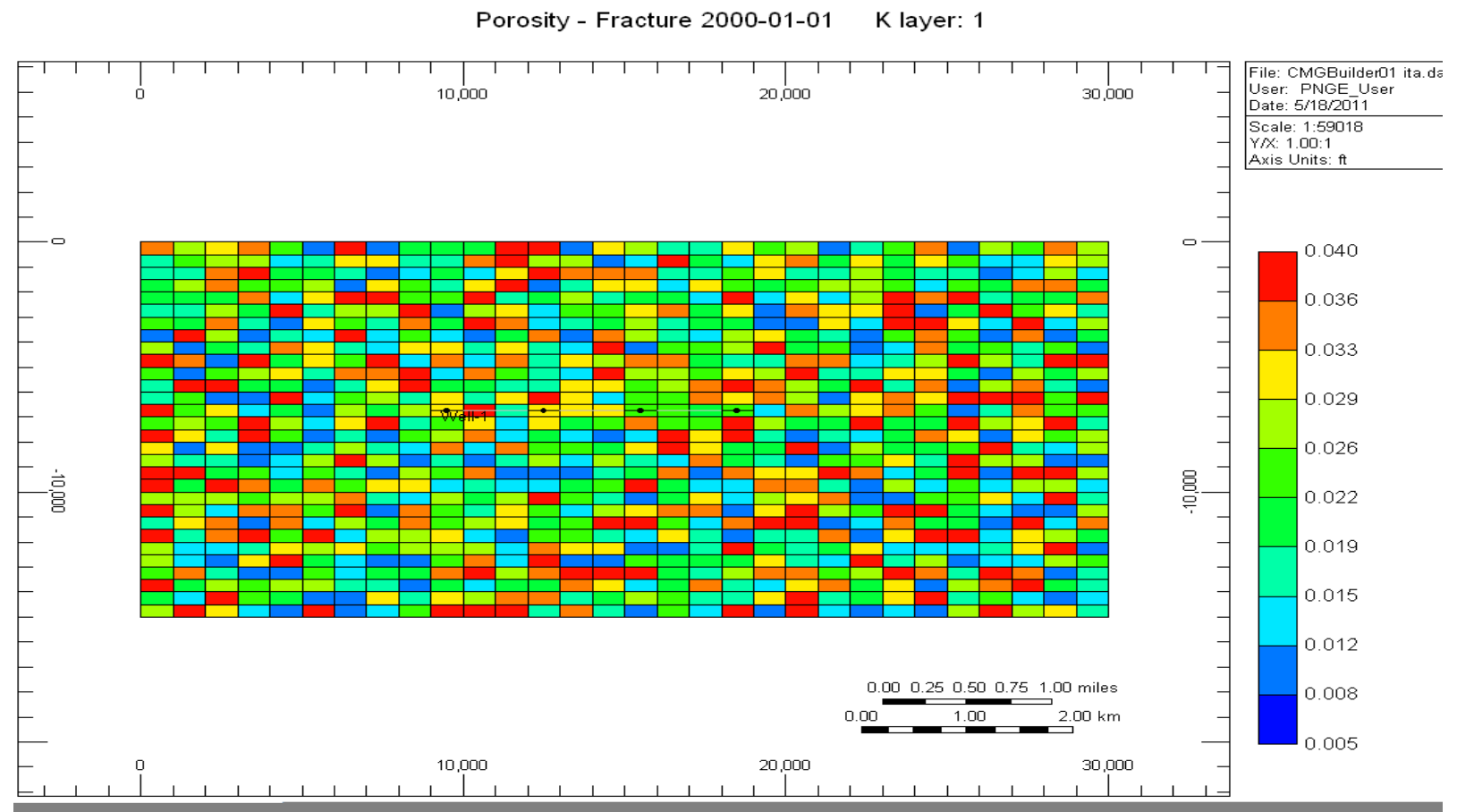

Figure A3; Fracture porosity values (Run 1.3)

Porosity - Fracture 2000-01-01 K layer: 1

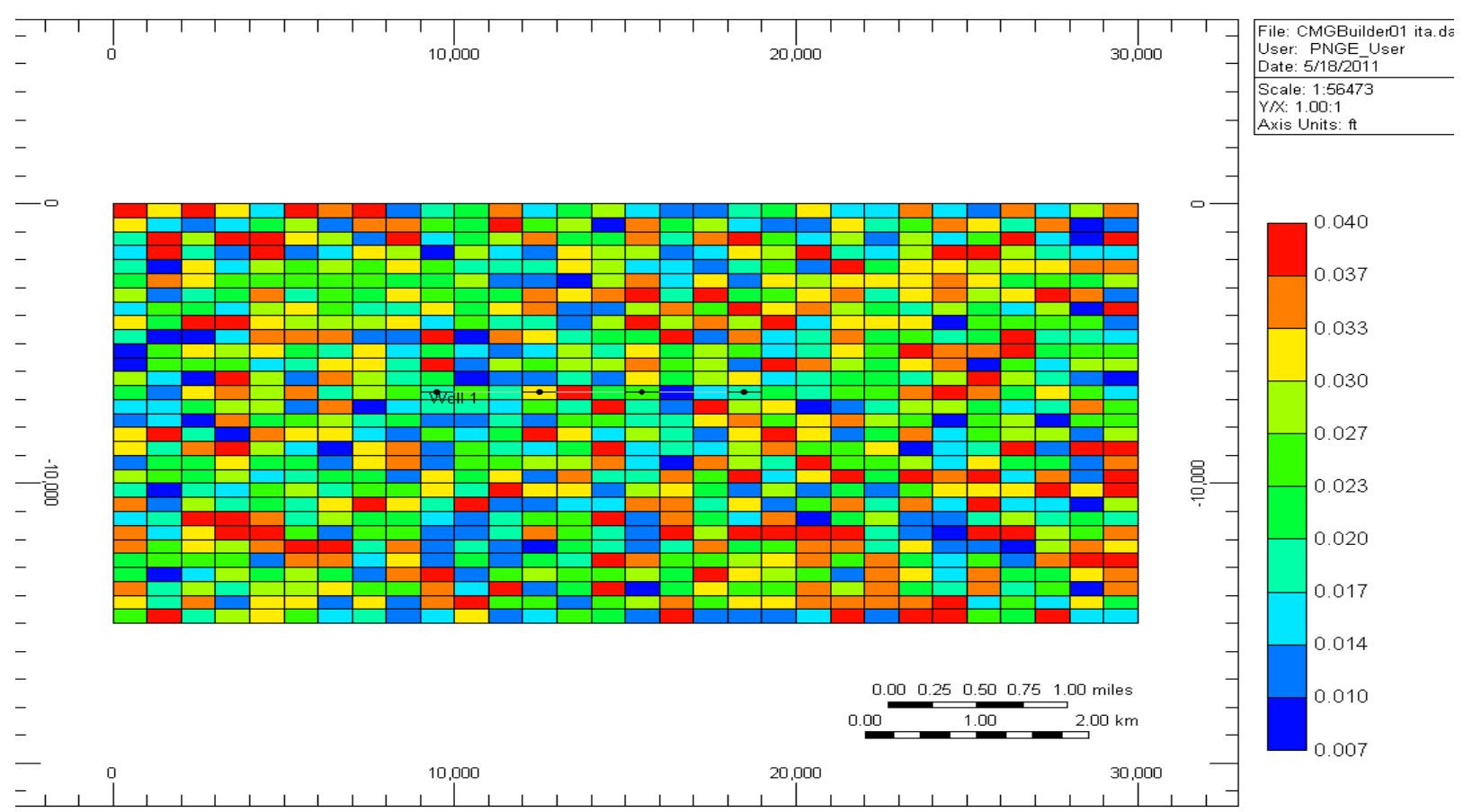

Figure A4; Fracture porosity values (Run 1.4) 


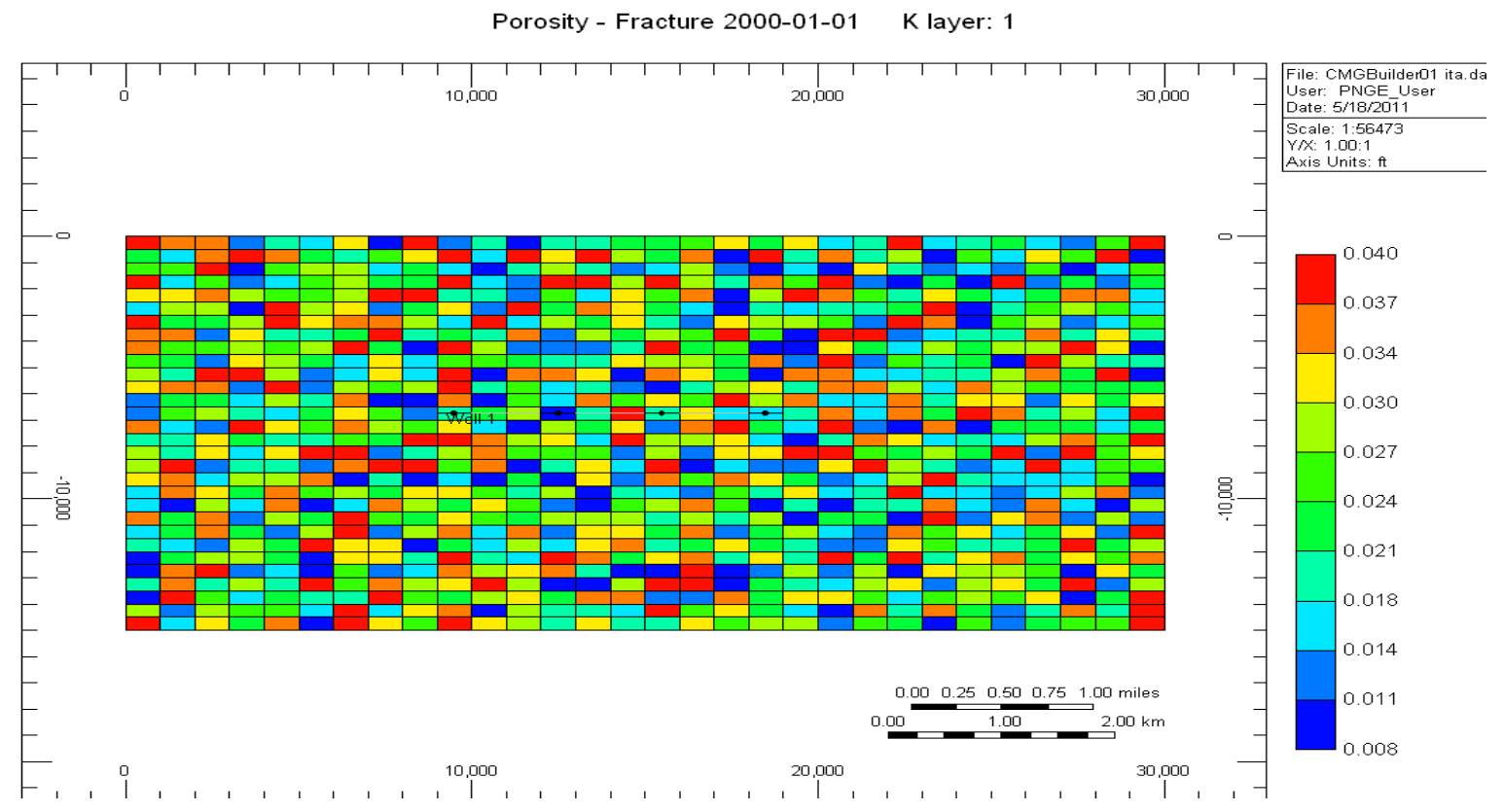

Figure A5; Fracture porosity values (Run 1.5)

Porosity - Fracture 2000-01-01 K layer: 1

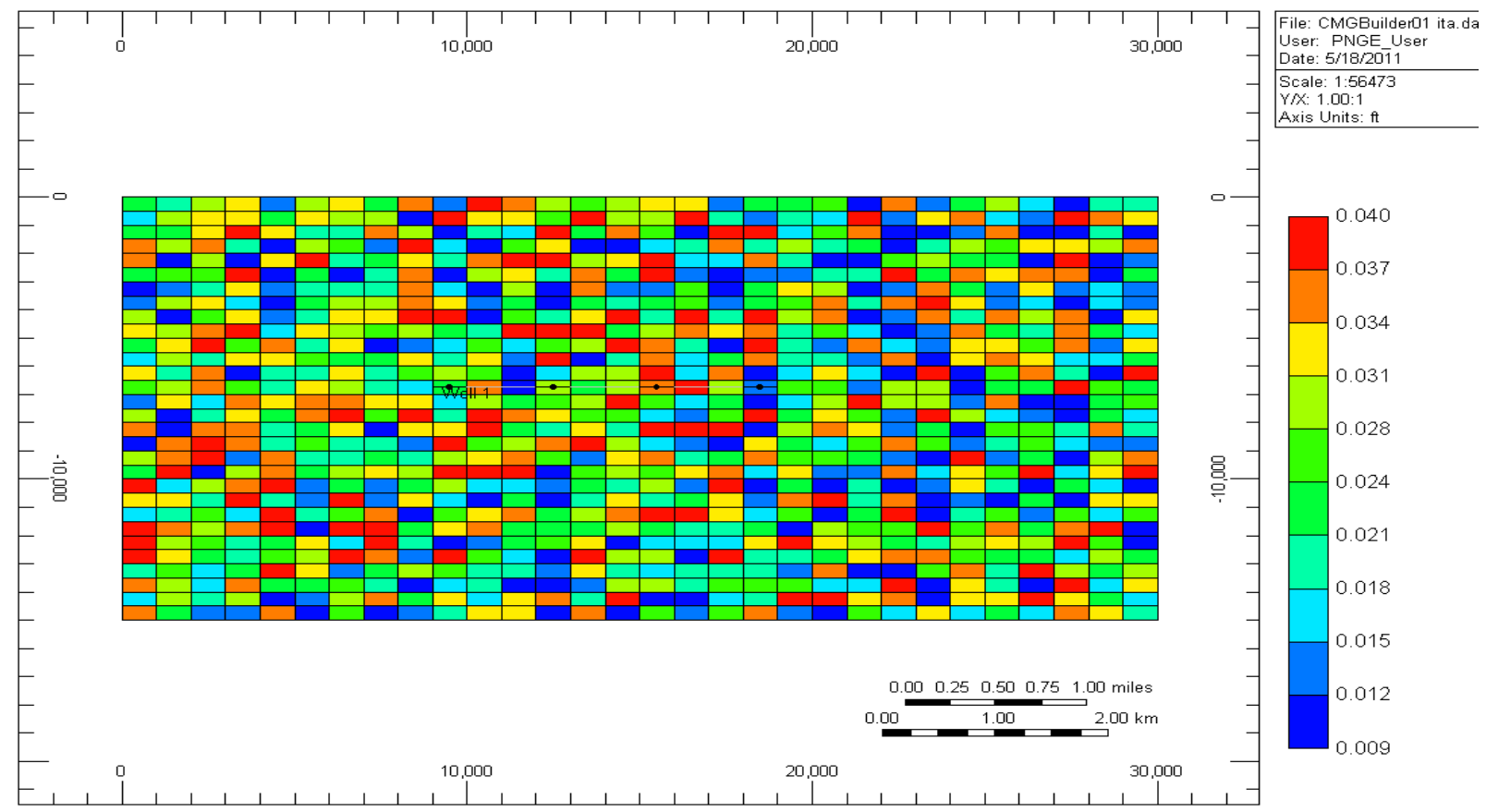

Figure A6; Fracture porosity values (Run 1.6) 


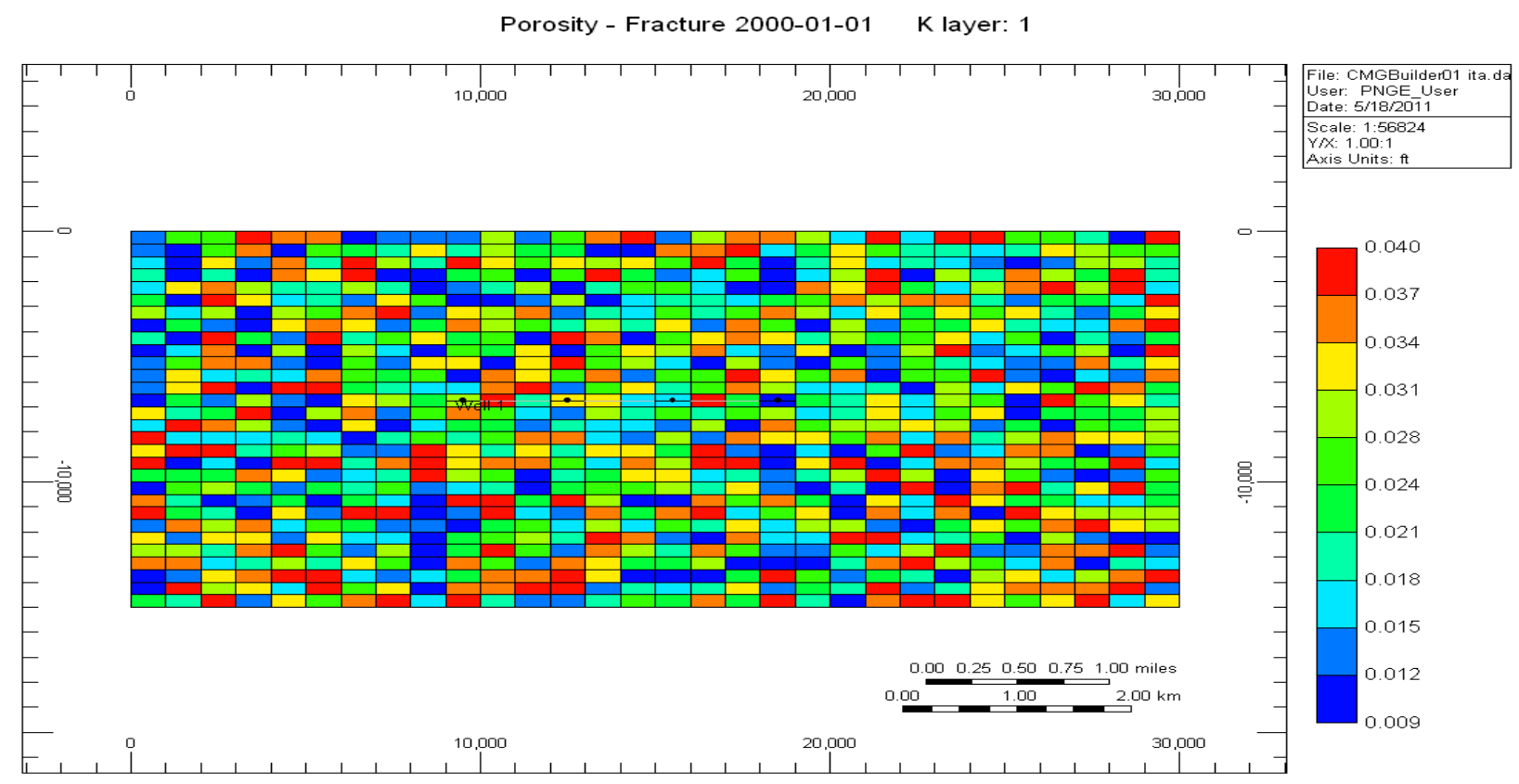

Figure A7; Fracture porosity values (Run 1.7)

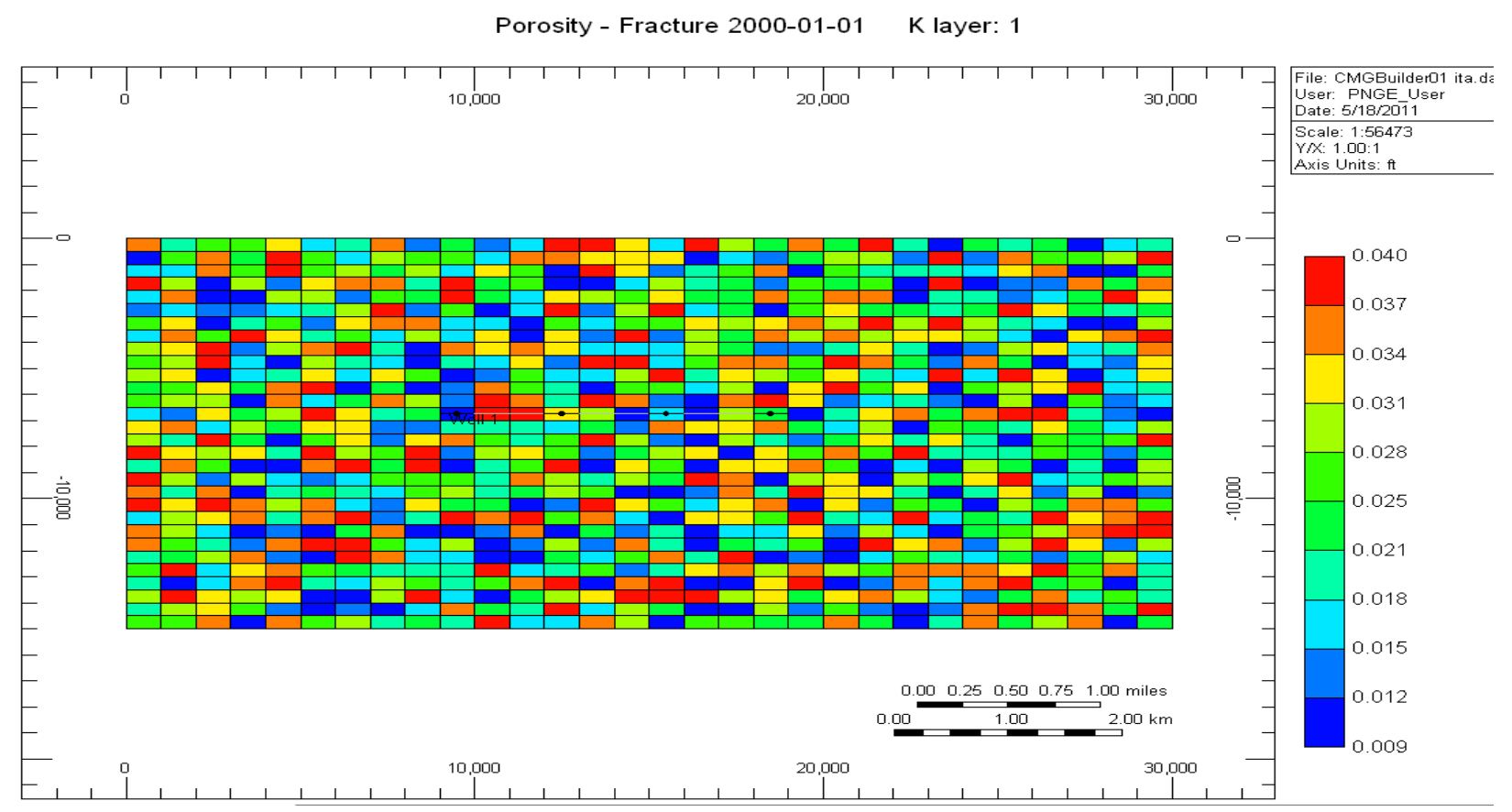

Figure A8; Fracture porosity values (Run 1.8) 


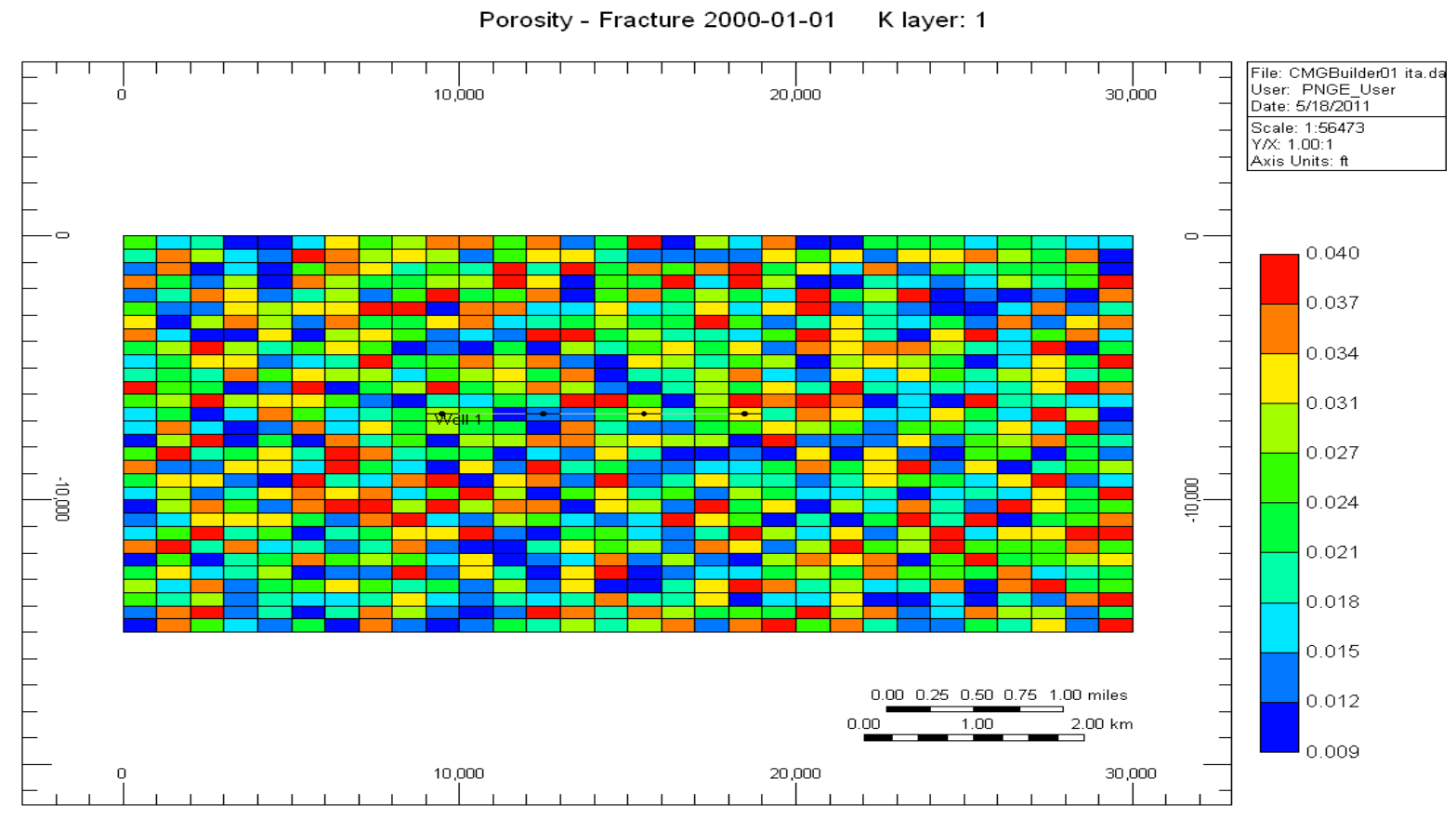

Figure A9; Fracture porosity values (Run 1.9)

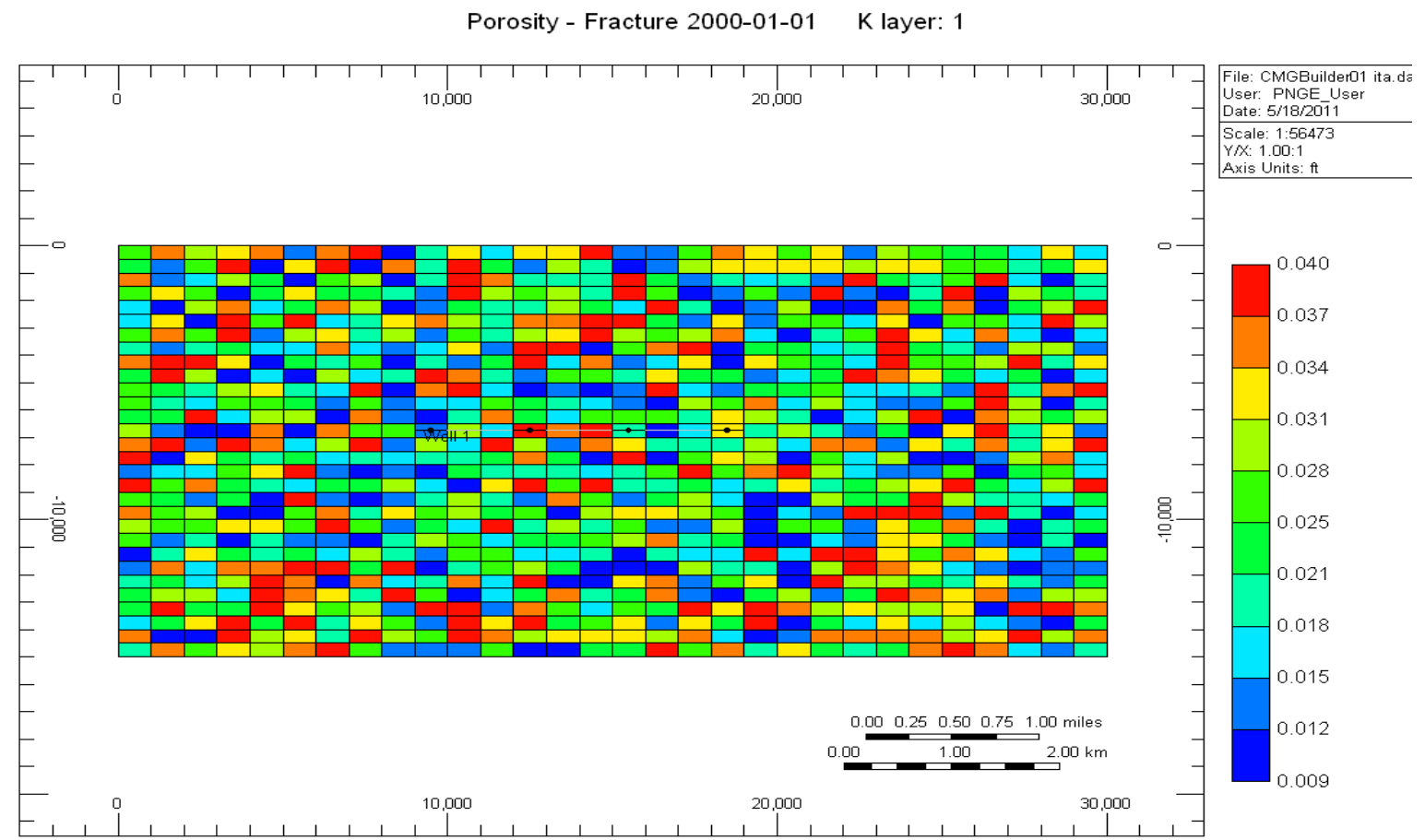

Figure A10; Fracture porosity values (Run 1.10) 


\section{MATRIX POROSITY DISTRIBUTIONS:}

Figure A11 through Figure A20 below show results for ten runs conducted for variable matrix porosity distribution.

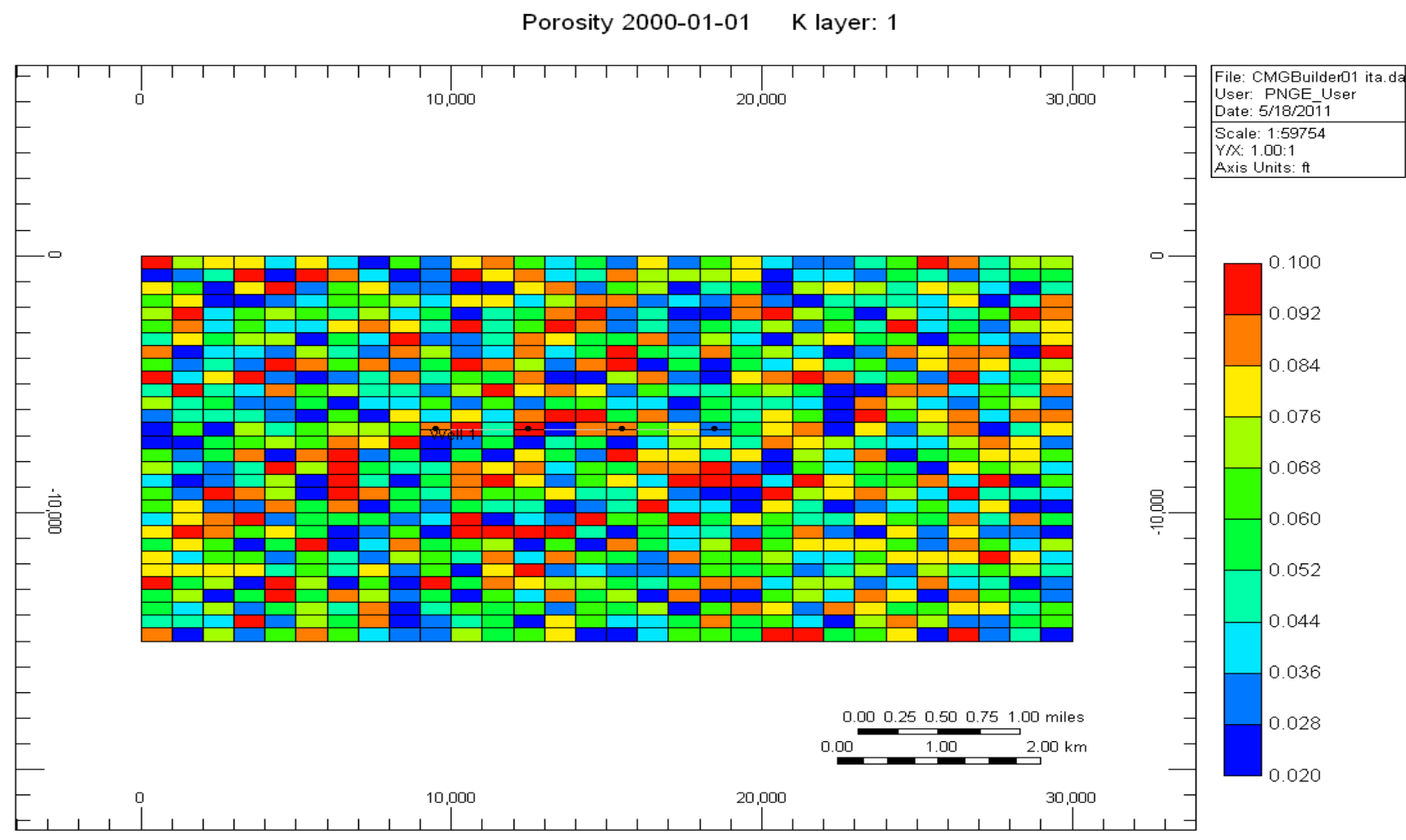

Figure A11; Matrix porosity values (Run 2.1) 
Porosity 2000-01-01 K layer: 1

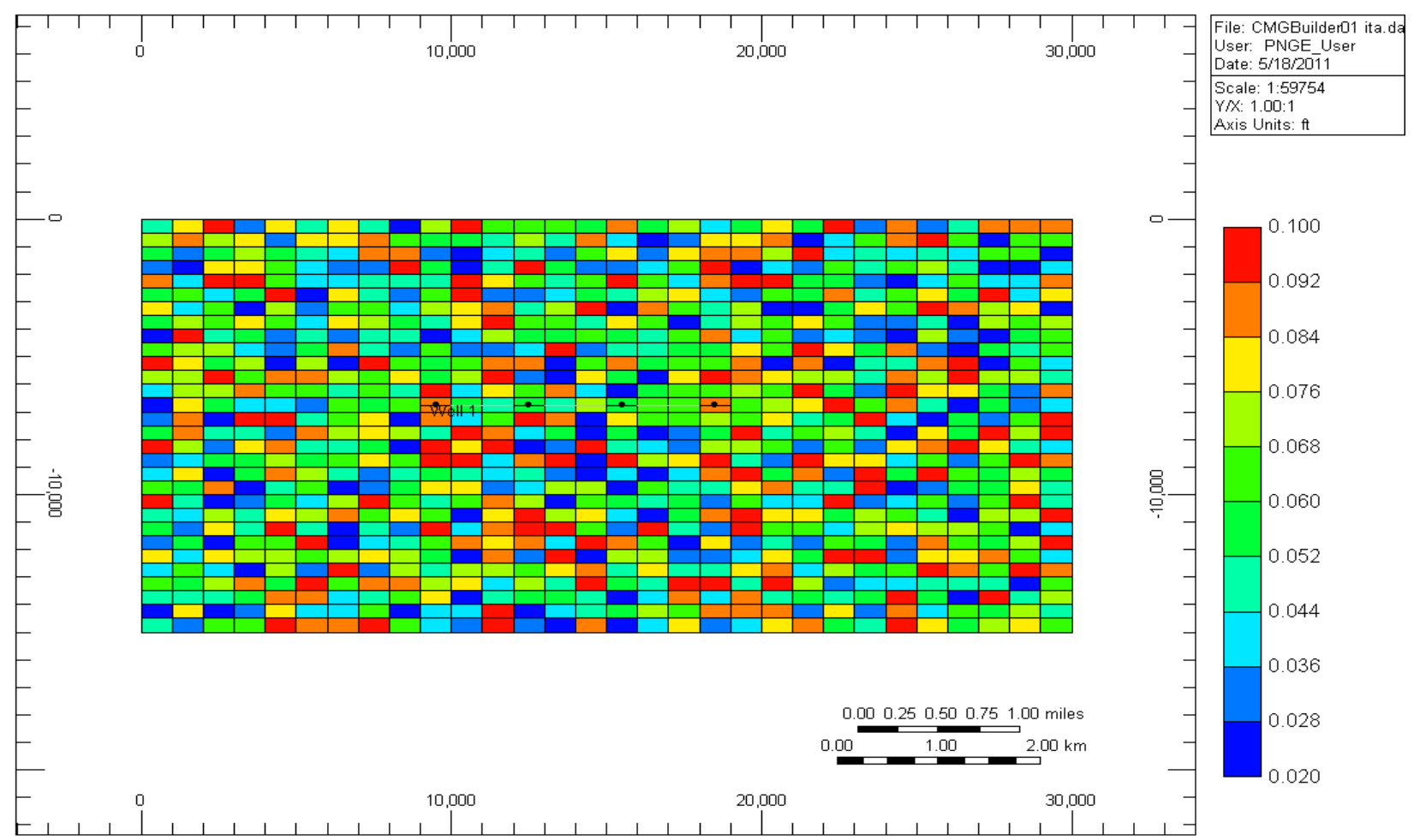

Figure A12; Matrix porosity values (Run 2.2)

Porosity 2000-01-01 K layer: 1

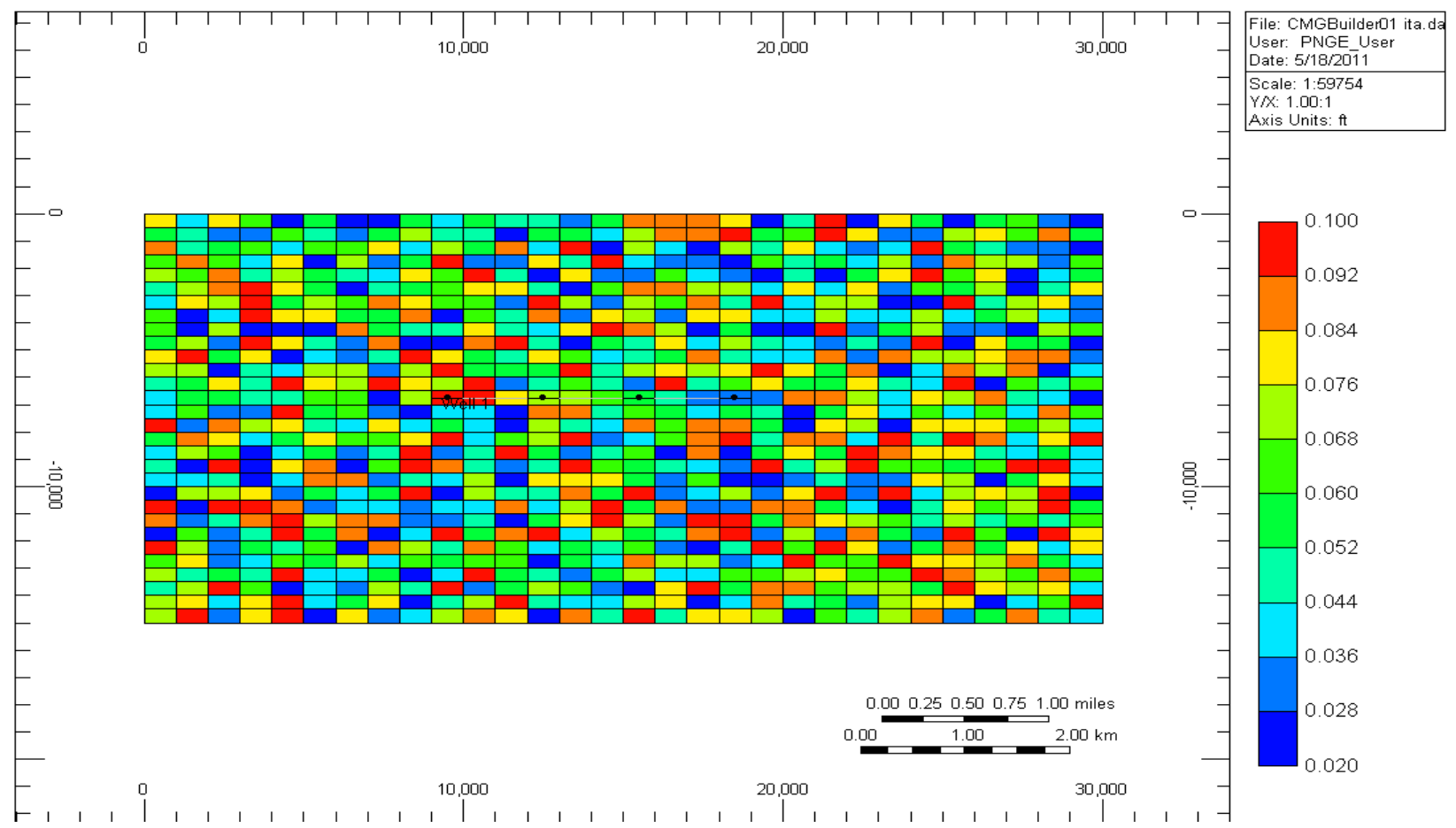

Figure A13; Matrix porosity values (Run 2.3) 
Porosity 2000-01-01 K layer: 1

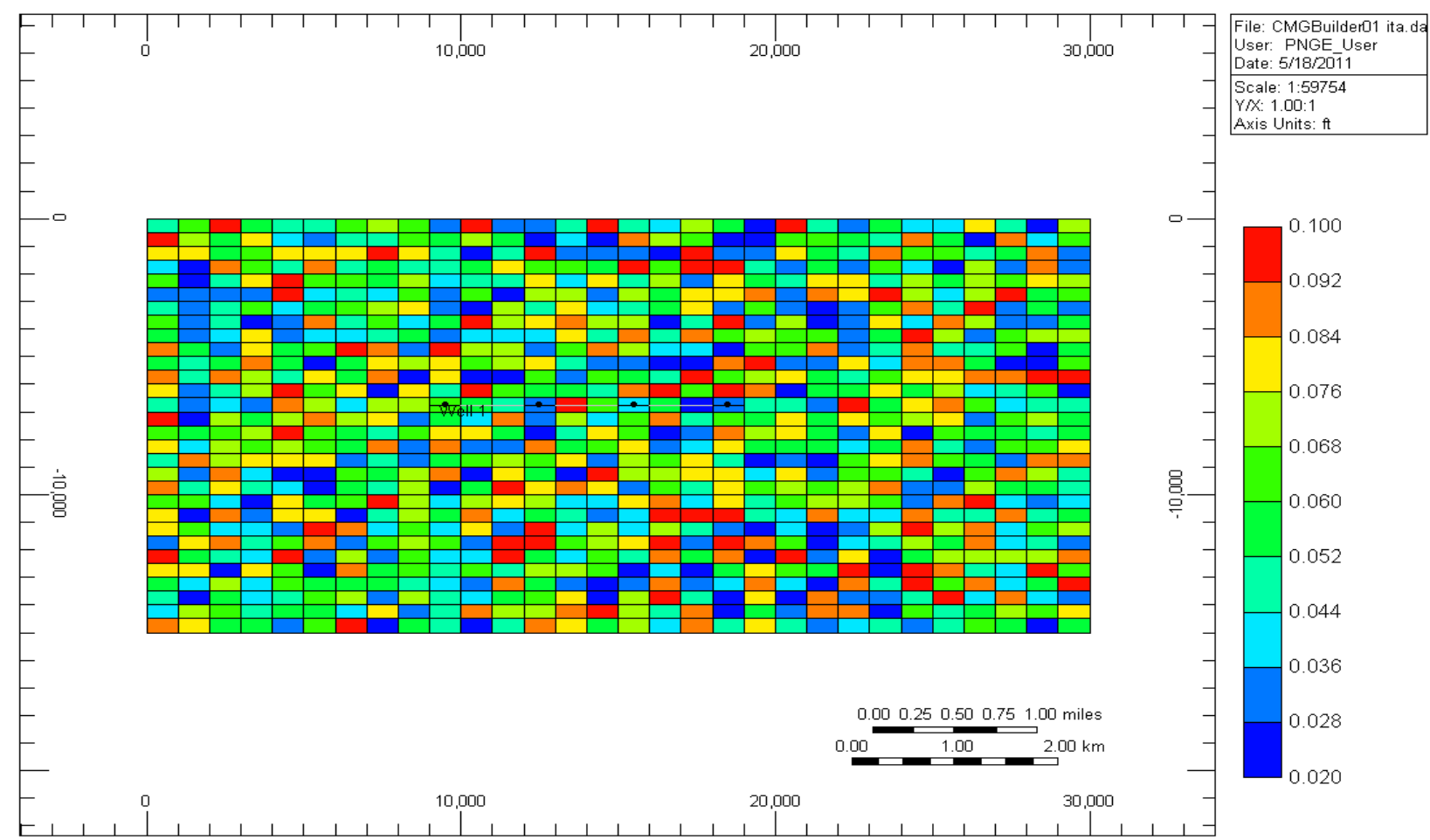

Figure A14; Matrix porosity values (Run 2.4)

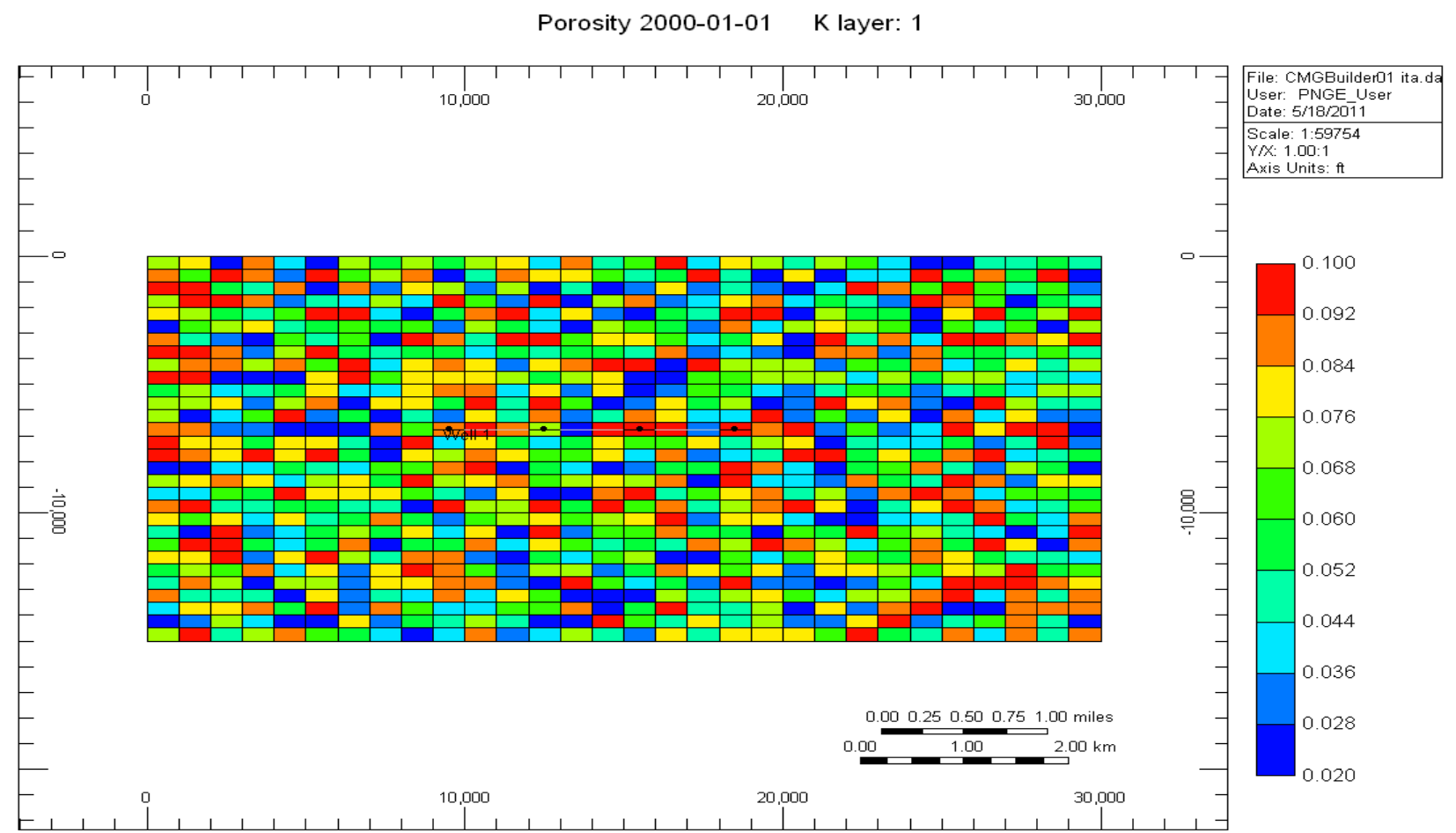

Figure A15; Matrix porosity values (Run 2.5) 
Porosity 2000-01-01 K layer: 1

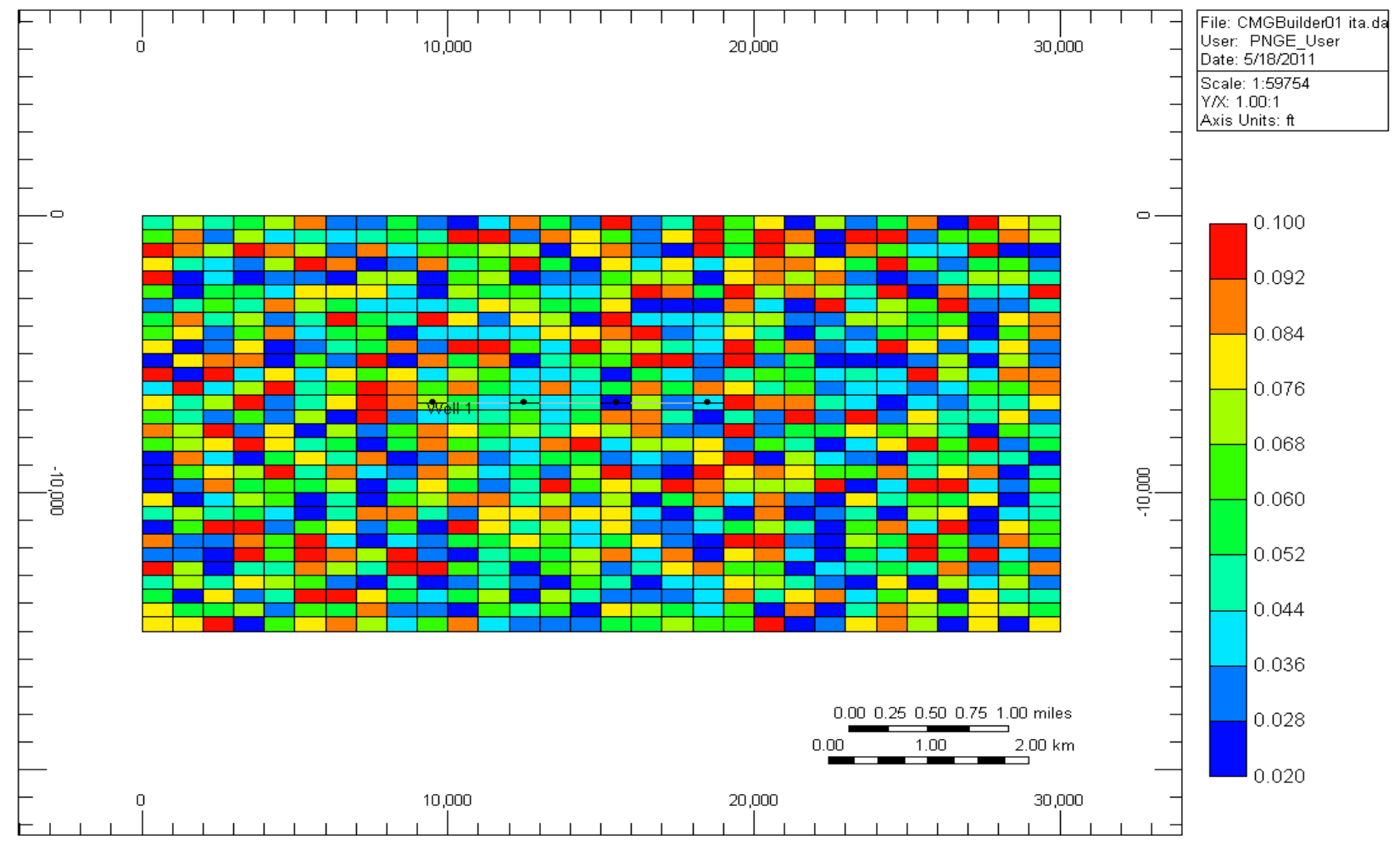

Figure A16; Matrix porosity values (Run 2.6)

Porosity 2000-01-01 K layer: 1

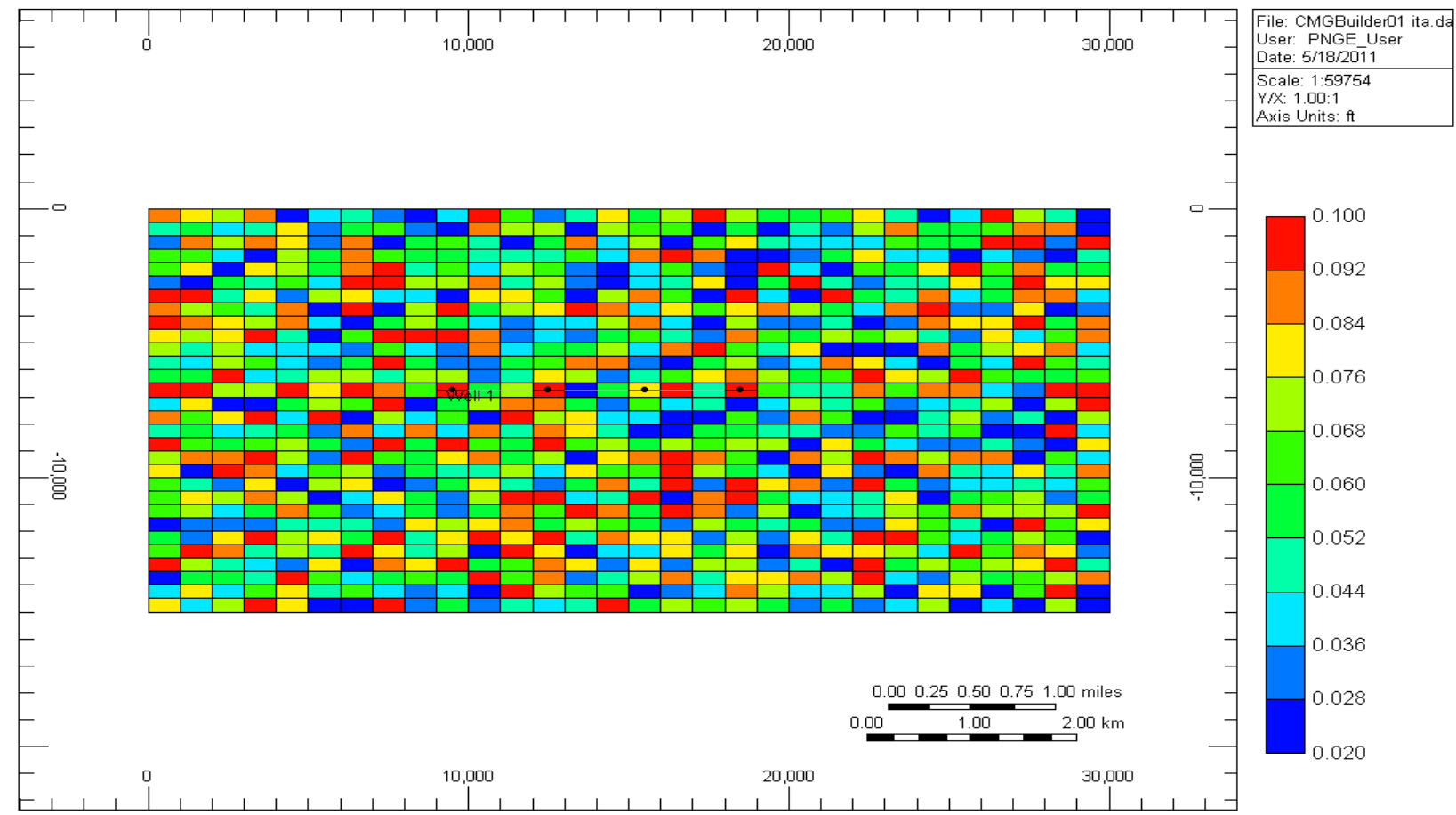

Figure A17; Matrix porosity values (Run 2.7) 
Porosity 2000-01-01 K layer: 1

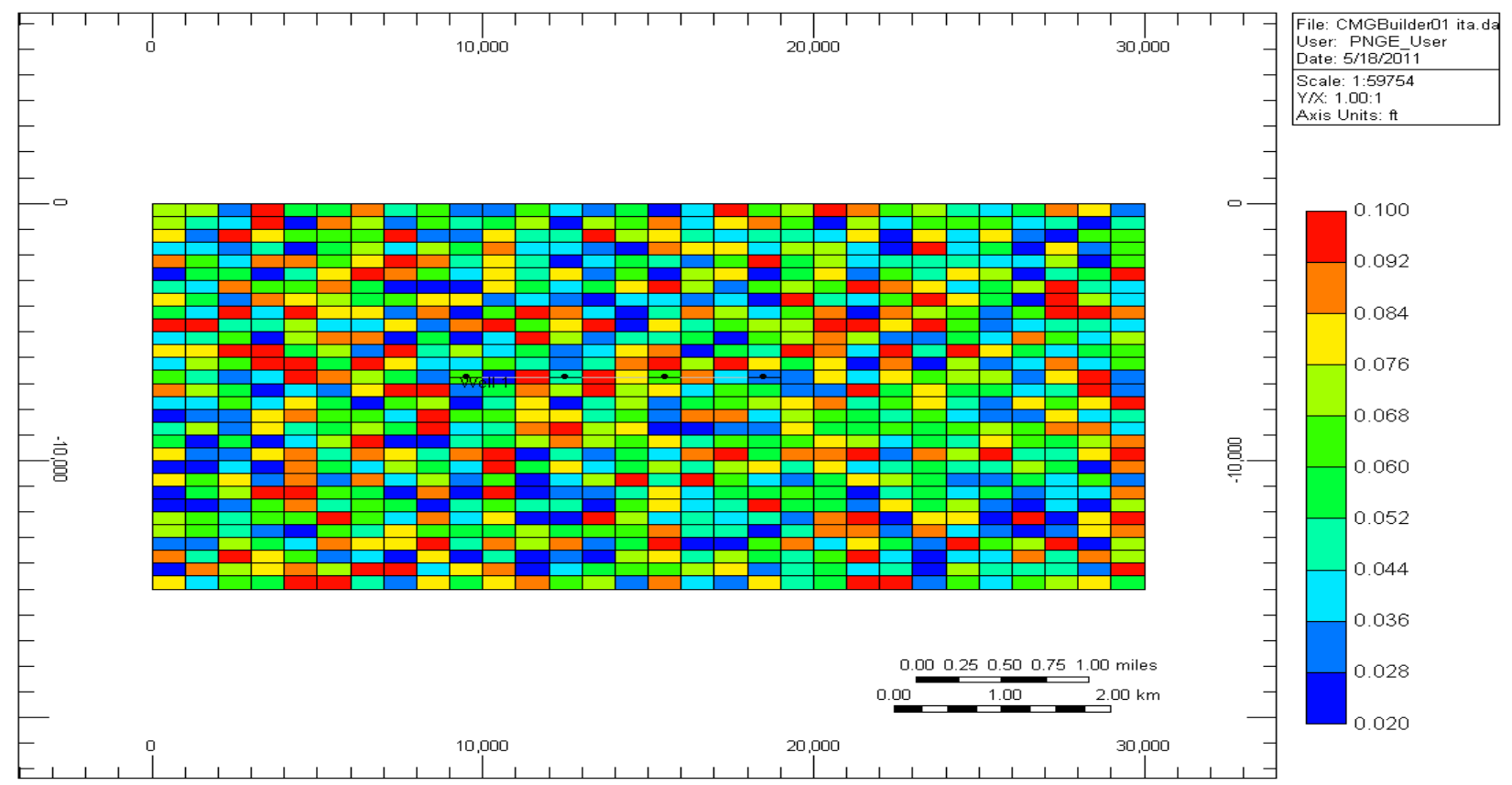

Figure A18; Matrix porosity values (Run 2.8)

Porosity 2000-01-01 K layer: 1

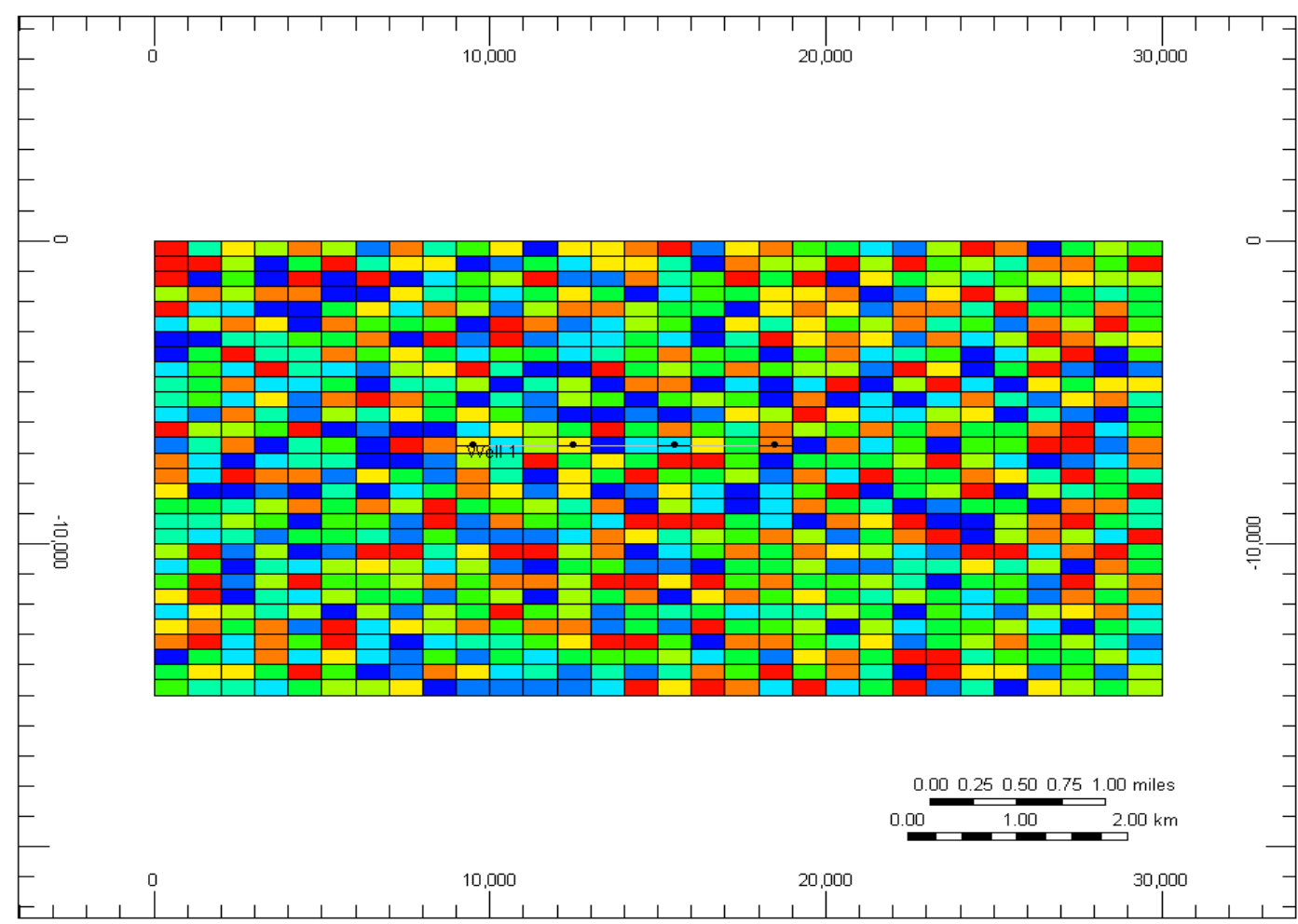

File: CMGBuilder01 ita.d User: PNGE_User

Date: $5 / 18 / 201$

Scale: $1: 59754$

$Y / X: 1.00:$

Axis Units: $\mathrm{ft}$

Figure A19; Matrix porosity values (Run 2.9) 
Porosity 2000-01-01 K layer: 1

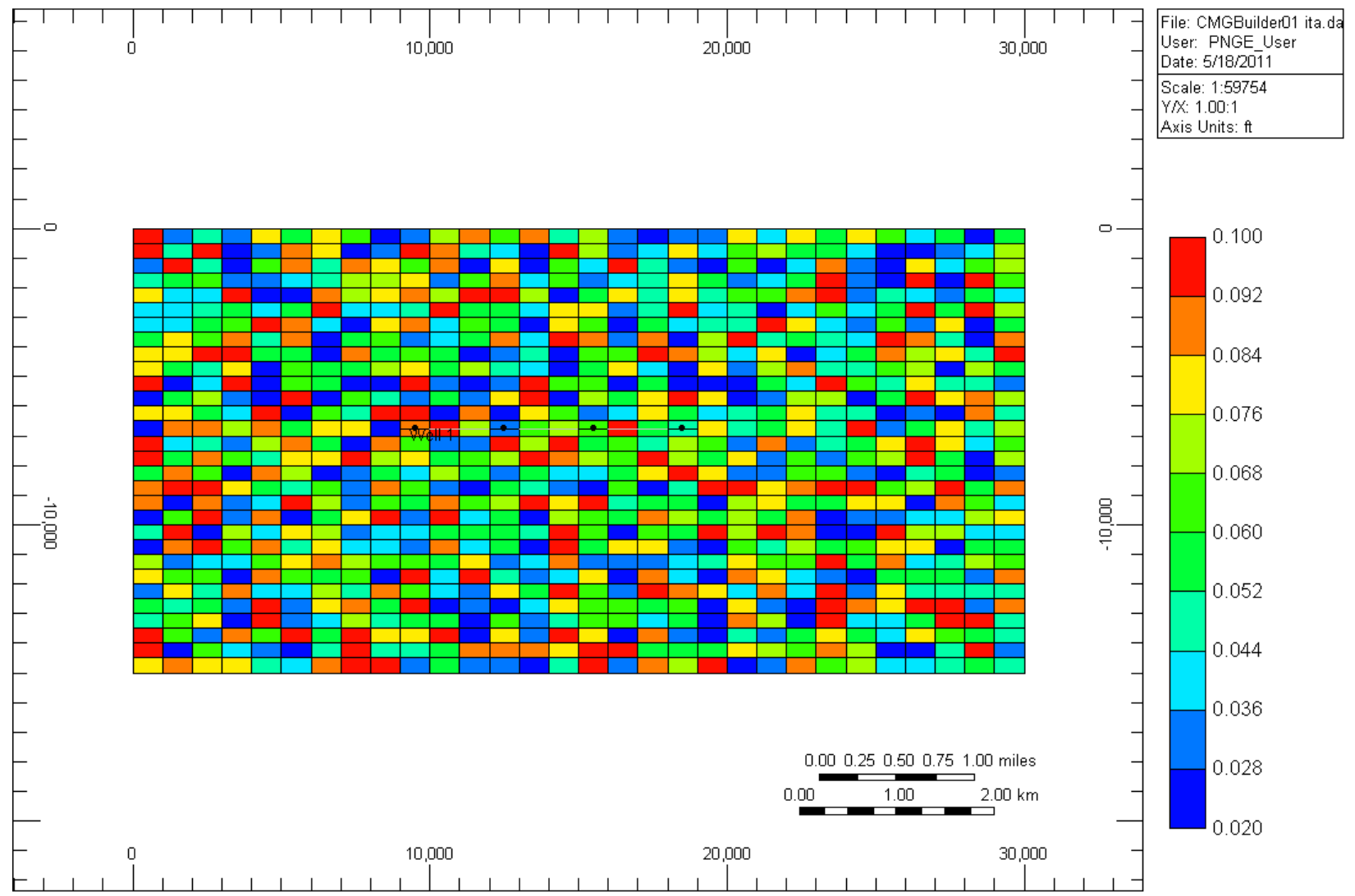

Figure A20; Matrix porosity values (Run 2.10) 


\section{FRACTURE PERMEABILITY DISTRIBUTIONS:}

Figure A21 through Figure A30 below show results for ten runs conducted for variable fracture permeability distribution.

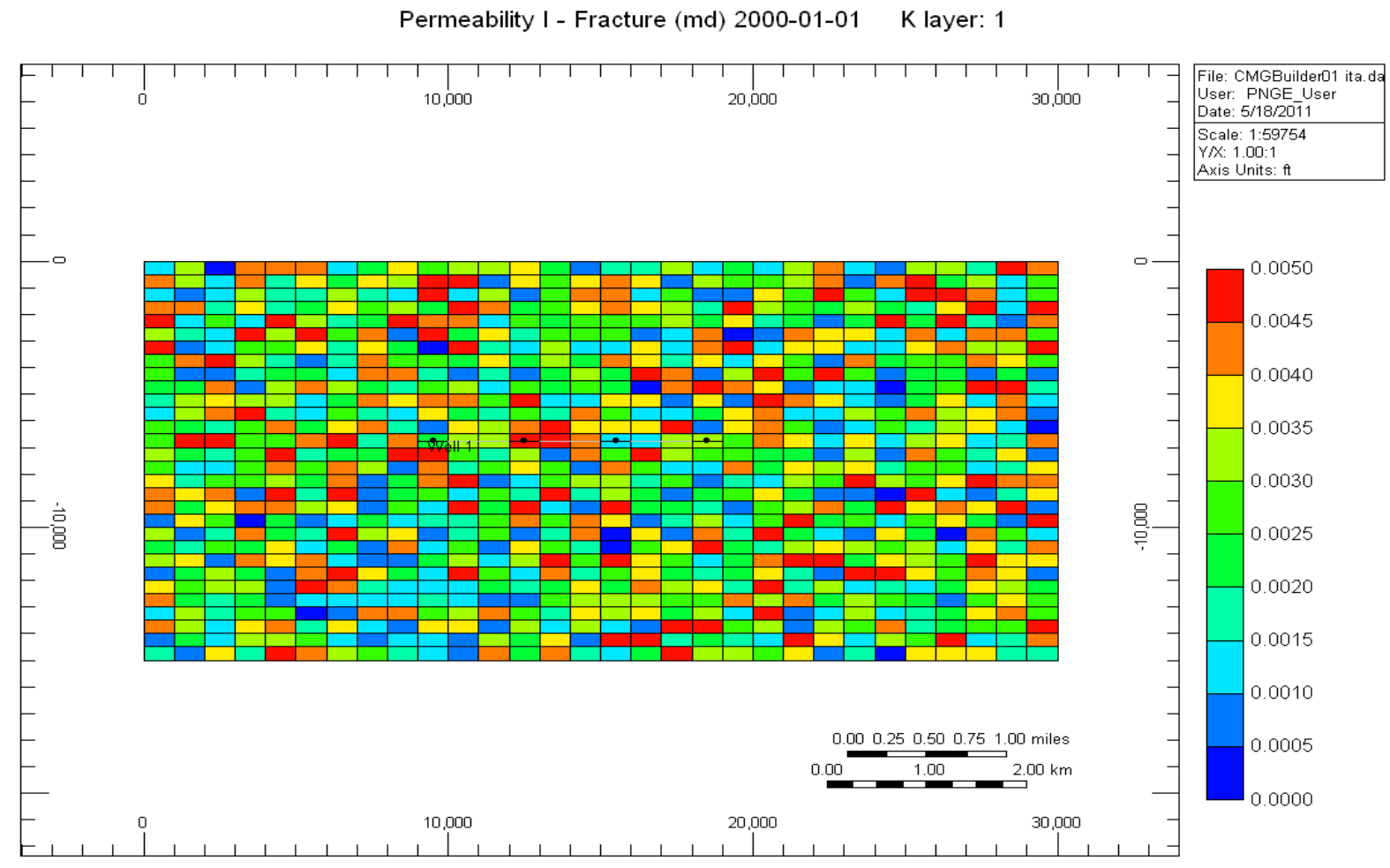

Figure A21; Fracture permeability values (Run 3.1) 
Permeability I - Fracture (md) 2000-01-01 K layer: 1

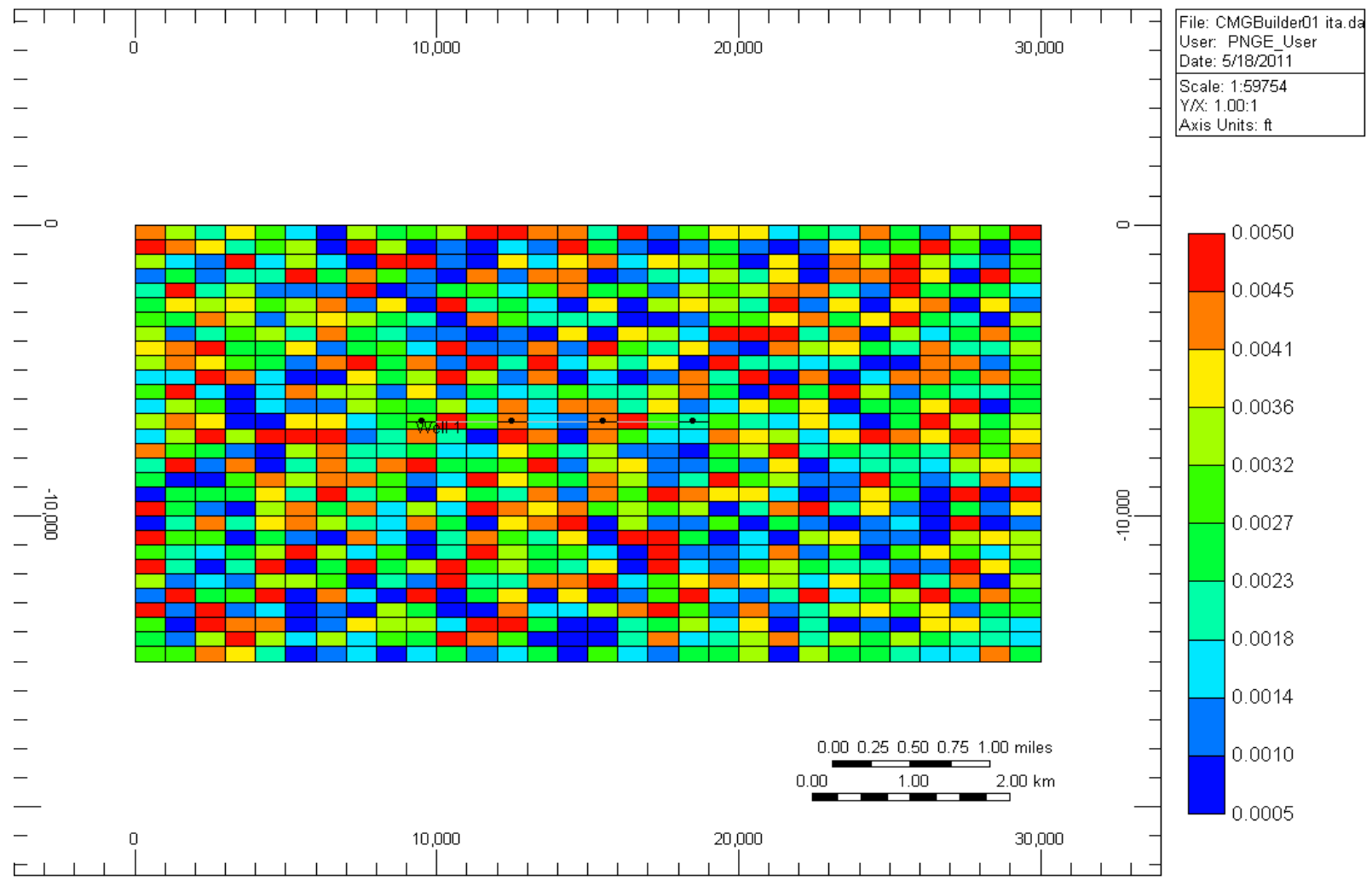

Figure A22; Fracture permeability values (Run 3.2)

Permeability I - Fracture (md) 2000-01-01 K layer: 1

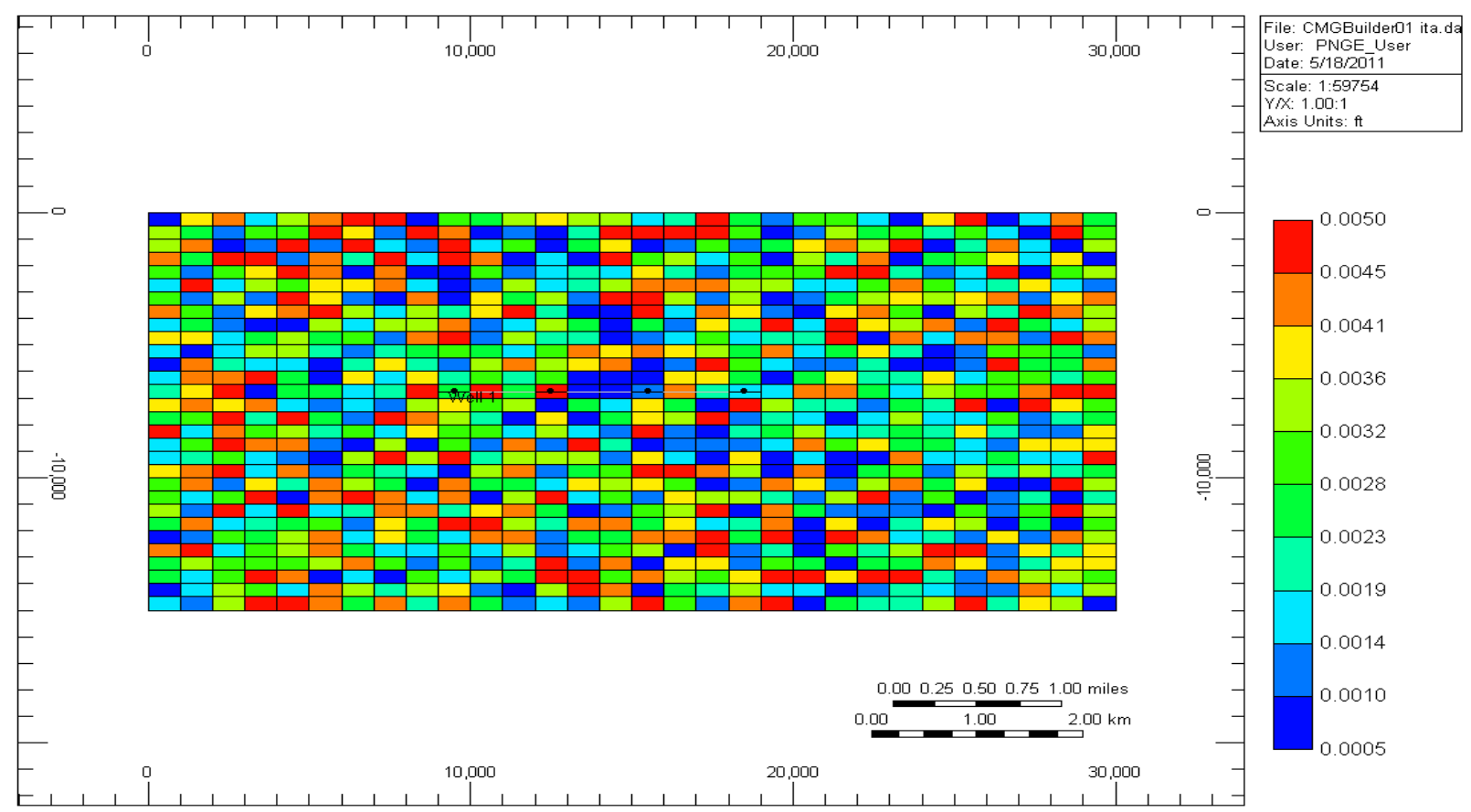

Figure A23; Fracture permeability values (Run 3.3) 
Permeability I - Fracture (md) 2000-01-01 K layer: 1

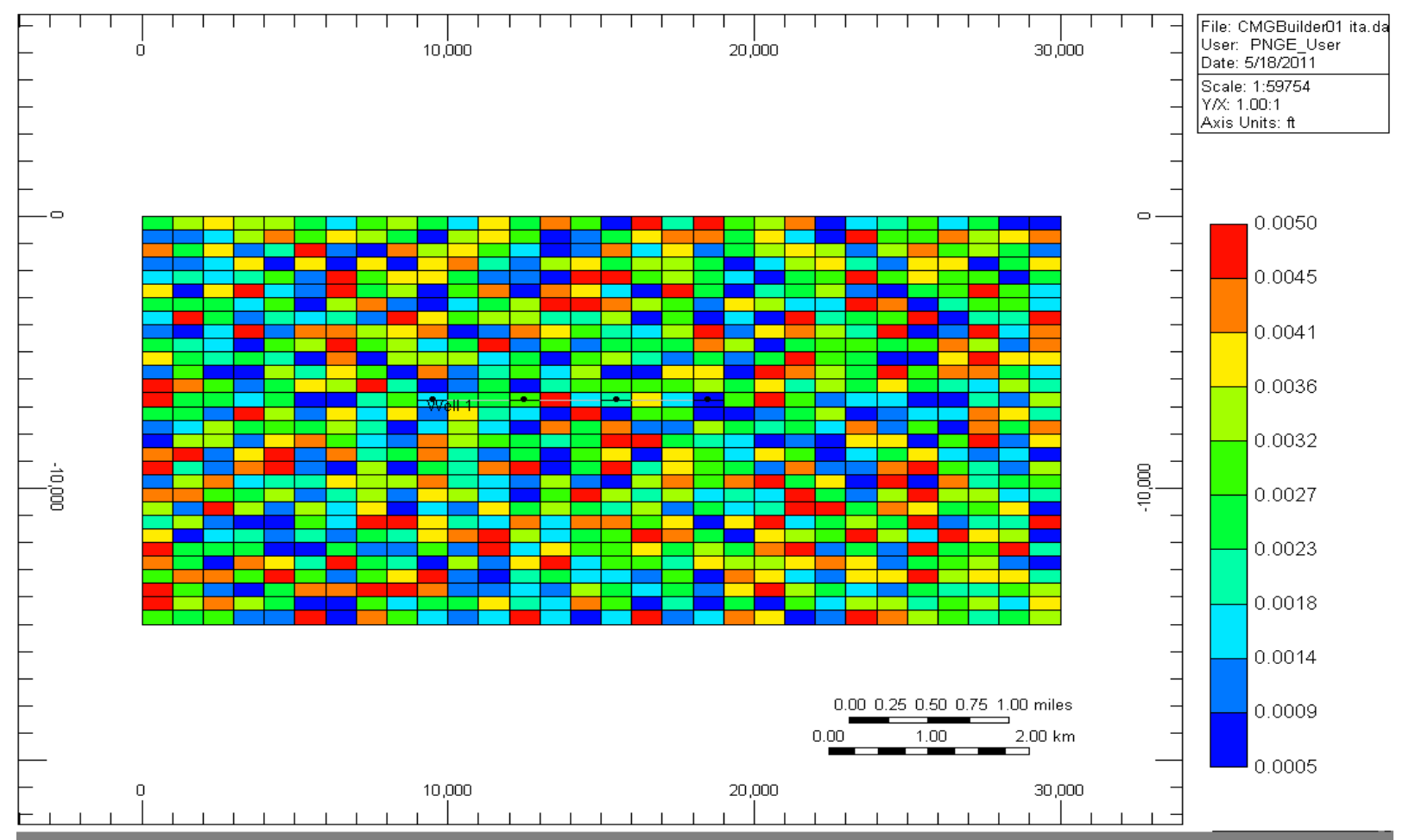

Figure A24; Fracture permeability values (Run 3.4)

Permeability I - Fracture (md) 2000-01-01 K layer: 1

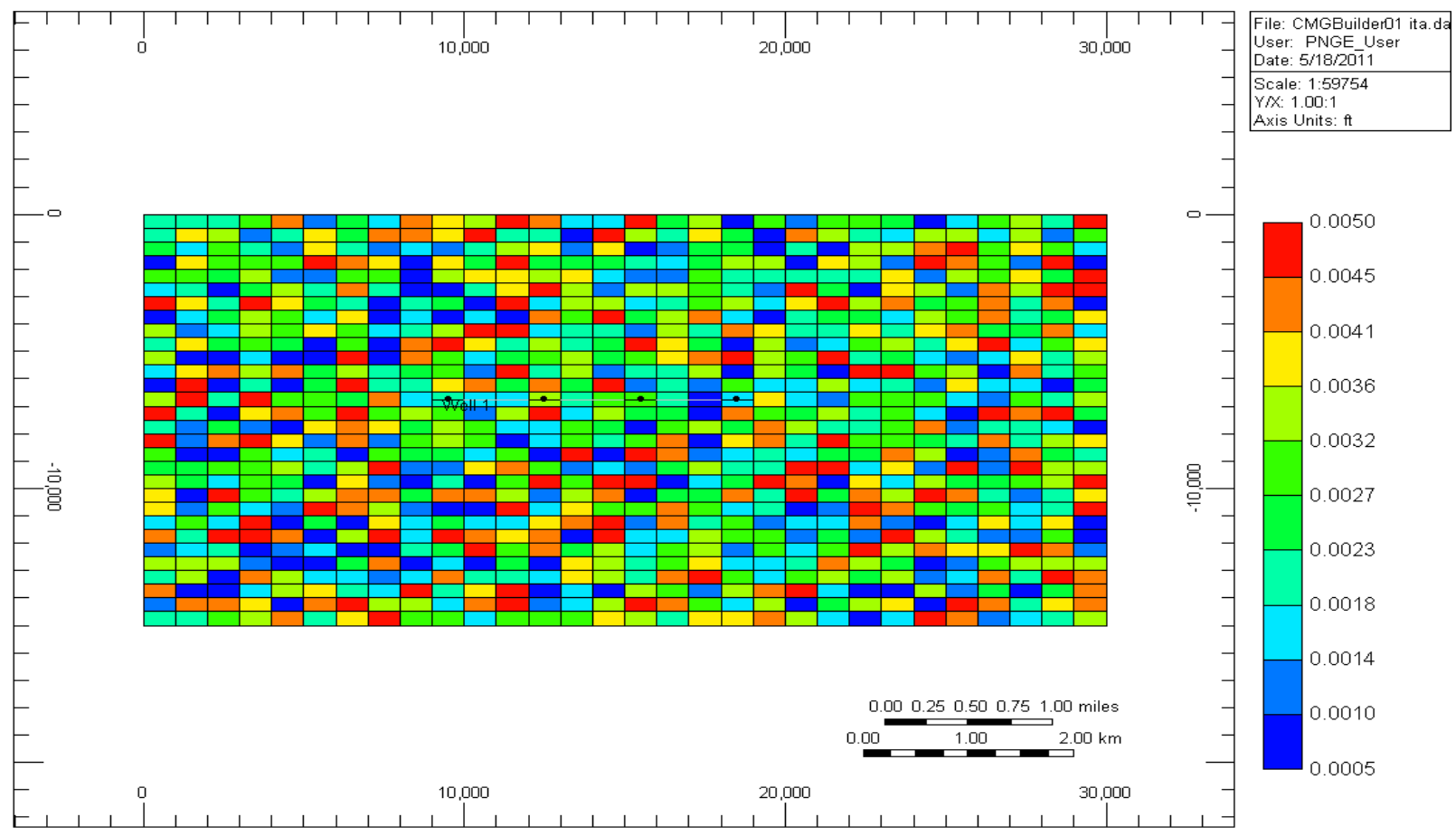

Figure A25; Fracture permeability values (Run 3.5) 
Permeability I - Fracture (md) 2000-01-01 K layer: 1

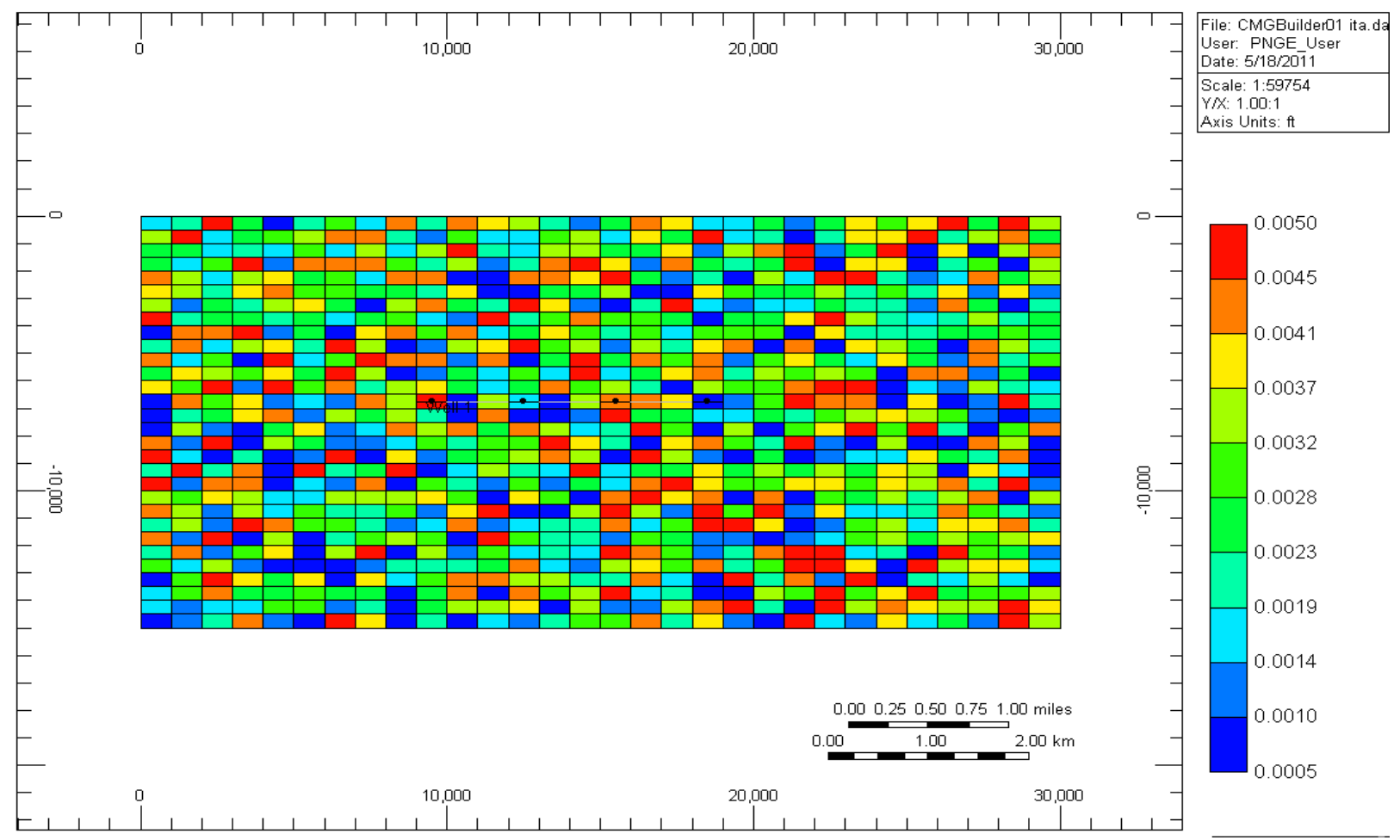

Figure A26; Fracture permeability values (Run 3.6)

Permeability I - Fracture (md) 2000-01-01 K layer: 1

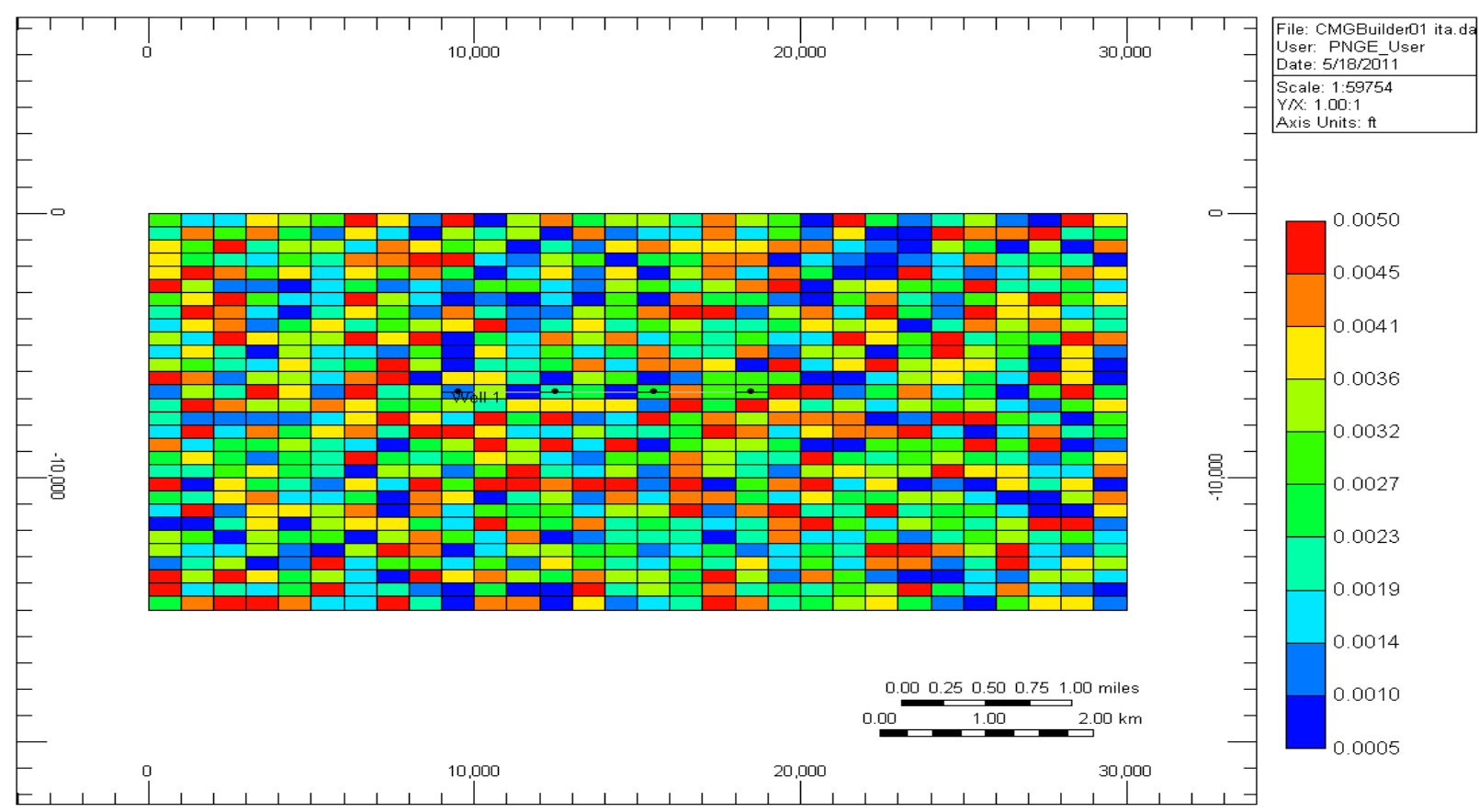

Figure A27; Fracture permeability values (Run 3.7) 
Permeability I - Fracture (md) 2000-01-01 K layer: 1

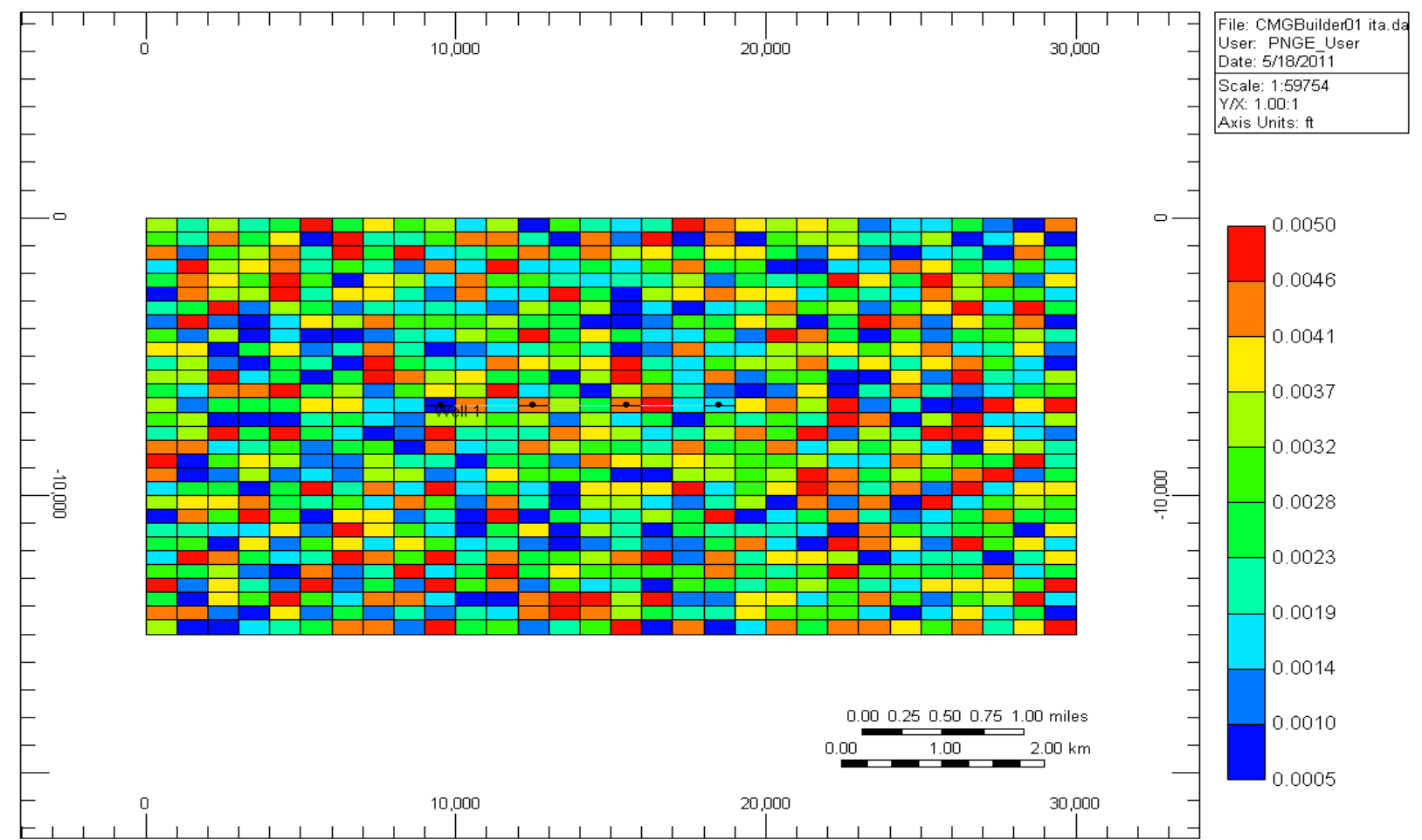

Figure A28; Fracture permeability values (Run 3.8)

Permeability I - Fracture (md) 2000-01-01 K layer: 1

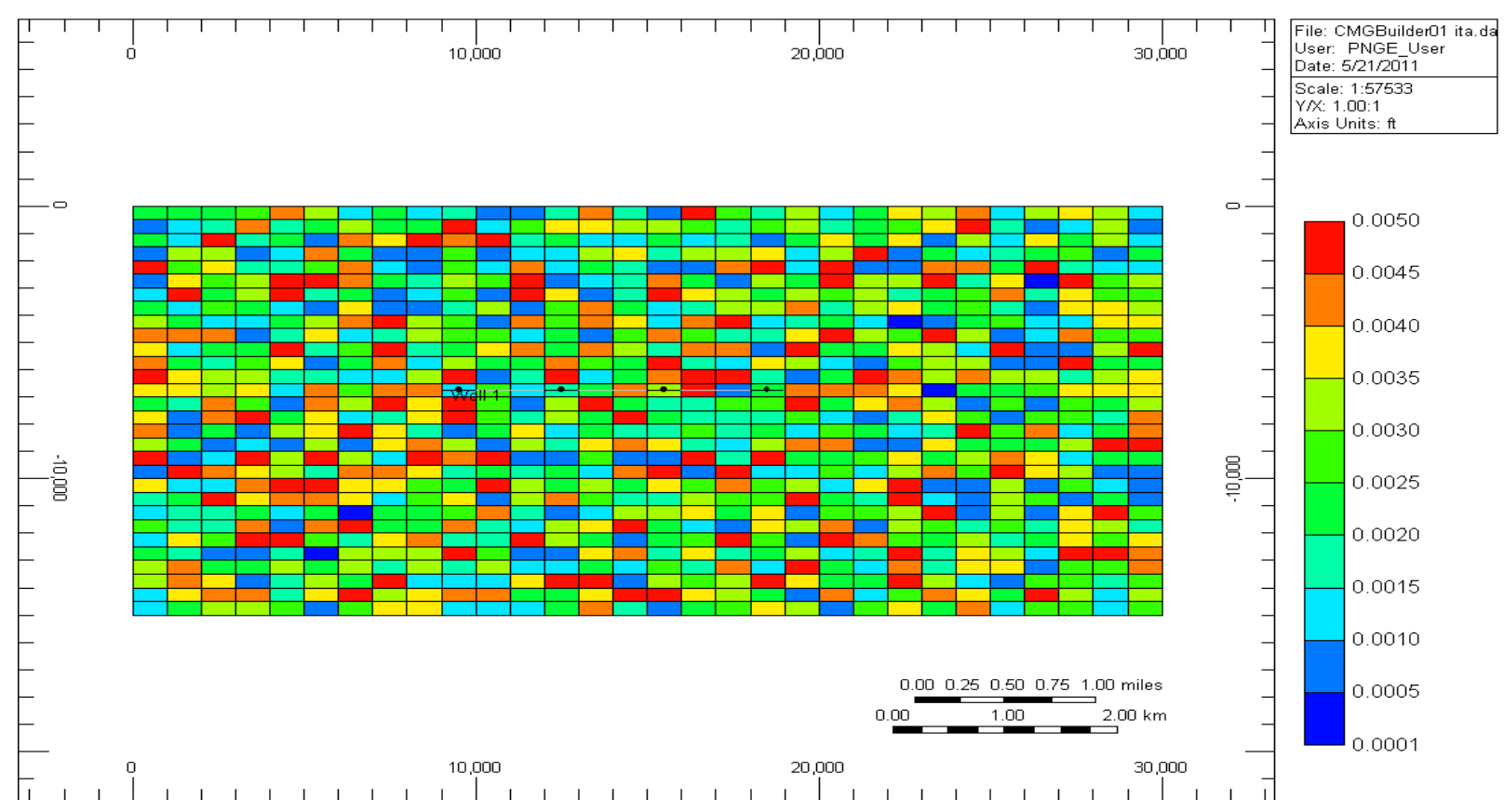

Figure A29; Fracture permeability values (Run 3.9) 
Permeability I - Fracture (md) 2000-01-01 K layer: 1

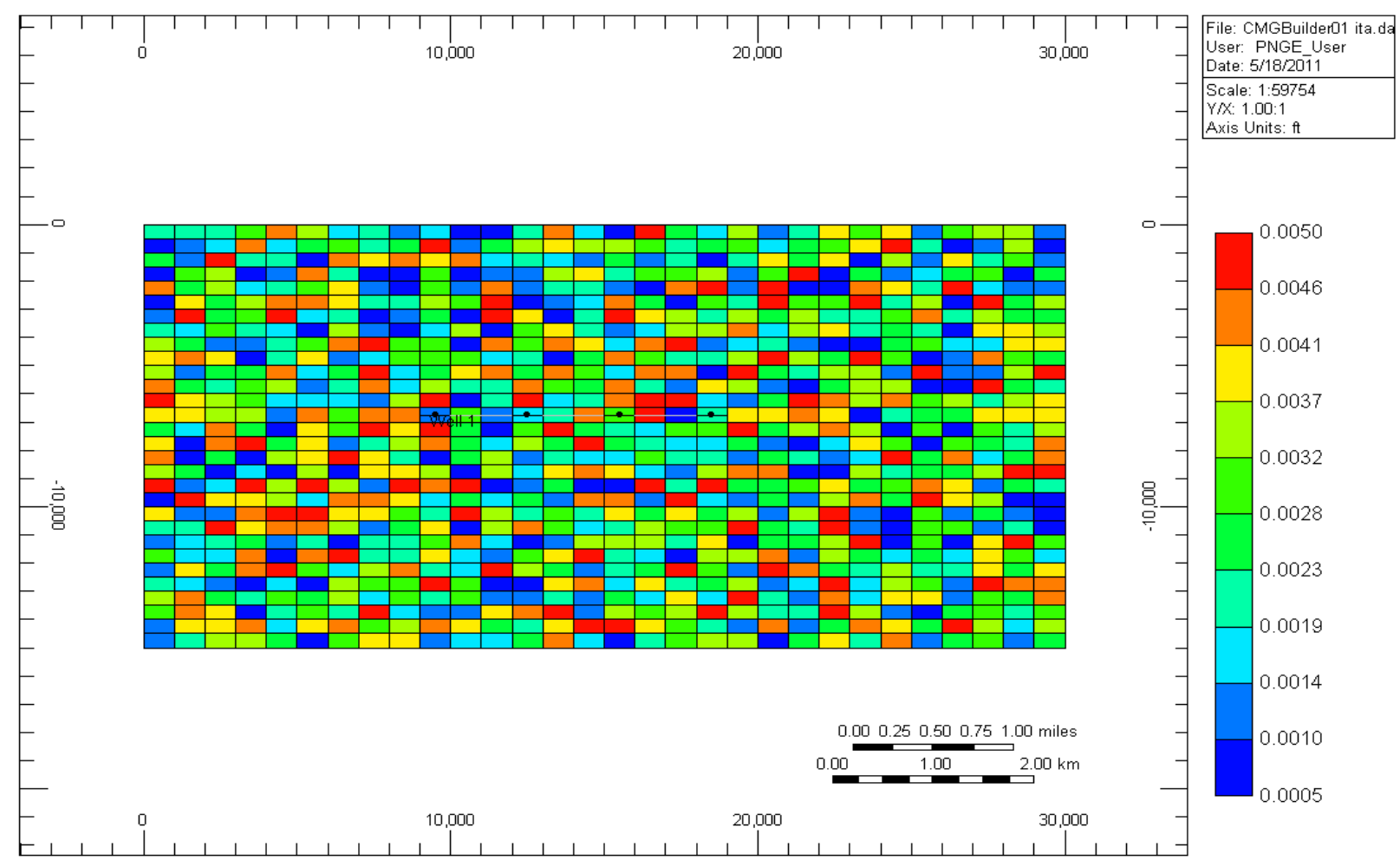

Figure A30; Fracture permeability values (Run 3.10) 


\section{MATRIX PERMEABILITY DISTRIBUTIONS:}

Figure A31 through Figure A40 below show results for ten runs conducted for variable matrix permeability distribution.

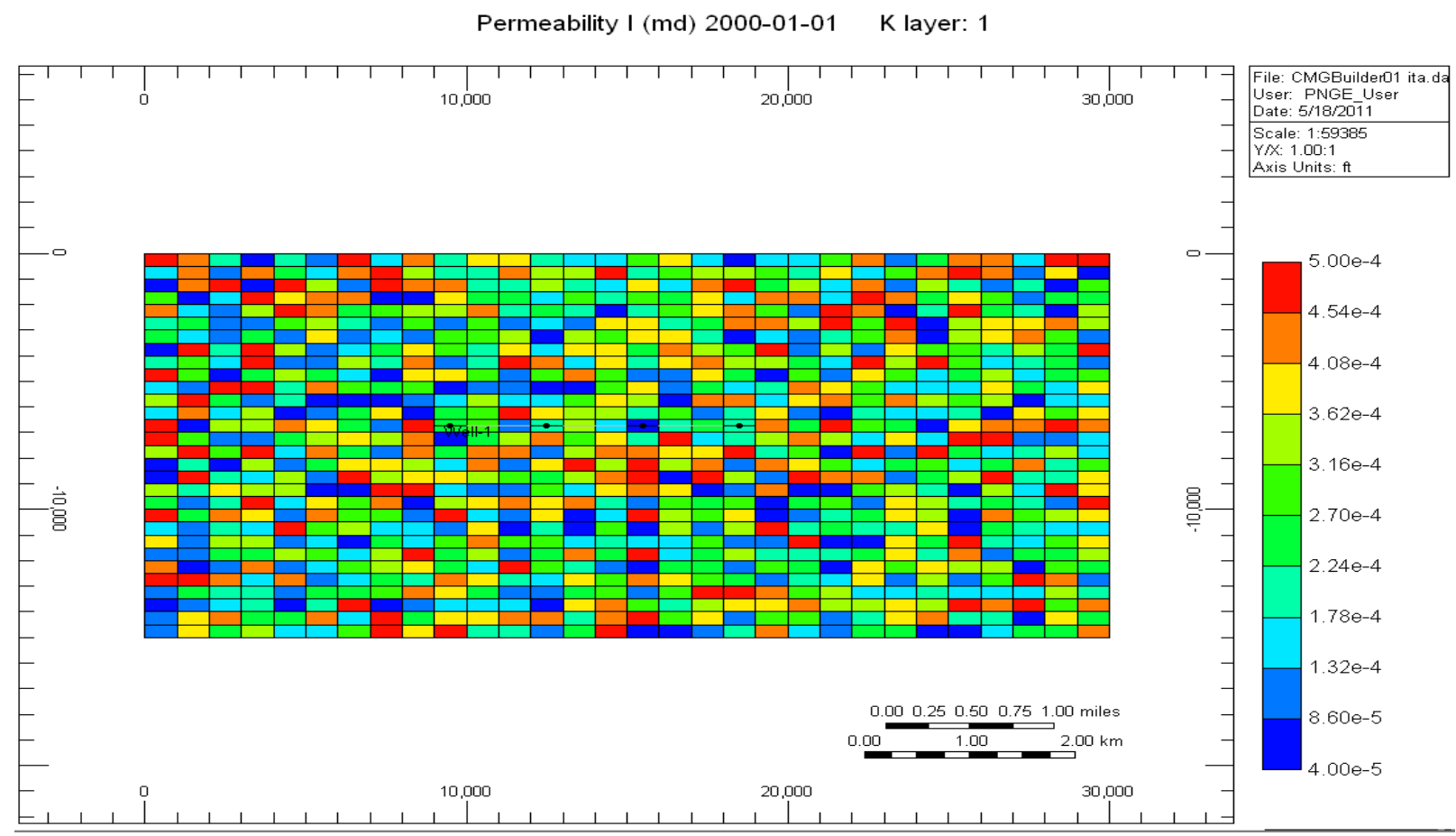

Figure A31; Matrix permeability values (Run 4.1) 
Permeability I (md) 2000-01-01 K layer: 1

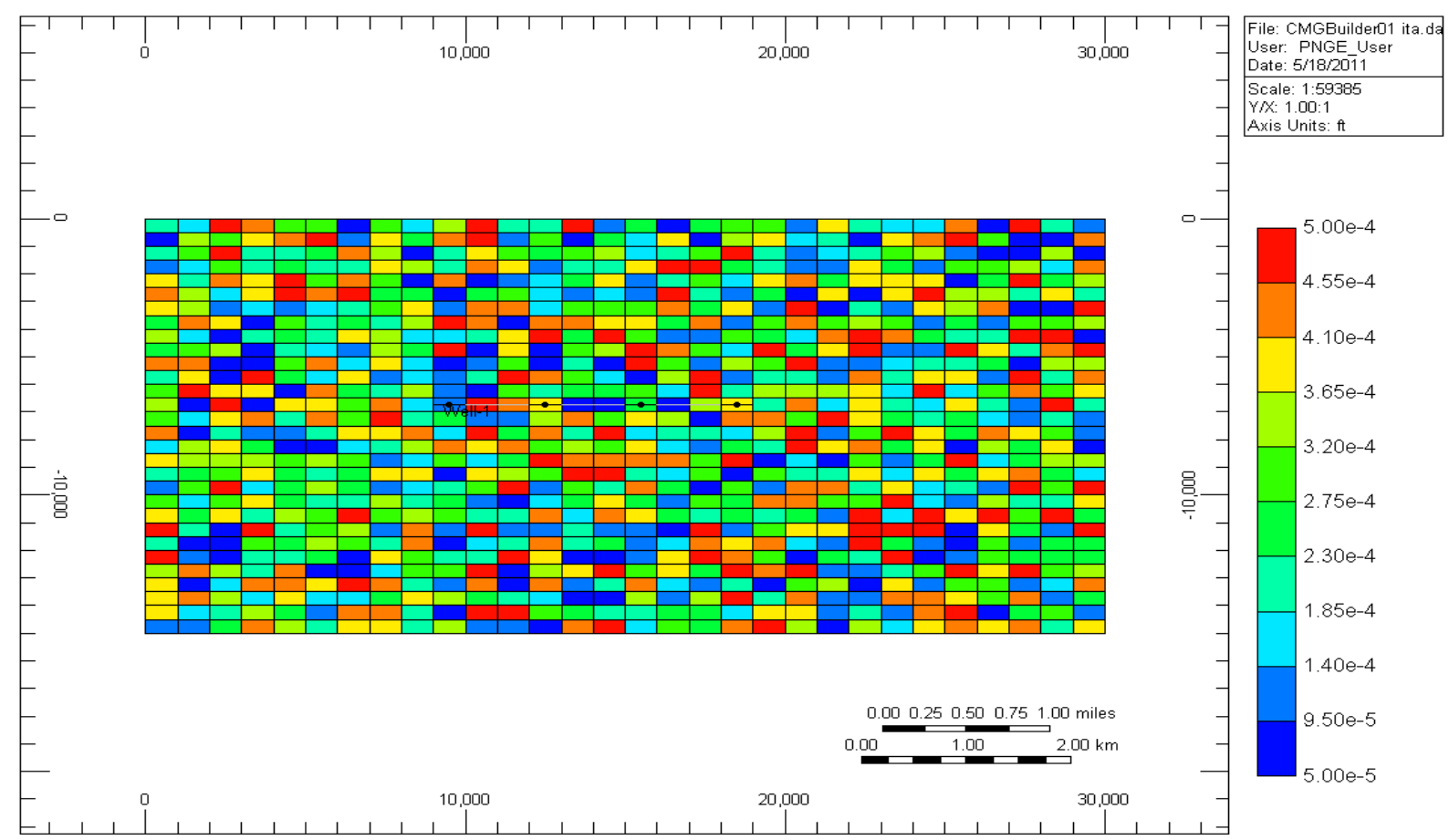

Figure A32; Matrix permeability values (Run 4.2)

Permeability I (md) 2000-01-01 K layer: 1

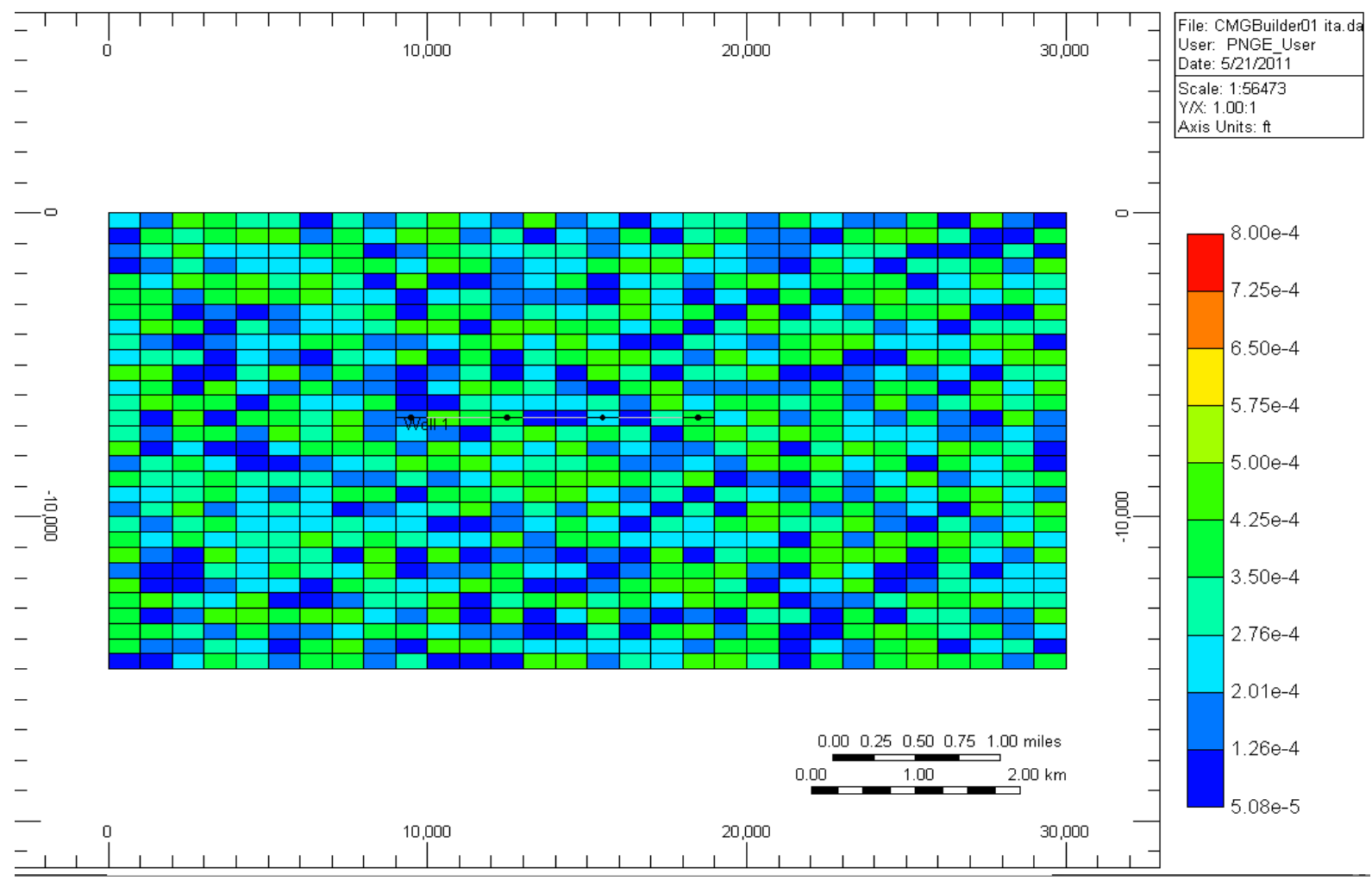

Figure A33; Matrix permeability values (Run 4.3) 
Permeability I (md) 2000-01-01 K layer: 1

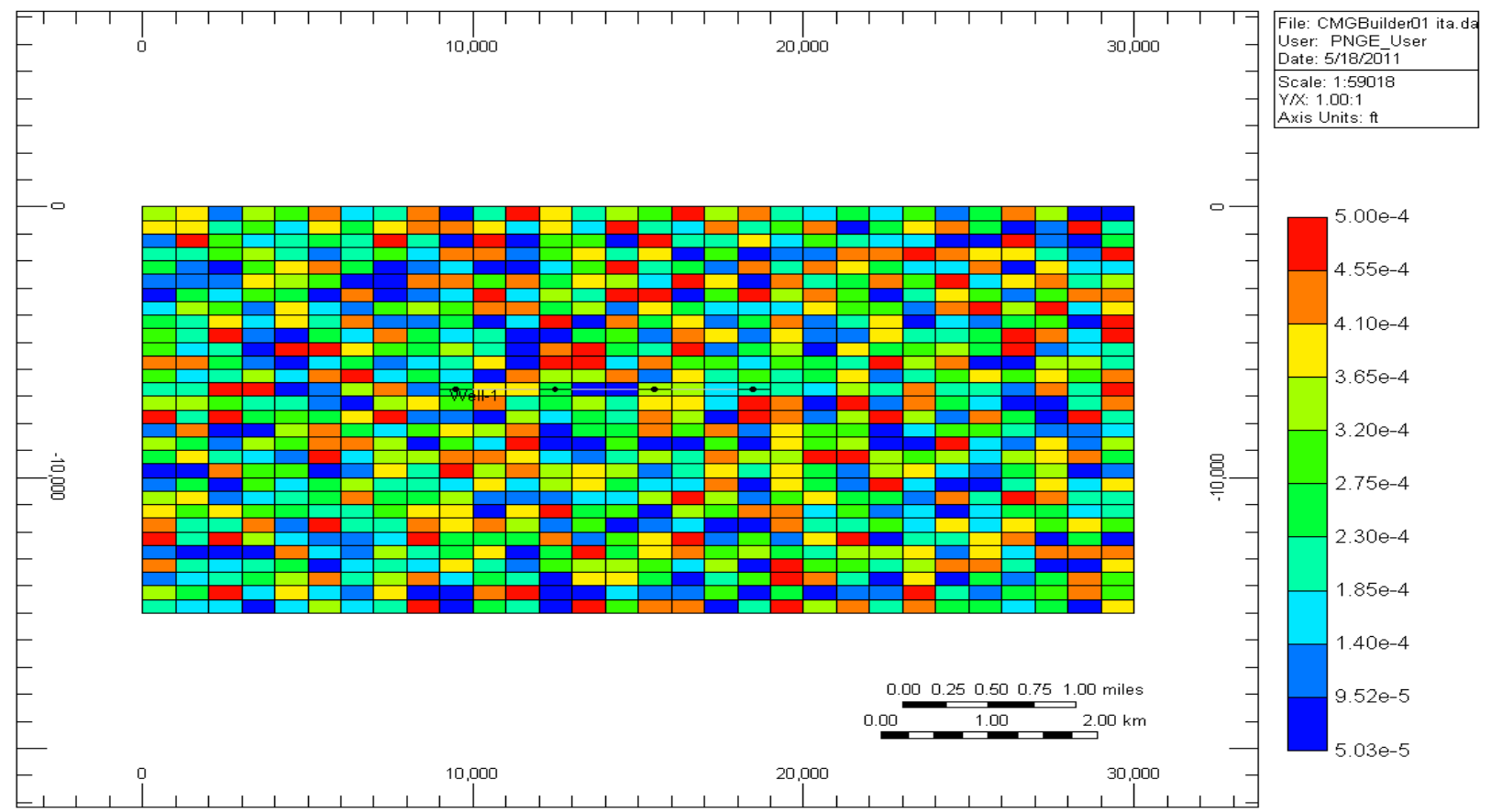

Figure A34; Matrix permeability values (Run 4.4)

Permeability I (md) 2000-01-01 K layer: 1

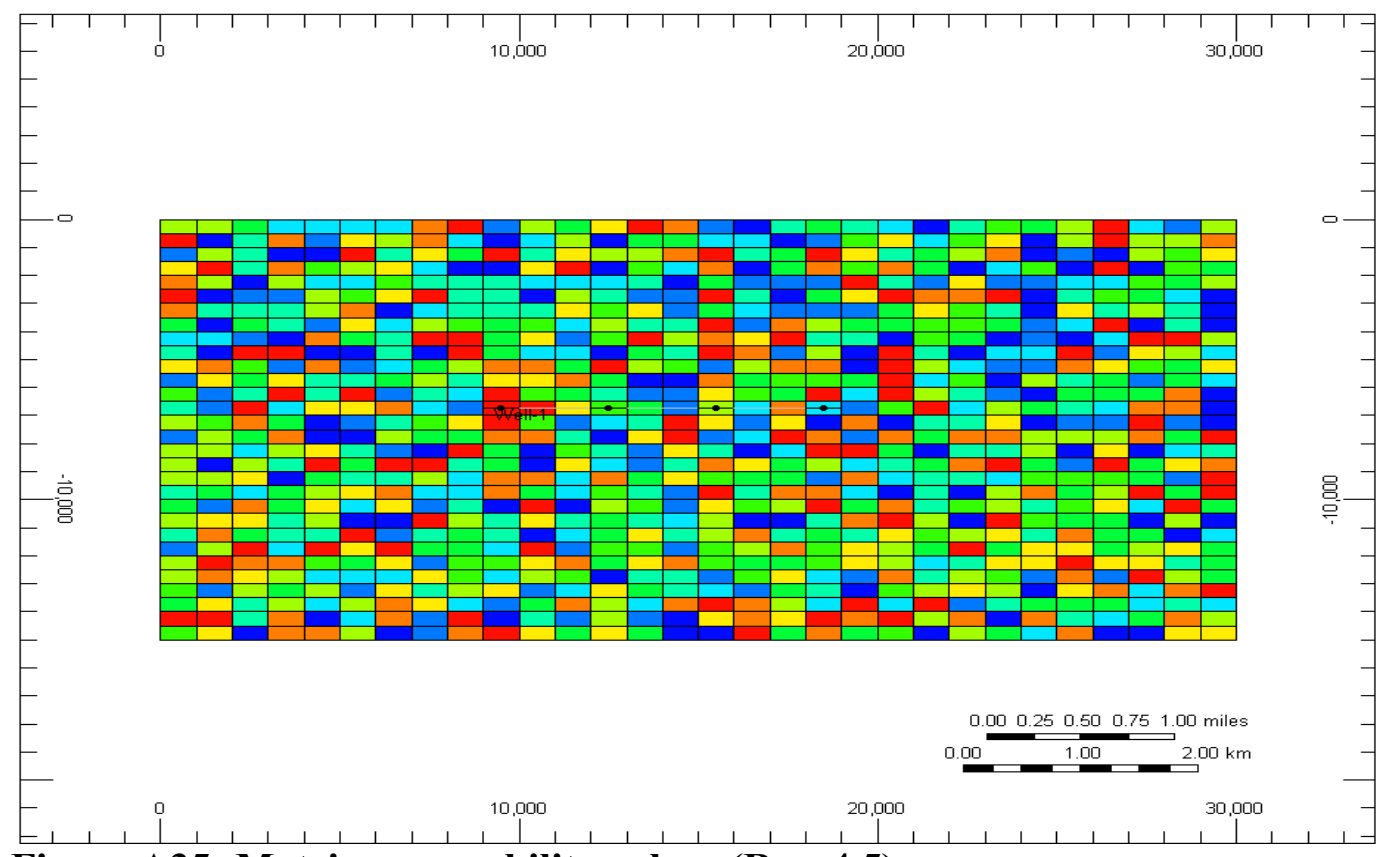

Figure A35; Matrix permeability values (Run 4.5)
File: CMGBuilder01 ita.d User: PNGE_User

Scale: $1: 59385$

Y/X: $1.00: 1$ Axis Units: $f$

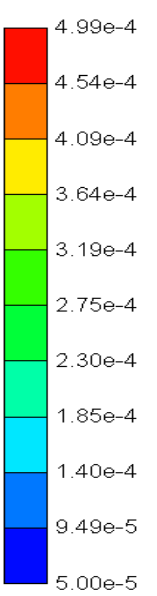




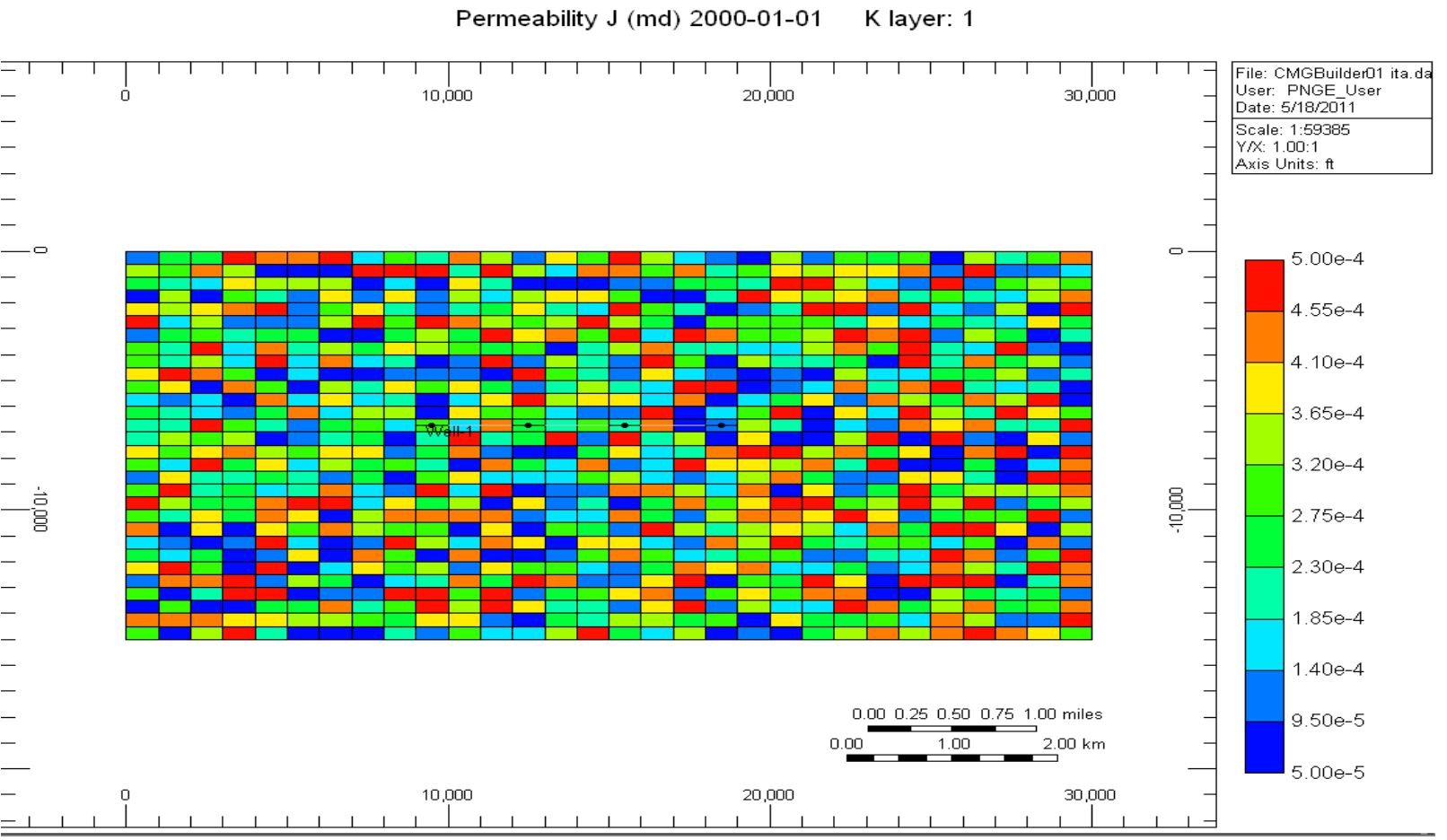

Figure A36; Matrix permeability values (Run 4.6)

Permeability I (md) 2000-01-01 K layer: 1

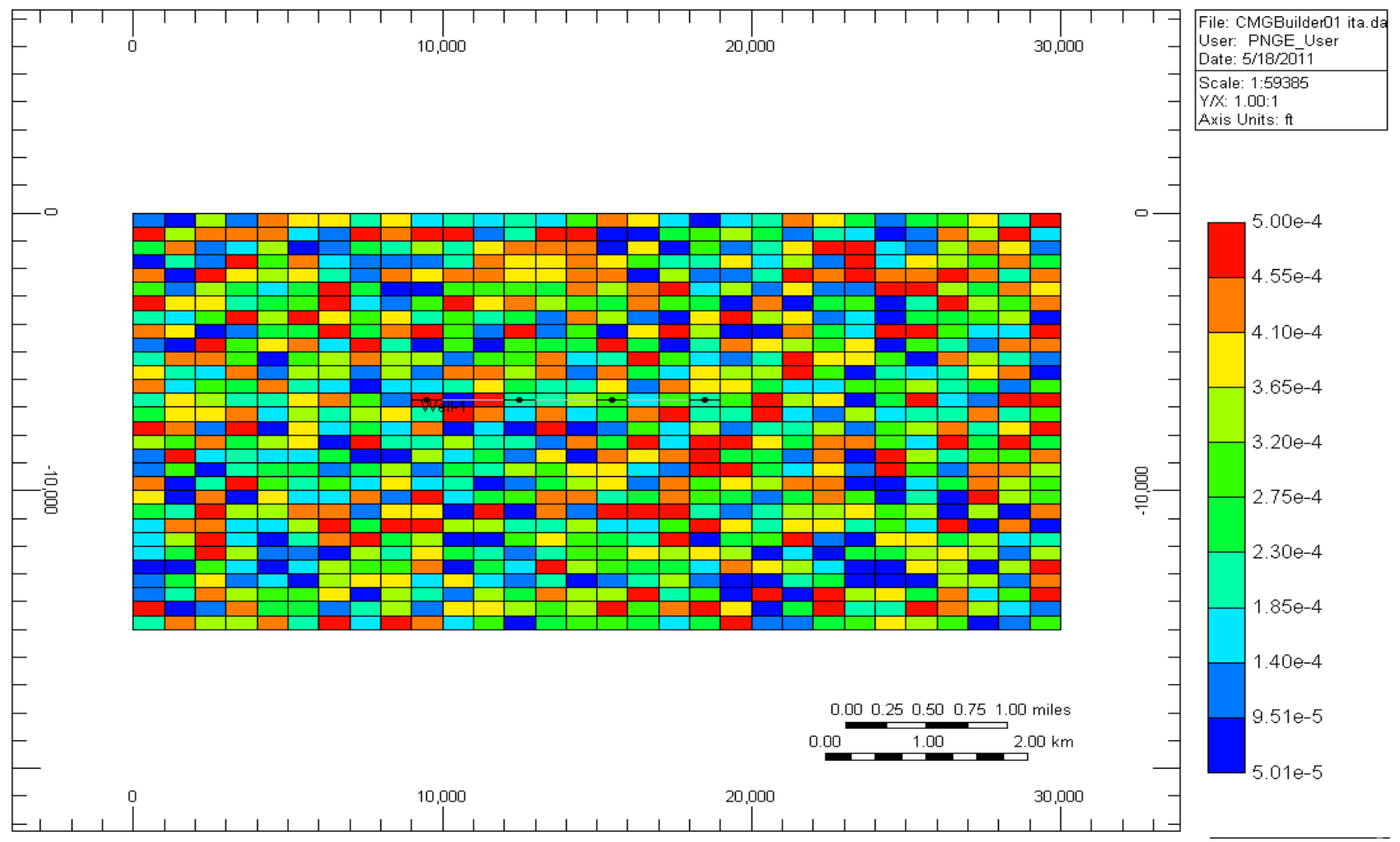

Figure A37; Matrix permeability values (Run 4.7) 


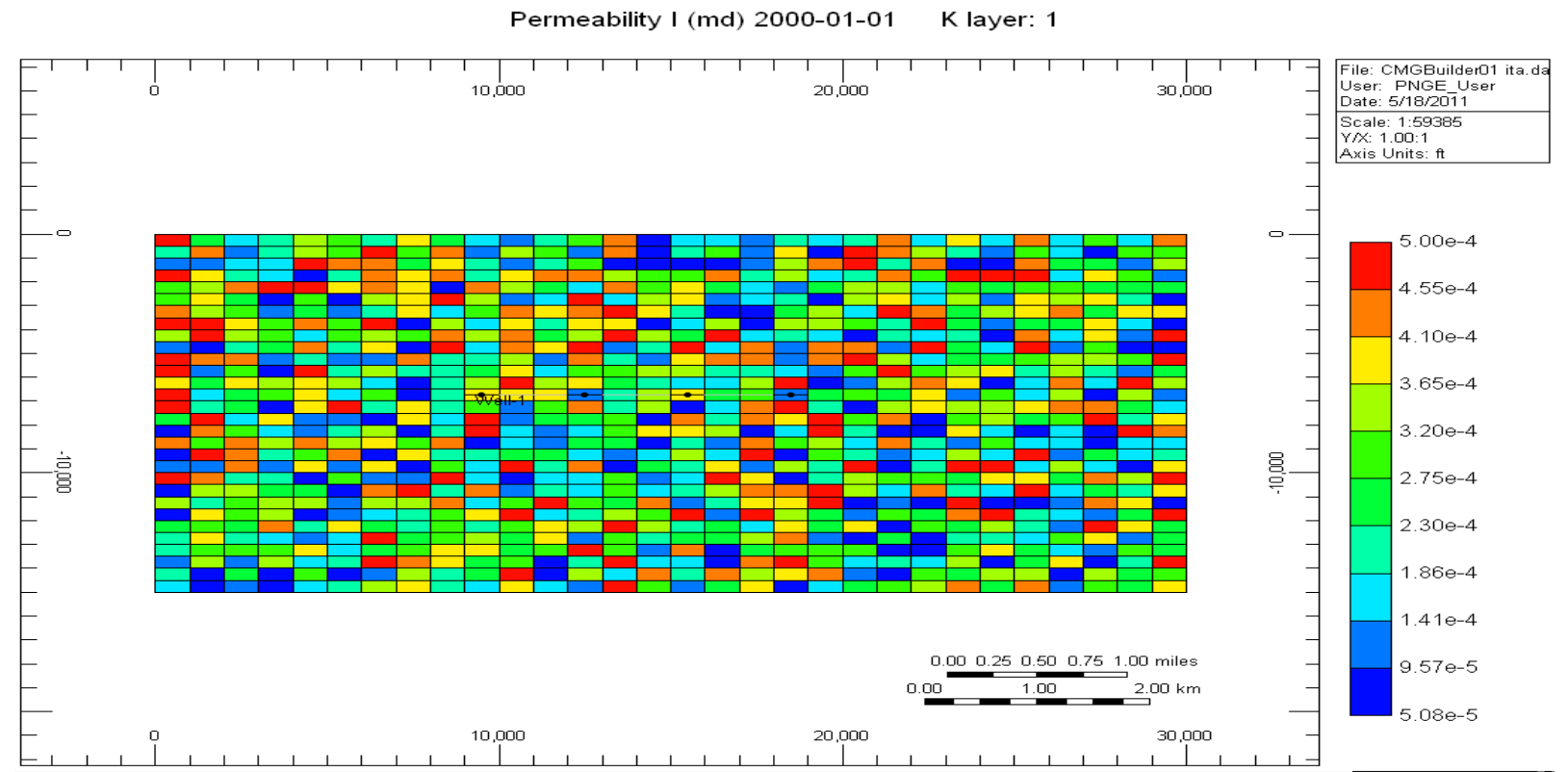

Figure A38; Matrix permeability values (Run 4.8)

Permeability I (md) 2000-01-01 K layer: 1

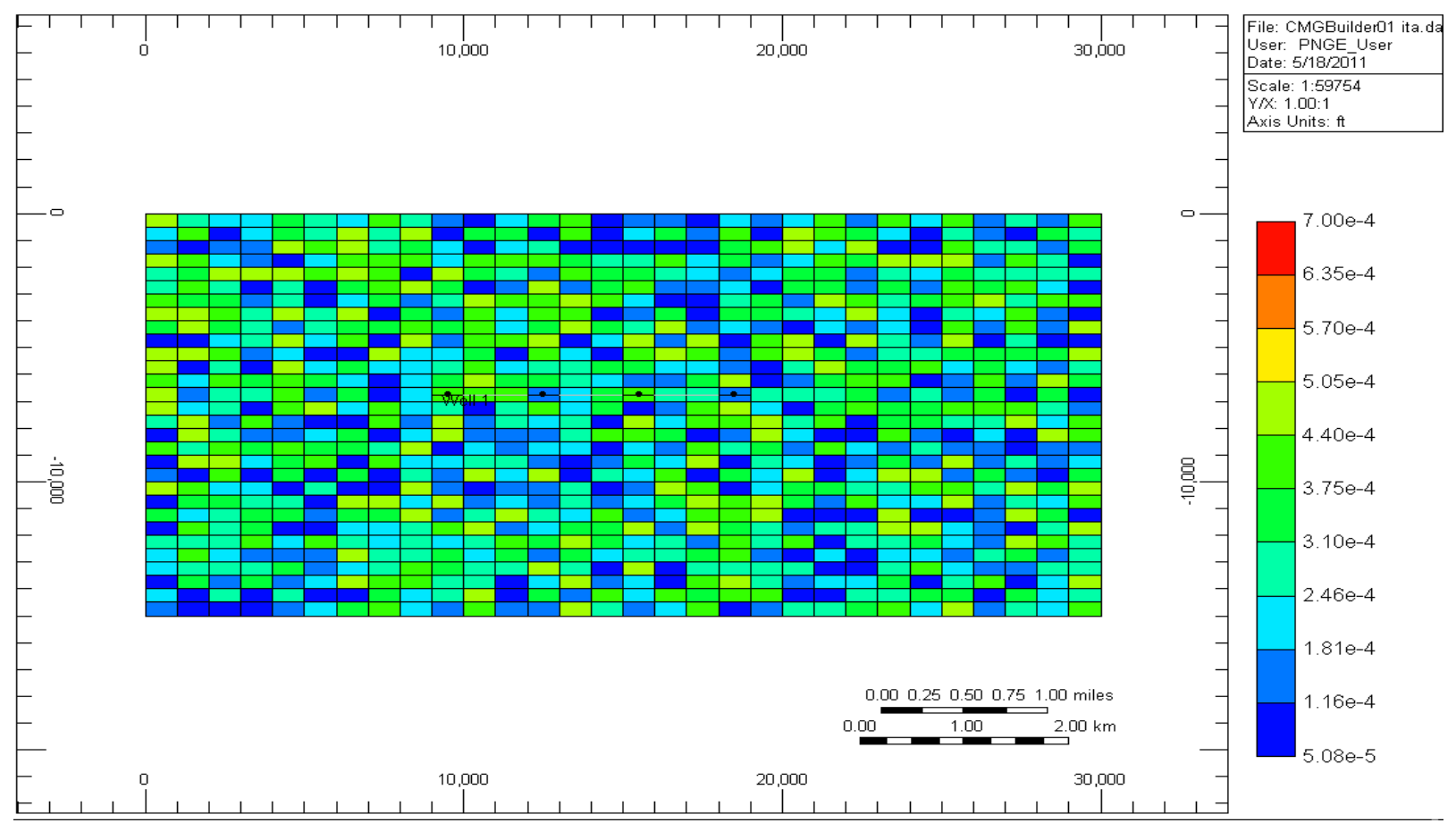

Figure A39; Matrix permeability values (Run 4.9) 
Permeability I (md) 2000-01-01 K layer: 1

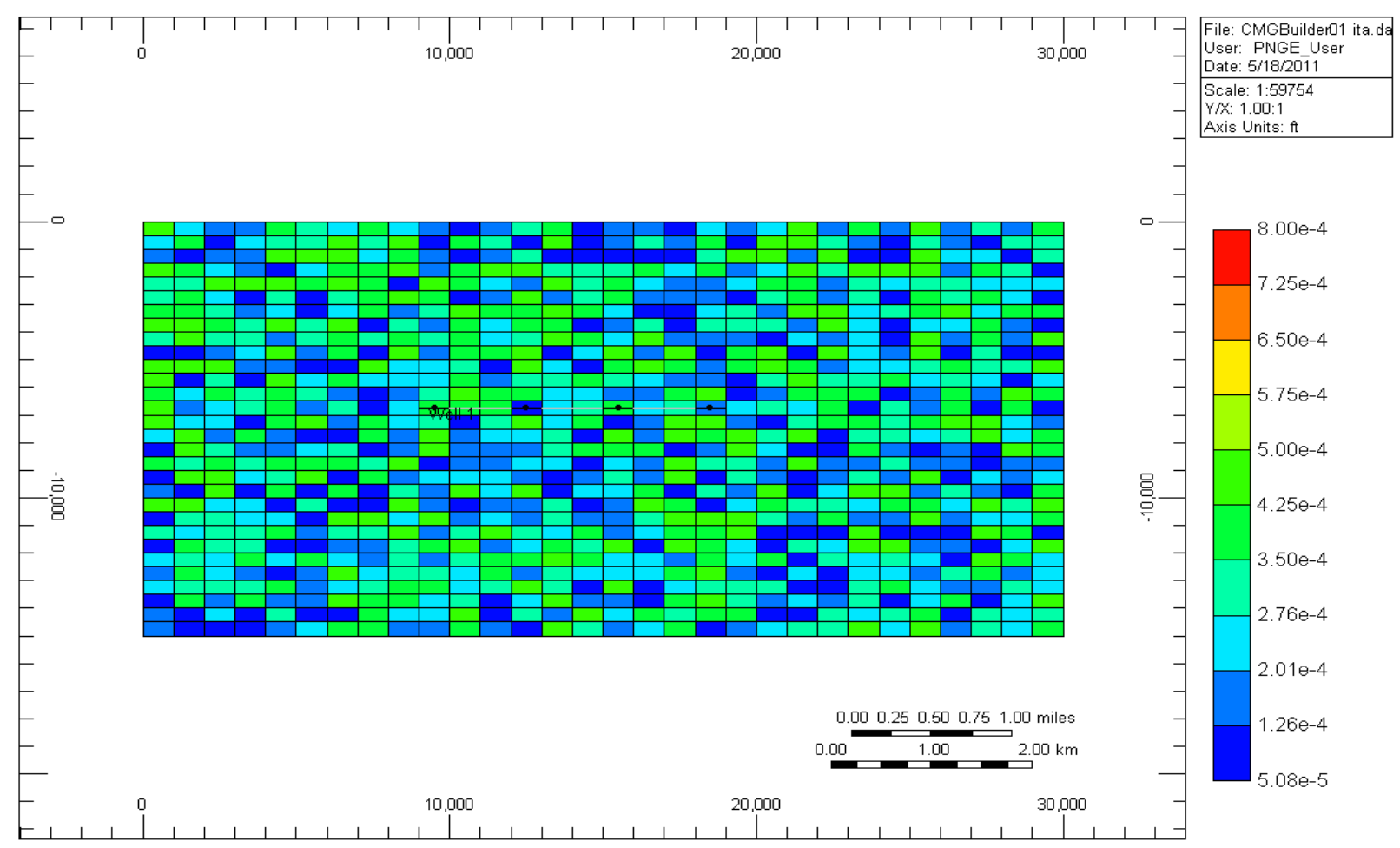

Figure A40; Matrix permeability values (Run 4.10)

John H. Virginia University Libraries, 